\title{
A COMPARISON OF RISK ASSESSMENT MODELS FOR PIPE REPLACEMENT AND REHABILITATION IN A WATER DISTRIBUTION SYSTEM
}

\author{
A Thesis \\ presented to \\ the Faculty of California Polytechnic State University, \\ San Luis Obispo
}

\author{
In Partial Fulfillment \\ of the Requirements for the Degree \\ Master of Science in Civil Engineering
}

by

Lyle Nemeth

June 2016 
(C) 2016

Lyle Nemeth

ALL RIGHTS RESERVED 
TITLE:

A Comparison of Risk Assessment Models for Pipe Replacement and Rehabilitation in a Water Distribution System

AUTHOR: $\quad$ Lyle Nemeth

DATE SUBMITTED: June 2016

COMMITTEE CHAIR: Dr. Shikha Rahman, Ph.D.

Associate Professor of Civil and Environmental Engineering

COMMITTEE MEMBER: Dr. Robb Moss, Ph.D., P.E.

Associate Professor of Civil and Environmental Engineering

COMMITTEE MEMBER: Dr. Rebekah Oulton, Ph.D., P.E.

Assistant Professor of Civil and Environmental Engineering

COMMITTEE MEMBER: Nick Panofsky, P.E.

Senior Project Engineer at MNS Engineers, Inc. 


\begin{abstract}
A Comparison of Risk Assessment Models for Pipe Replacement and Rehabilitation in a Water Distribution System

Lyle Nemeth
\end{abstract}

A water distribution system is composed of thousands of pipes of varying materials, sizes, and ages. These pipes experience physical, environmental, and operational factors that cause deterioration and ultimately lead to their failure. Pipe deterioration results in increased break rates, decreased hydraulic capacity, and adverse effects on water quality. Pipe failures result in economic losses to the governing municipality due to loss of service, cost of pipe repair/replacement, damage incurred due to flooding, and disruptions to normal business operations. Inspecting the entire water distribution system for deterioration is difficult and economically unfeasible; therefore, it benefits municipalities to utilize a risk assessment model to identify the most critical components of the system and develop an effective rehabilitation or replacement schedule.

This study compared two risk assessment models, a statistically complex model and a simplified model. Based on the physical, environmental, and operational conditions of each pipe, these models estimate the probability of failure, quantify the consequences of a failure, and ultimately determine the risk of failure of a pipe. The models differ in their calculation of the probability of failure. The statistically complex model calculates the probability of failure based on pipe material, diameter, length, internal pressure, land use, and age. The simplified model only accounts for pipe material and age in its calculation of probability of failure. Consequences of a pipe failure include the cost to replace the pipe, service interruption, traffic impact, and customer criticality impact. The risk of failure of a pipe is determined as the combination of the probability of failure and the consequences of a failure. Based on the risk of failure of 
each pipe within the water distribution system, a ranking system is developed, which identifies the pipes with the most critical risk. Utilization of this ranking system allows municipalities to effectively allocate funds for rehabilitation.

This study analyzed the 628-pipe water distribution system in the City of Buellton, California. Four analyses were completed on the system, an original analysis and three sensitivity analyses. The sensitivity analyses displayed the worst-case scenarios for the water distribution system for each assumed variable. The results of the four analyses are provided below.

\begin{tabular}{|c|c|c|}
\hline Risk Analysis & Simplified Model & Complex Model \\
\hline Original Analysis & All pipes were low risk & All pipes were low risk \\
\hline $\begin{array}{c}\text { Sensitivity Analysis: } \\
\text { Older Pipe Age }\end{array}$ & Identified 2 medium risk pipes & Identified 2 medium risk pipes \\
\hline $\begin{array}{l}\text { Sensitivity Analysis: } \\
\text { Lower Anticipated } \\
\text { Service Life }\end{array}$ & Identified 2 medium risk pipes & $\begin{array}{l}\text { Identified } 9 \text { high risk pipes } \\
\text { and } 283 \text { medium risk pipes }\end{array}$ \\
\hline $\begin{array}{l}\text { Sensitivity Analysis: } \\
\text { Older Pipe Age and } \\
\text { Lower Anticipated } \\
\text { Service Life }\end{array}$ & $\begin{array}{l}\text { Identified } 1 \text { high risk pipe and } \\
330 \text { medium risk pipes }\end{array}$ & $\begin{array}{l}\text { Identified } 111 \text { critical risk } \\
\text { pipes, } 149 \text { high risk pipes, } \\
\text { and } 137 \text { medium risk pipes }\end{array}$ \\
\hline
\end{tabular}

Although the results appeared similar in the original analysis, it was clear that the statistically complex model incorporated additional deterioration factors into its analysis, which increased the probability of failure and ultimately the risk of failure of each pipe. With sufficient data, it is recommended that the complex model be utilized to more accurately account for the factors that cause pipe failures.

This study proved that a risk assessment model is effective in identifying critical components and developing a pipe maintenance schedule. Utilization of a risk assessment model will allow municipalities to effectively allocate funds and optimize their water distribution system.

Keywords: Water Distribution System/Network, Risk of Failure, Monte Carlo Simulation, Normal Random Variable, Conditional Assessment, Sensitivity Analysis. 


\section{ACKNOWLEDGMENTS}

First off, I would like to express appreciation for my thesis advisor, Dr. Shihka Rahman for providing me with this research opportunity, for all the classes I have taken with her, and for all her support and guidance throughout my years at Cal Poly. I would also like to thank my committee members, Dr. Rob Moss, Dr. Rebekah Oulton, and Nick Panofsky, for their sincere interest in my study and for their technical support with respect to water resources and risk analysis.

I would like to make a special thanks to MNS Engineers, Inc. and the City of Buellton for providing me with the water distribution data. I also want to thank Kurt Shellhause for all his technical support and suggestions with regards to ArcGIS and VBA.

Lastly, I wish to thank God, my parents, my brother, my fiancée, and all of my friends and family for their love and encouragement throughout this research endeavor and my entire collegiate experience. 


\section{TABLE OF CONTENTS}

Page

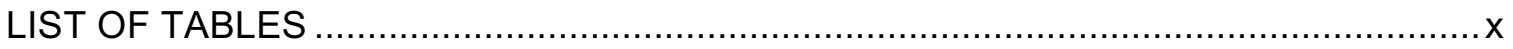

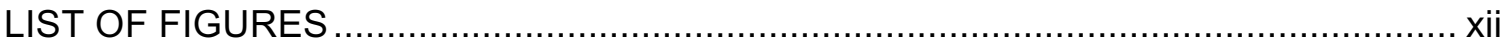

CHAPTER

1. INTRODUCTION

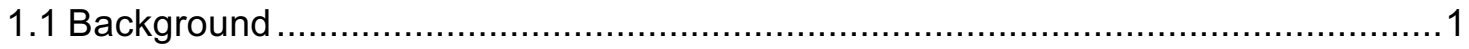

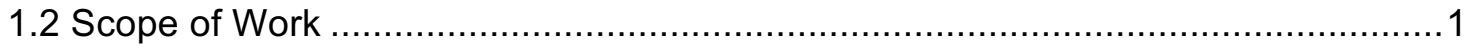

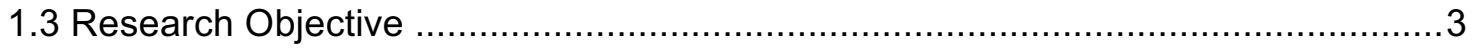

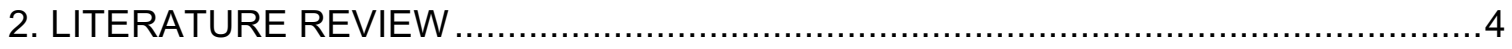

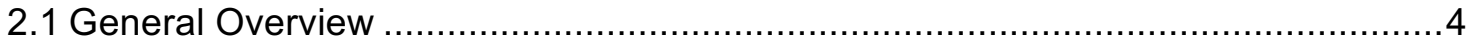

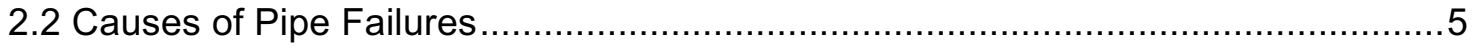

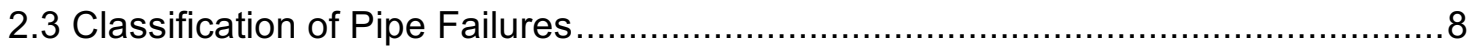

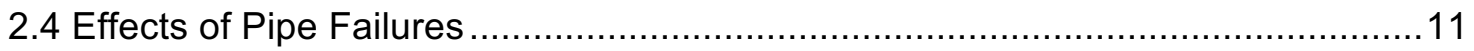

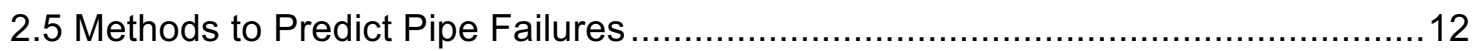

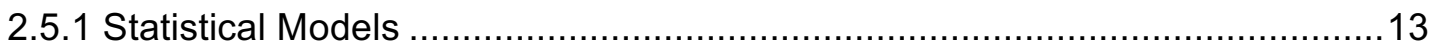

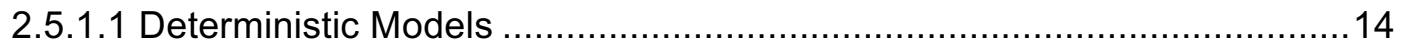

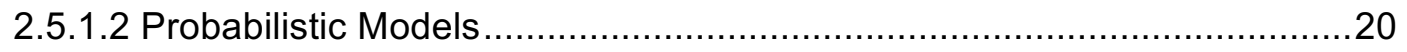

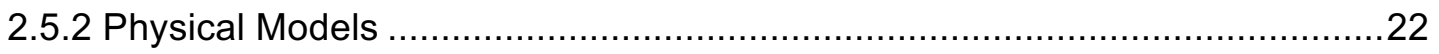

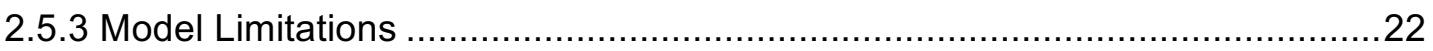

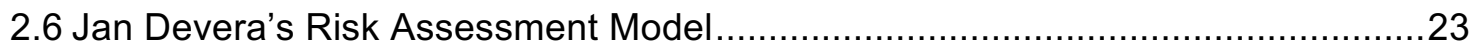

2.7 Hernan Cortez's Risk Assessment Model ....................................................28

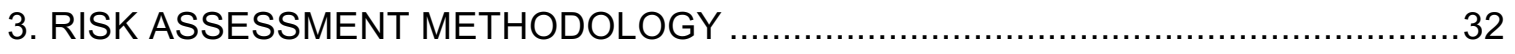

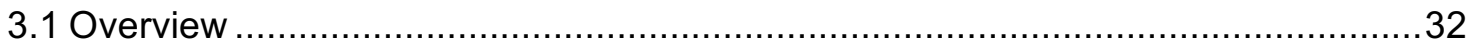


3.2 Stage 1: Computing Remaining Useful Life

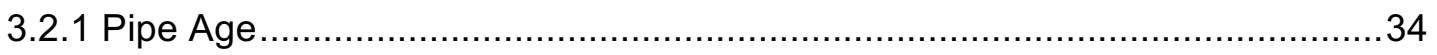

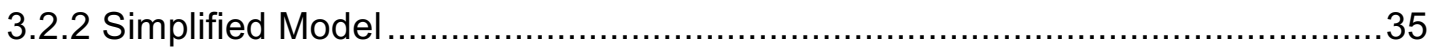

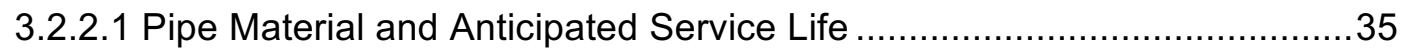

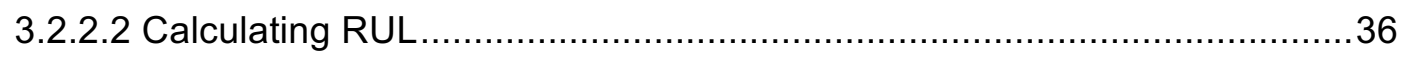

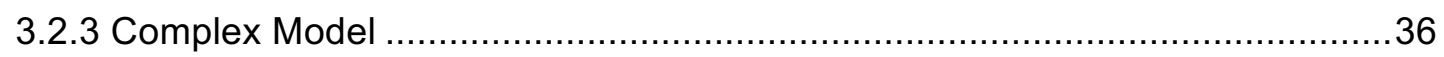

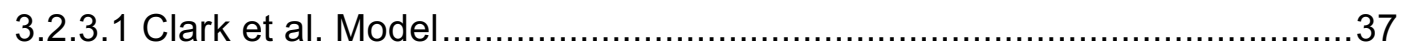

3.2.3.2 Regression Parameters and Pipe Materials ……..................................38

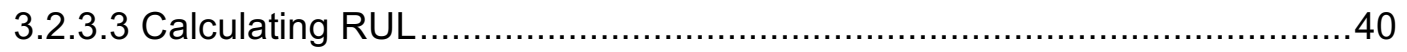

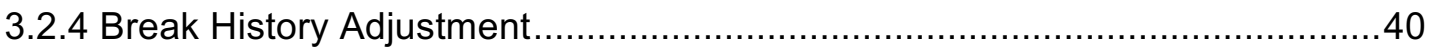

3.3 Stage 1: Determining Probability of Failure ……….......................................... 41

3.4 Stage 2: Computing Degree of Impact ………..............................................42

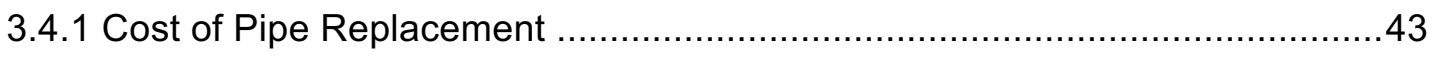

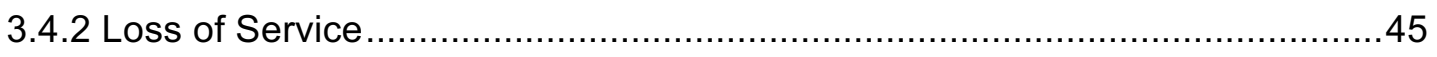

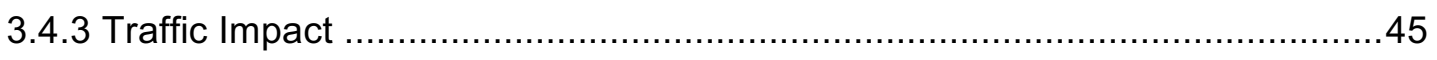

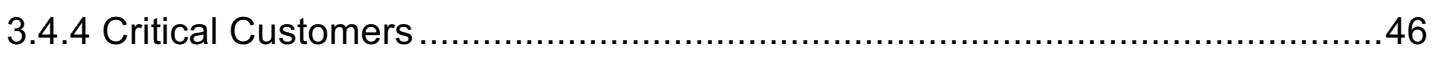

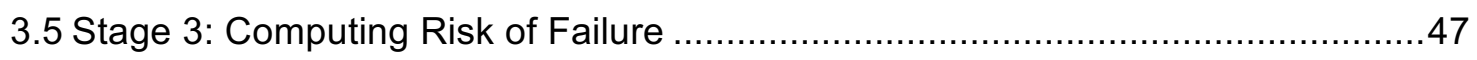

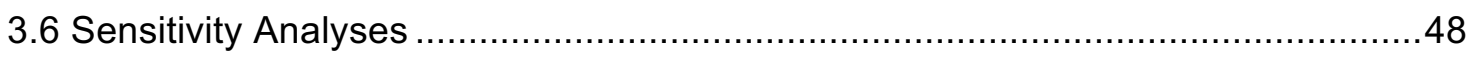

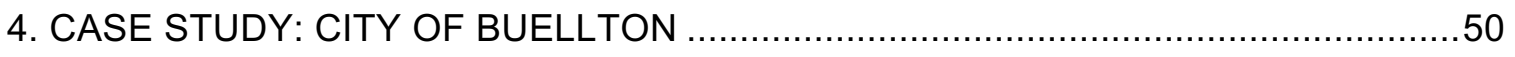

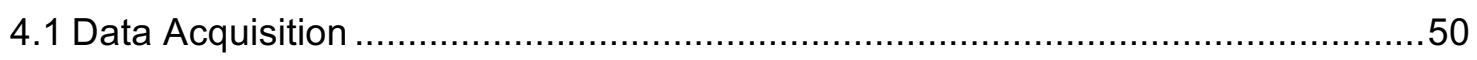

4.2 Computer Modeling and Data ANALYSIS ........................................................

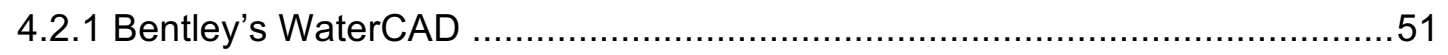

4.2.2 Microsoft's Excel and Visual Basic for Applications (VBA) ............................51

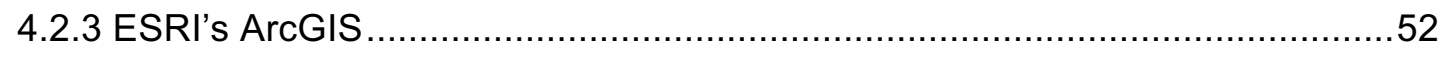

4.2.3.1 Establishment of an ArcGIS Model for Analysis ...................................53 
5. RESULTS

5.1 Risk Analysis Visual Representation

5.2 Risk Analysis Results 62

5.3 Sensitivity Analysis 66

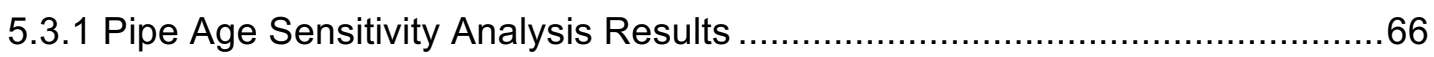

5.3.2 Anticipated Service Life Sensitivity Analysis Results ..................................69

5.3.3 Combined Sensitivity Analysis Results ................................................ 72

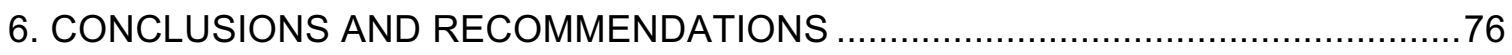

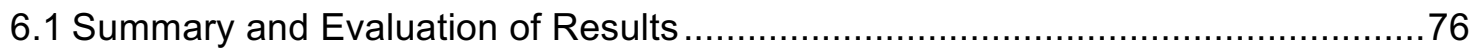

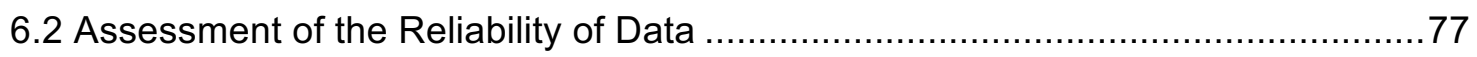

6.3 Recommendations for Improvement and Further Research ..............................78

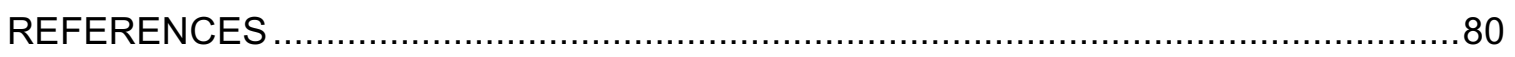

\section{APPENDICES}

Appendix A: City of Buellton Data and Results ........................................... 82

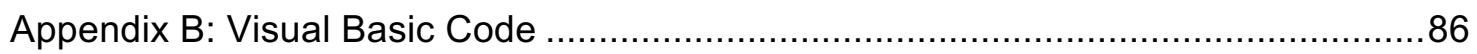




\section{LIST OF TABLES}

Table

Page

2.1 FAILURE MODE CHARACTERISTICS (MAYS, 2000) ...................................

2.2 PIPE MATERIALS AND ANTICIPATED SERVICE LIFE (DEVERA, 2013) ............24

2.3 BREAK HISTORY ADJUSTMENT (DEVERA, 2013) ......................................24

2.4 PROBABILITY OF FAILURE SCORING CRITERIA (DEVERA, 2013) ..................25

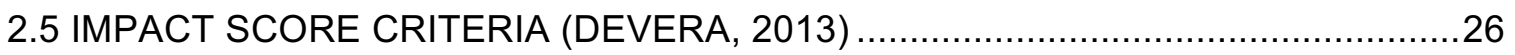

2.6 RISK OF FAILURE SCORE FOR VARIED PF AND IS (DEVERA, 2013) ..............27

2.7 RISK OF FAILURE CATEGORY (DEVERA, 2013) .......................................28

2.8 REGRESSION PARAMETERS (CORTEZ, 2015) ..........................................

2.9 RISK OF FAILURE CATEGORY (CORTEZ, 2015) ….................................... 31

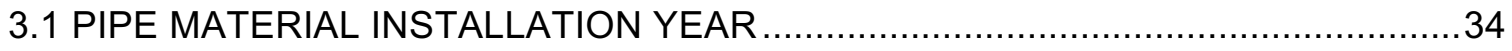

3.2 PIPE MATERIAL ANTICIPATED SERVICE LIFE ....................................... 35

3.3 PERCENT RESIDENTIAL AND INDUSTRIAL COVER ...................................38

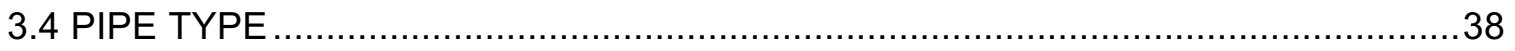

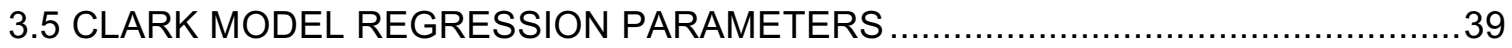

3.6 PIPE MATERIAL ANTICIPATED SERVICE LIFE ...........................................

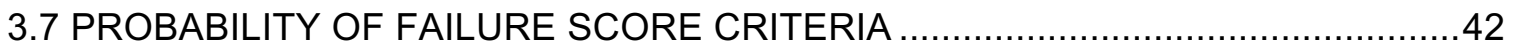

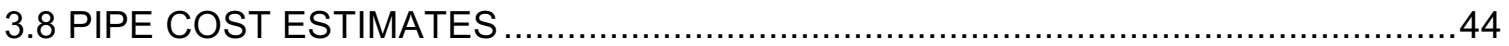

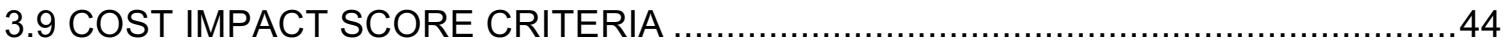

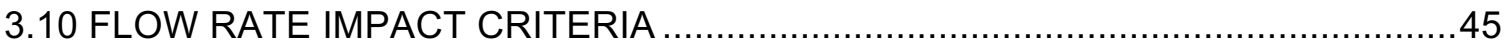


3.11 TRAFFIC IMPACT CRITERIA

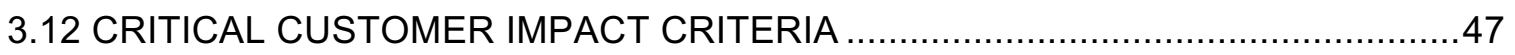

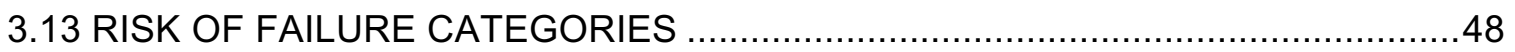

3.14 ADJUSTED PIPE MATERIAL INSTALLATION YEAR ...................................49

3.15 ADJUSTED PIPE MATERIAL ANTICIPATED SERVICE LIFE ..........................49

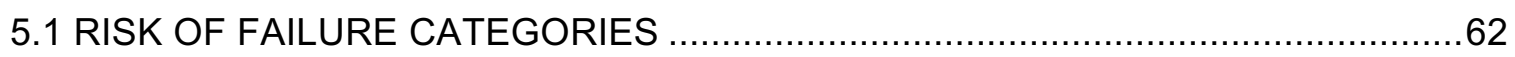

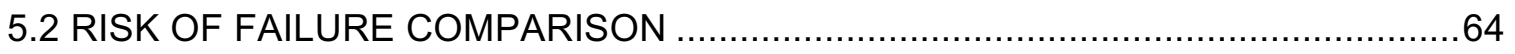

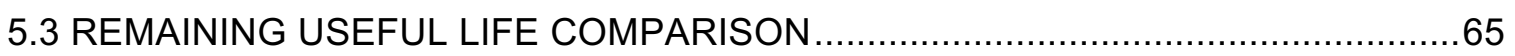

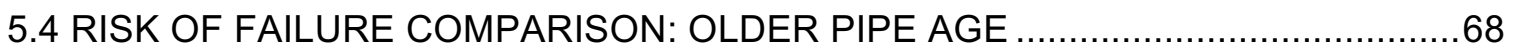

5.5 REMAINING USEFUL LIFE COMPARISON: OLDER PIPE AGE .......................69

5.6 RISK OF FAILURE COMPARISON: LOWER ASL ....................................... 71

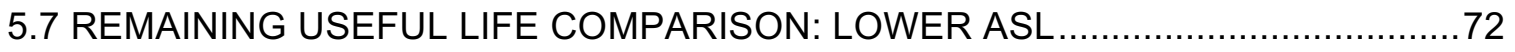

5.8 RISK OF FAILURE COMPARISON: OLDER PIPE AGE AND LOWER ASL ..........74

5.9 REMAINING USEFUL LIFE COMPARISON: OLDER PIPE AGE AND

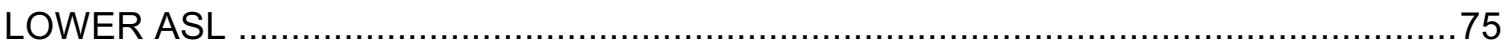

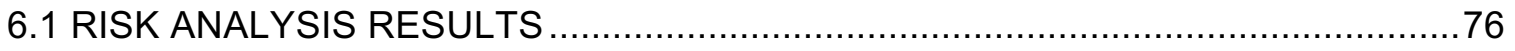

A.1 EXAMPLE OF REQUIRED DATA FROM THE "WDS DATA" SPREADSHEET ......83

A.2 EXAMPLE OF ORIGINAL RISK ANALYSIS RESULTS FROM THE "RISK ANALYSIS" SPREADSHEET 
LIST OF FIGURES

Figure

Page

2.1 PIPE WITH TUBERCULATION (AWWA, 2014) 4

2.2 PIPE REHABILITATION DECISION MAKING TREE (KLEINER, 2001) .................6

2.3 MAIN FACTORS AFFECTING PIPE DETERIORATION (WANG, 2009)................. 7

2.4 FAILURE MODES FOR BURIED PIPES (RAJANI, 2001) ...............................10

2.5 FAILURE MODES FOR SMALL PIPES (MAKAR, 2001) .................................11

2.6 FAILURE MODES FOR MEDIUM PIPES (MAKAR, 2001) ..................................11

2.7 FAILURE MODES FOR LARGE PIPES (MAKAR, 2001) .................................11

2.8 BATHTUB CURVE OF THE LIFE CYCLE OF A BURIED PIPE (KLEINER, 2001) ..13

2.9 OVERVIEW OF STATISTICAL MODELS (KLEINER, 2001) ..............................14

2.10 PROPORTIONAL HAZARDS MODEL (KLEINER, 2001) ..................................21

2.11 RISK OF FAILURE COMPUTATION (DEVERA, 2013) .....................................

2.12 MONTE CARLO SIMULATION HISTOGRAM FOR CAST IRON PIPES ...............29

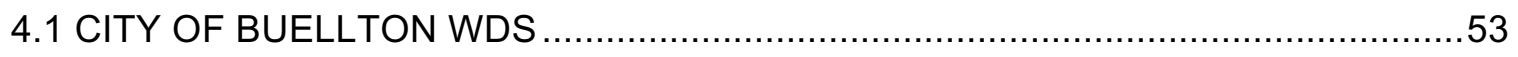

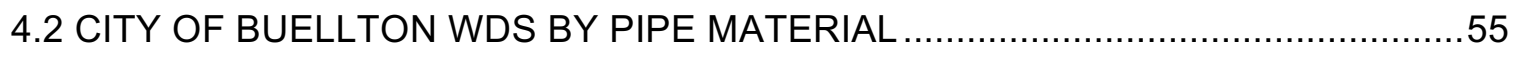

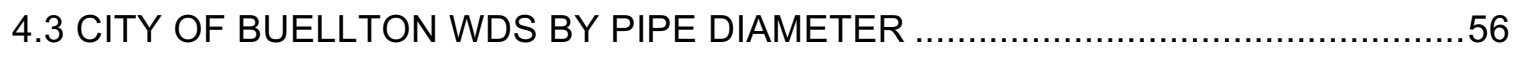

4.4 CITY OF BUELLTON ROADWAY CLASSIFICATIONS AND LAND USE ..............57

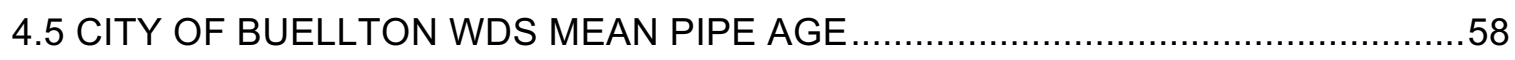

4.6 CITY OF BUELLTON CRITICAL CUSTOMERS .........................................60

5.1 CITY OF BUELLTON WDS: SIMPLIFIED MODEL RESULTS ............................63 
5.2 CITY OF BUELLTON WDS: COMPLEX MODEL RESULTS

5.3 CITY OF BUELLTON WDS WITH OLDER PIPE AGE:

SIMPLIFIED MODEL RESULTS

5.4 CITY OF BUELLTON WDS WITH OLDER PIPE AGE:

COMPLEX MODEL RESULTS

5.5 CITY OF BUELLTON WDS WITH LOWER ASL:

SIMPLIFIED MODEL RESULTS

5.6 CITY OF BUELLTON WDS WITH LOWER ASL:

COMPLEX MODEL RESULTS

5.7 CITY OF BUELLTON WDS WITH OLDER PIPE AGE AND LOWER ASL:

SIMPLIFIED MODEL RESULTS

5.8 CITY OF BUELLTON WDS WITH OLDER PIPE AGE AND LOWER ASL:

COMPLEX MODEL RESULTS 


\section{CHAPTER 1 \\ INTRODUCTION}

\subsection{Background}

Material deterioration is an inevitable process that occurs over time due to physical, environmental, and operational factors. Deterioration affects every type of infrastructure within the United States, which includes transportation systems, buildings, electric and fiber optic grids, stormwater and sewer systems, and potable water distribution systems. The effect of material deterioration is augmented with continued population growth, which increases the demands that infrastructure's experience. Each city is responsible for ensuring that their infrastructure is capable of serving the public safely and effectively. Thus, infrastructure maintenance is required to counteract the results of deterioration and population growth. Infrastructure maintenance, replacement, and/or rehabilitation is a large capital investment; therefore, municipalities rely on the identification of the most critical components of a system in order to effectively allocate their funds.

This study focused on the identification of the critical components within a potable water distribution system, which provides municipalities with the information necessary to develop an effective rehabilitation or replacement schedule. Critical components are determined with the application of a risk assessment model.

\subsection{Scope of Work}

This study evaluated and compared two risk assessment models developed in previous studies, a statistically complex model provided by Cortez (2015) and a simplified model presented by Devera (2013). The statistically complex model incorporates factors that account for pipe deterioration, while the simplified model does 
not integrate pipe deterioration factors and is solely based on intuition. Cortez (2015) and Devera (2013) applied their models to the water distribution system of the City of Arroyo Grande, which allowed for an initial comparison of the models. The models produced a similar result, which suggests that the simplified model provided by Devera (2013) is preferred due to its simplicity and economic affordability.

Both models analyzed the risk of failure of a pipe by determining the pipe's probability of failure and quantifying the consequences of a failure. The probability of failure is based on the pipe's remaining useful life; determination of remaining useful life is where the models differ. Remaining useful life is decreased due to pipe deterioration. The statistically complex model accounts for pipe deterioration based on pipe material, diameter, length, internal pressure, land use, and age. On the other hand, the simplified model does not account for pipe deterioration factors and is only based on pipe material and age. The consequences due to a pipe failure include the cost to replace the pipe, service interruption impact, traffic impact, and customer criticality impact.

The risk analysis required the application of Bentley's WaterCAD, Microsoft's Excel and Visual Basic for Applications, and ESRI's ArcGIS. WaterCAD provides the hydraulic properties of each pipe within the system. Visual Basic for Applications was used as the primary calculation tool and Excel was used for data organization and as the secondary calculation tool. ArcGIS was used to visually present the results of the risk assessment.

This study applied each model to the City of Buellton water distribution system in order to compare their results. Similar results will verify the effectiveness of the simplified model and varying results will suggest that the statistically based model is more accurate. To further evaluate the effectiveness of each model, sensitivity analyses were completed to evaluate the effects of the assumed data on the results, which was necessary due to uncertainty within the data. 


\subsection{Research Objective}

Access to safe, potable water through a functioning water distribution system is essential for everyday life. A poorly maintained system results in an increase in break rates, a decrease of hydraulic capacity, and deterioration of water quality. Therefore, municipalities can improve the functionality of their system by utilizing a risk assessment model to repair or replace the most crucial pipes within their system.

A risk assessment model will provide municipalities with a maintenance schedule that will allow them to maintain pipes before they experience a failure, which is much costlier to repair. Thus, by rehabilitating or replacing the most critical components in the system, the municipality will save money and prevent the unexpected loss of service and damage that occurs with a failure. A properly applied risk assessment model will ensure that water distribution system continues to function as designed, which will benefit the entire community. 


\section{CHAPTER 2}

\section{LITERATURE REVIEW}

\subsection{General Overview}

Structural and functional deterioration of water mains within water distribution systems is inevitable and is difficult to monitor. Ensuring that water distribution systems continue to function as designed is a challenge for all municipalities. Completion of water main rehabilitation counteracts deterioration that results in an increase in break rates, a decrease of hydraulic capacity, and a reduction of water quality. Figure 2.1 exhibits an example of a deteriorated pipe tuberculation caused by corrosion.

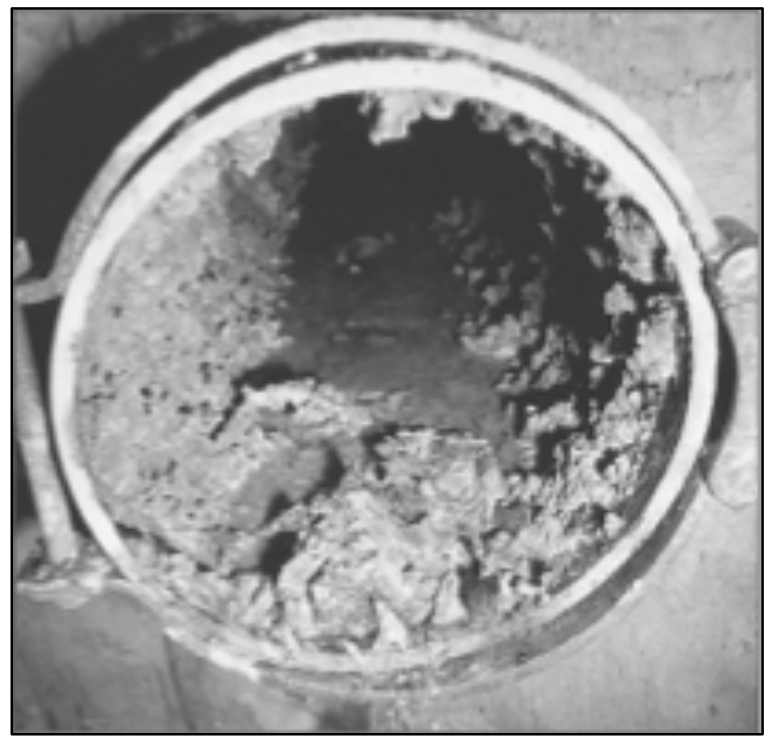

Figure 2.1 Pipe with Tuberculation (AWWA, 2014)

Millions of miles of pipes that comprise the water distributions system are almost at the end of their service life. Restoring and/or replacing these pipes and expanding them to serve the growing population will cost at least $\$ 1$ trillion over the next 25 years (AWWA, 2011). Because pipes are frequently more than 100 years old and there are an estimated 240,000 water main breaks per year in the United States, America's water infrastructure has received an overall grade of D (ASCE, 2013); however, water quality 
remains high and disease outbreaks caused by drinking water are rare. Access to safe, potable water through a functioning water distribution system is essential for everyday life.

Eighty percent of water supply systems' expenditures are for distribution networks. With scarce capital resources, it is essential to have a cost-effective restoration strategy (Kleiner, 2001). Municipalities do not have the resources or capital to replace every deteriorating pipe in a water distribution system and replacing pipes arbitrarily without any knowledge of the pipes condition is inefficient and costly. Identifying high-risk pipes through a conditional-based risk model will allow municipalities to more effectively use capital funding to repair or replace the pipes that are near the end of their life.

\subsection{Causes of Pipe Failures}

Pipe deterioration, and ultimately pipe failure, occur due to factors that reduce the lifespan of a pipe. These factors do not allow the pipe to last the duration of its designed service life. Mavin (1996) concluded that common factors that led to pipe failures include:

- Pipe manufacturing defects: dimensional irregularities, discontinuities, or inclusions

- Poor storage and handling: structural damage, such as stress deformations, impact cracks, scratches on pipe wall or coating, or over weathering

- Improper installation: incorrect laying, fitment, taping, and/or soil cover

- Soil erosion: loss of bed support as a result of flooding from groundwater or rain

- Impact damage: structural damage of the pipe during installation 
- Pipe corrosion: diminished structural strength, reduction in water quality, and decreased hydraulic capacity

Kleiner (2001) classified pipe deterioration into two major categories: structural deterioration and inner surface deterioration. Structural deterioration diminishes the pipe's structural resiliency and its ability to withstand induced stresses (Kleiner, 2001). Inner surface deterioration of pipes decreases hydraulic capacity, reduces water quality, and diminishes internal structural resistance due to internal corrosion (Kleiner, 2001). Kleiner (2001) developed a decision making tree that includes all of the factors that should be considered in the rehabilitation or replacement of a water main. Figure 2.2 displays the pipe rehabilitation decision-making tree.

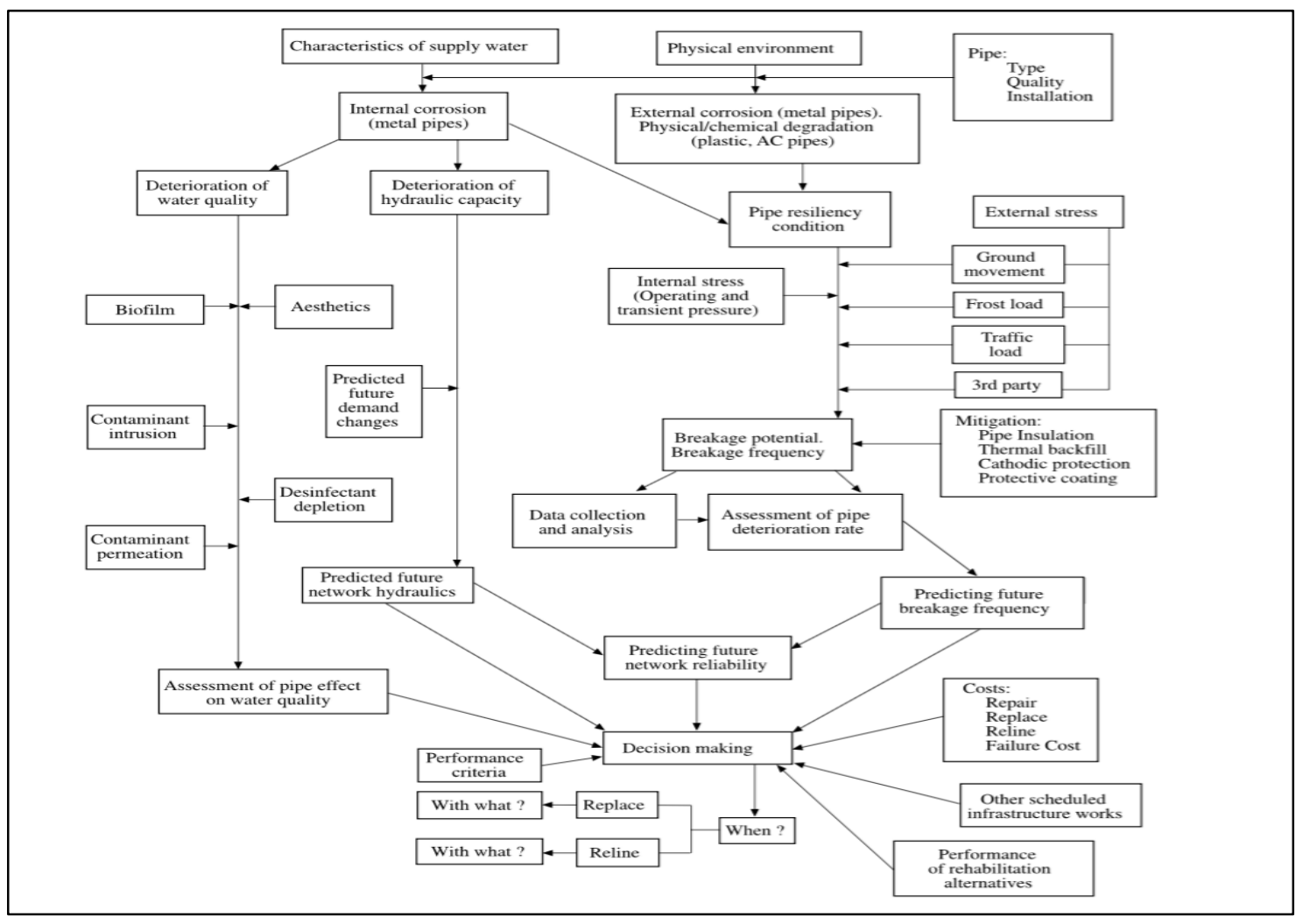

Figure 2.2 Pipe Rehabilitation Decision Making Tree (Kleiner, 2001)

The factors causing rehabilitation of water mains are classified into the following categories: water quality, hydraulic capacity, structural performance and behavior, pipe 
breakage, network reliability, economics, and decision-making process (Kleiner, 2001). AWWA (2014) confirmed that the three primary reasons for conducting pipe rehabilitation is the deterioration of water quality, the reduction of hydraulic capacity, and the physical/chemical structural deterioration of the pipe (AWWA, 2014).

Wang (2009) concluded that the factors affecting pipe deterioration can either be dynamic, dependent on time, or static, independent of time (Wang, 2009). Dynamic factors include parameters such as pipe age, water pressure, and previous pipe breaks. Static factors include parameters such as pipe diameter and material. Wang (2009) completed research that categorized static and dynamic factors into three main categories: physical, operation and maintenance, and environmental. Figure 2.3 displays the main factors affecting pipe deterioration.

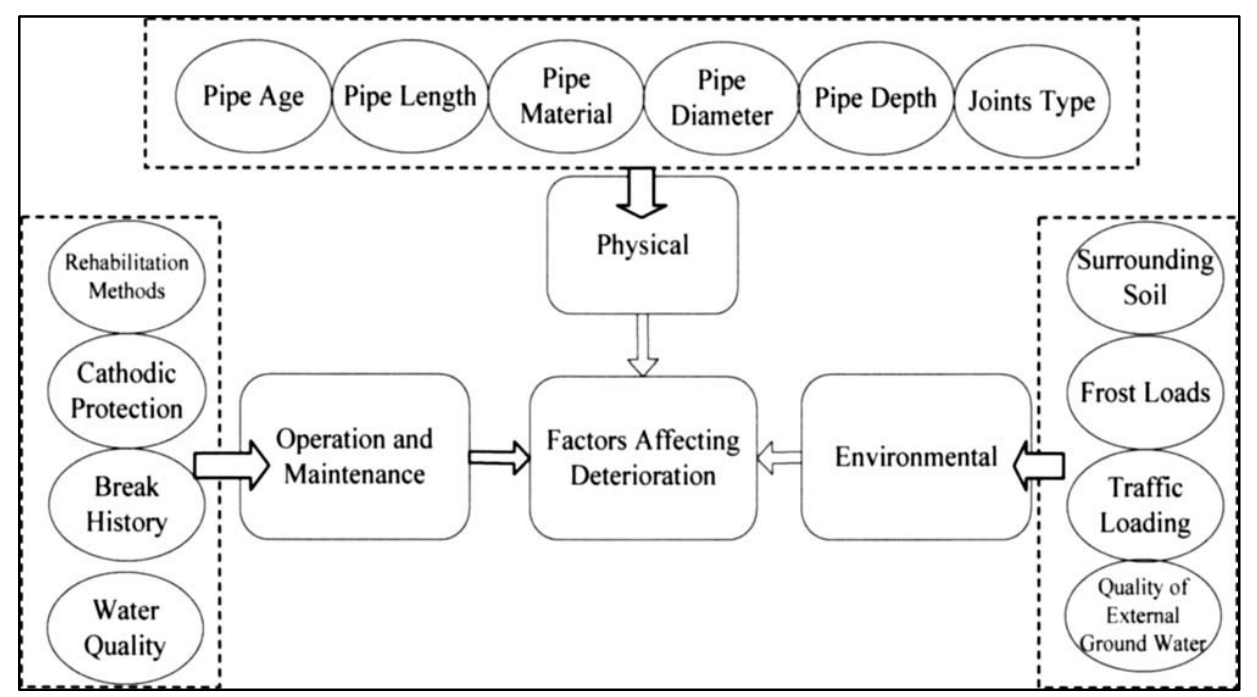

Figure 2.3 Main Factors Affecting Pipe Deterioration (Wang, 2009)

No model has the capability of incorporating all of the factors discussed above (Kleiner, 2001). Therefore, the selected model is one that best fits the data that the municipality has gathered since the installation of the water distribution network. 


\subsection{Classification of Pipe Failures}

The physical mechanisms that cause pipe failures are very complex. Rajani (2001) concluded that these physical mechanisms can be classified into three principal aspects: (1) pipe structural properties, material type, pipe-soil interaction, and quality of installation; (2) internal loads due to operational pressure and external loads due to soil overburden, traffic loads, frost loads and third party interference; (3) material deterioration due largely to the external and internal chemical, bio-chemical and electrochemical environment (Rajani, 2001).

In addition, pipe failures can occur due to any factor or combination of factors as mentioned in Section 2.2. The failure mode, break or leak, depends on the magnitude and consequences of a water main's failure. A pipe break is the structural failure of the pipe and occurs when a load exceeds the pipe's material strength (Clark, 2010). A pipe leak is a loss of water at joints due to improper sealing or displacement causing water to escape (Clark, 2010). Table 2.1 displays the characteristics of pipe breaks and pipe leaks.

The designation between a break and a leak is very important in the modeling of a water distribution system. Breaks require immediate rehabilitation as break repairs interrupt service. Leaks are difficult to detect and often remain uncorrected; making leaks the major source of water that is unaccounted for within water distribution systems. Leaks may be associated with breaks due to the weakening of the bedding material supporting the pipes, which causes a localized concentration of stresses (Yamijala, 2007). 
Table 2.1 Failure Mode Characteristics (Mays, 2000)

\begin{tabular}{|c|c|c|}
\hline Category & Pipe Leaks & Pipe Breaks \\
\hline Occurrence Location & $\begin{array}{l}\text { Pipe joints and connection to } \\
\text { laterals. }\end{array}$ & $\begin{array}{l}\text { Structural failure along the } \\
\text { length of the pipe. }\end{array}$ \\
\hline Detection & $\begin{array}{l}\text { Difficult to detect and may } \\
\text { remain undetected. Requires } \\
\text { specialized testing equipment. }\end{array}$ & $\begin{array}{c}\text { Easily identified due to loss of } \\
\text { flow/pressure and ground } \\
\text { level conditions (i.e. surfacing } \\
\text { water). }\end{array}$ \\
\hline Repair Urgency & $\begin{array}{l}\text { Repairs are not urgent and } \\
\text { may be scheduled. }\end{array}$ & Requires immediate attention. \\
\hline Service Impact & $\begin{array}{l}\text { Low likelihood of service } \\
\text { interruption during repair. }\end{array}$ & $\begin{array}{l}\text { Requires service shutdown } \\
\text { during repair or replacement. }\end{array}$ \\
\hline
\end{tabular}

Water main breaks occur due to induced operational and environmental stresses on a structurally deteriorated pipe due to corrosion, degradation, inadequate installation, and/or manufacturer defects. Pipe break types were classified into four categories: (1) circumferential breaks, caused by longitudinal stresses; (2) longitudinal breaks, caused by transverse stresses (hoop stress); (3) split bell, caused by transverse stresses on the pipe joint; (4) holes due to corrosion (Rajani, 2001). Figure 2.4 graphically demonstrates pipe failures that occur due to direct tension (top), bending or flexure (middle), and hoop stress (bottom). 


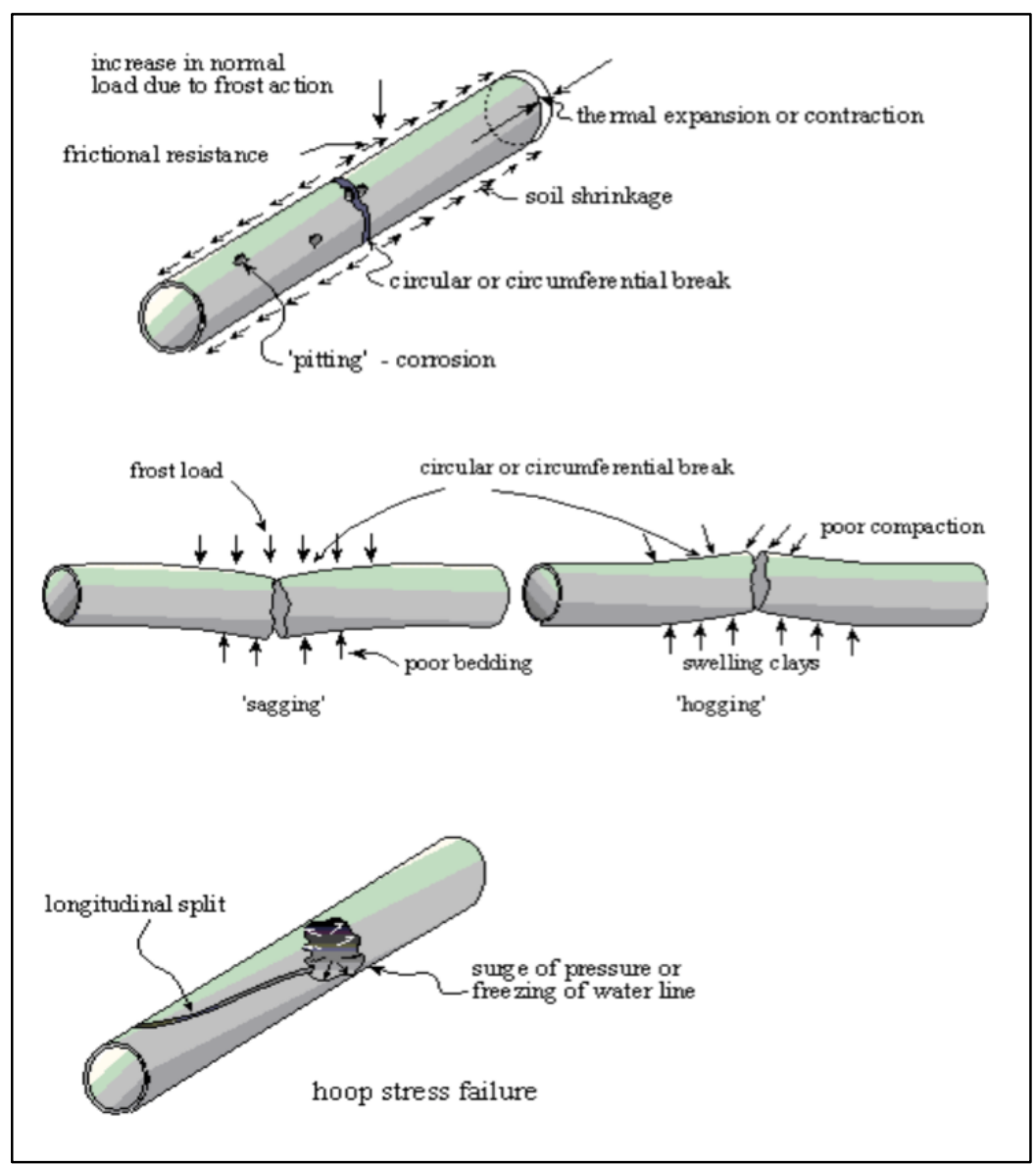

Figure 2.4 Failure Modes for Buried Pipes (Rajani, 2001)

Makar (2001) identified frequently occurring break modes associated with different diameter pipes. Figure 2.5 exhibits bell splitting (top of the pipe) and circumferential cracking (middle of the pipe), which are the most common failure types for smaller pipes (diameters less than 15 inches). Figure 2.6 demonstrates spiral failure, which is exclusive to, and the most common failure for medium pipes (diameters between 15 inches and 20 inches). Figure 2.7 displays longitudinal cracking (left pipe) and bell shearing (right pipe) which are the most common failure modes for large pipes (diameters greater than 20 inches). In addition to these failure modes, all pipe sizes experience corrosion pitting failures (Makar, 2001). 


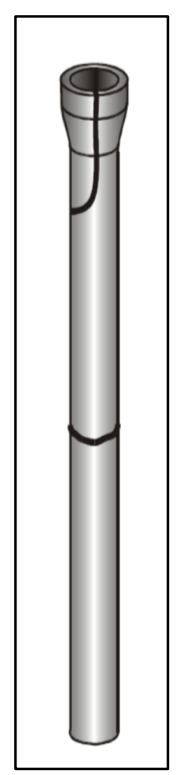

Figure 2.5 Failure Modes for Small Pipes

(Makar, 2001)

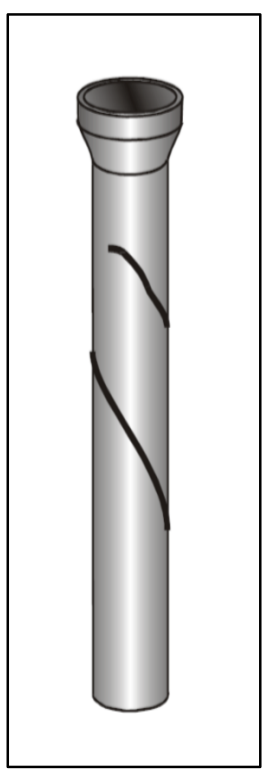

Figure 2.6 Failure Modes for Medium Pipes (Makar, 2001)

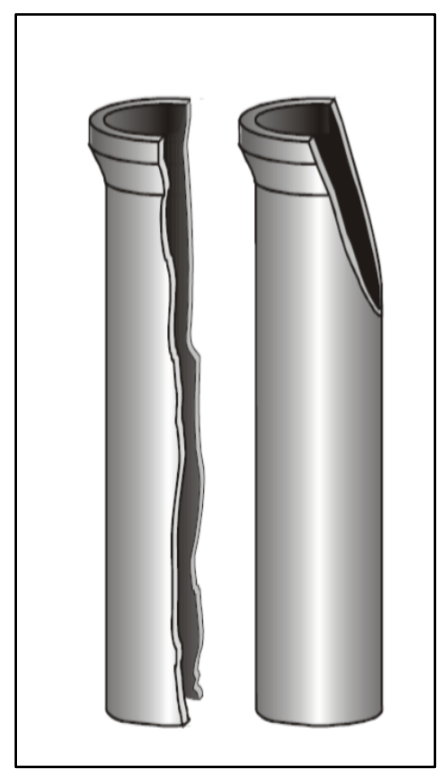

Figure 2.7 Failure Modes for Large Pipes

(Makar, 2001)

Accurately predicting a pipe break before it occurs is the goal of this study due to the variety of pipe break modes and the diversity in the factors causing pipe failures. Identifying the pipes that have the highest risk of breaking will help to prevent catastrophic failures that result in major service interruptions and costly repairs.

\subsection{Effects of Pipe Failures}

The causes of pipe failures and the type of failure modes may vary; however, the result of a pipe break always requires rehabilitation or replacement. Pipes that fail unexpectedly will have large capital costs and economic consequences, and each pipe failure has a unique magnitude of capital costs and economic consequences associated with it. Economic consequences can be direct or indirect. Direct economic consequences include the cost of repairing the pipe and any damage incurred during the break due to flooding or liquefaction, as well as the loss of serviceability (Cortez, 2015). 
An indirect economic consequence is the disruption of normal business operations due to the break, such as increased traffic caused by construction work to repair the pipe.

Factors that determine the magnitude of the consequences include: project size, pipeline size, rehabilitation method used, bypass system requirements, traffic conditions, number of laterals, number of valves or fittings, paving requirements, importance of the customers served, and severity of the break (AWWA, 2014). For instance, a large pipe that serves a hospital, which fails due to a longitudinal crack under a street in the heart of the city, would have a much larger economic consequence than a small pipe that serves an apartment, which fail, due to a corrosion hole under a small street in the suburbs.

Predicting pipe failures through statistical modeling allows the replacement or rehabilitation of pipes before an unexpected failure, which will save the municipality and the surrounding community from undergoing large capital costs and economic consequences.

\subsection{Methods to Predict Pipe Failures}

The life cycle of a water main pipe may be represented by a bathtub curve (Kleiner, 2001). A bathtub curve describes the rate of occurrence of failure (ROCOF) in respect to the service life of the pipe. A pipe's service life has three phases: a burn-in phase, an in-usage phase, and a wear-out phase. The burn-in phase represents the time shortly after installation when failures occur due to improper installation. After initial breaks have been purged, the in-usage phase begins. The pipe experiences little to no failures, with exceptions occurring due to random phenomena such as random heavy loads and third party interference (Kleiner, 2001). The wear-out phase originates when increasing failures occur due to pipe deterioration and aging. Varying pipe 
characteristics and environment conditions will determine the length of each phase, with some pipes not experiencing all the phases. Figure 2.8 exhibits a bathtub curve.

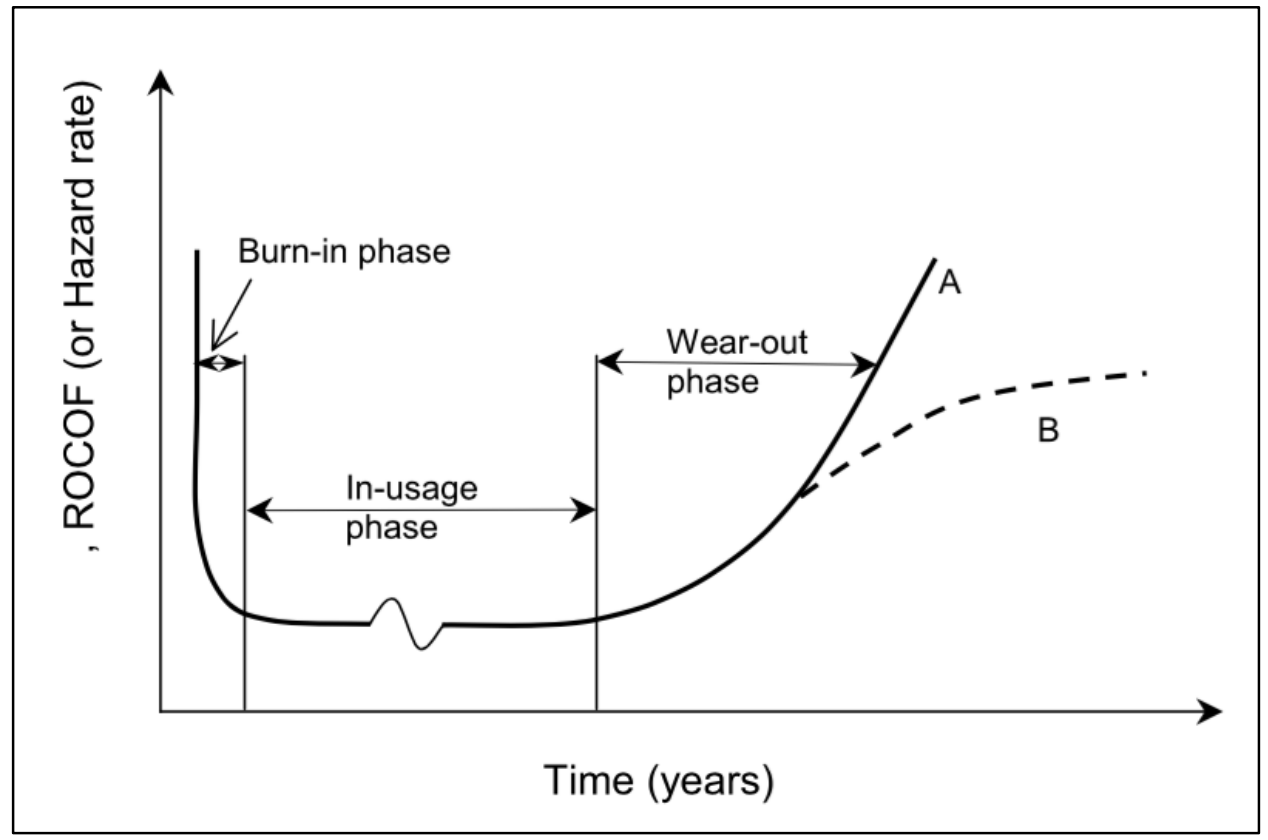

Figure 2.8 Bathtub Curve of the Life Cycle of a Buried Pipe (Kleiner, 2001)

The models that are available to predict water main failures are deterministic models, probabilistic models, and physical/mechanical models. Kleiner (2001) and Rajani (2001) assessed each of the models and provided a description, critique, and data requirement for each model.

\subsubsection{Statistical Models}

Statistical models use historic water main breakage data to identify breakage patterns in water distribution systems. An important assumption for these models is that the historic patterns will continue into the future. Figure 2.9 provides an overview of the statistical models. 


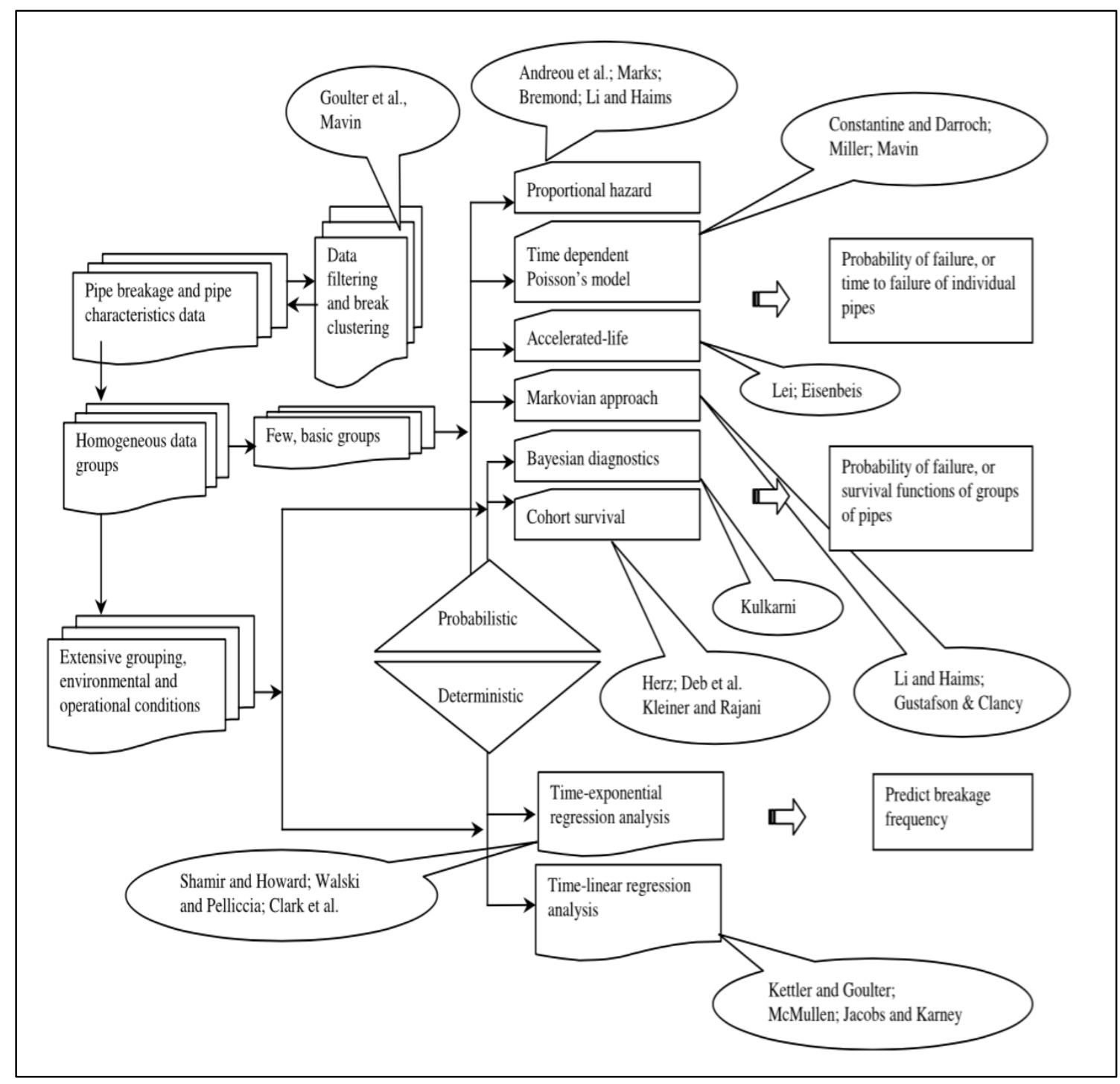

Figure 2.9 Overview of Statistical Models (Kleiner, 2001)

\subsubsection{Deterministic Models}

Deterministic models use two or three parameter equations in order to model breakage patters, based on pipe age and breakage history. Water mains within a water distribution system divided into relatively homogeneous groups, with respect to the determined parameters, for the capture of a true breakage pattern. Simplifying the variability of a water distribution system into homogeneous groups allows for simple 
mathematical framework; however, it is challenging, as the groups must be small enough to allow uniformity but large enough to provide significant results.

Shamir and Howard (1979) used regression analysis to relate a pipe's breakage to the exponent of its age. The pipe breakage model is as follows:

$$
N(t)=N\left(t_{0}\right) e^{A(t+g)}
$$

Where: $\quad N(t)=$ number of breaks per unit length per year

$N\left(t_{0}\right)=$ number of breaks per unit length per year at the year of installation of the pipe

$A=$ growth rate coefficient $\left(\right.$ years $\left.^{-1}\right)$

$t=$ time between the present time and the time of a given break in the past (years)

$g=$ age of pipe time $t$ (years)

The location of the study included no details, the quality and quantity of data used, or the method of analysis. The model requires pipe length, installation date and breakage history, as well as the formation of homogeneous groups based on criteria that include pipe type, diameter, soil type, break type, overburden characteristics, etc. Kleiner (2001) recommended careful treatment in applying the model to data partitioned into homogeneous groups (Kleiner, 2001).

Walski and Pellicia (1982) proposed to enhance Shamir and Howard's exponential model by including two additional parameters in the analysis based on observations made by the US Army Corps of Engineers in Binghamton, New York. The 
enhanced exponential model is as follows:

$$
N(t)=C_{1} C_{2} N\left(t_{0}\right) e^{A(t+g)}
$$

Where: $\quad C_{1}=$ ratio between (break frequency for pit/sandspun) cast iron with no/one or more) previous breaks\} and \{overall break frequency for pit/sandspun) cast iron\}

$C_{2}=$ ratio between $\{$ break frequency for pit cast pipes

$500 \mathrm{~mm}$ diameter\} and \{overall break frequency for pit cast pipes\}

The first factor accounted for known previous breaks and the second factor accounted for observed differences in breakage rates for large diameter pit cast iron pipes. Walski and Pellicia (1982) did not provide any information on the derivation of the correction factors and reason for multiplicative application, nor did they indicate if the prediction quality improved. The data required for this model is the same as the model by Shamir and Howard (1979) with the addition of pipe casing data.

McMullen (1982) recommended a linear regression model that related soil properties to the age of a pipe at its first breakage. The regression model is as follows:

$$
\text { Age }=0.028 S R-6.33 p H-0.049 r_{d}
$$

$$
\text { Where: } \begin{aligned}
A g e & =\text { age of pipe at first break (years) } \\
S R & =\text { saturated soil resistivity }(\Omega \mathrm{cm}) \\
p H & =\text { soil } \mathrm{pH} \\
r_{d} & =\text { redox potential (millivolts) }
\end{aligned}
$$

An analysis of a water distribution system in Des Moines, lowa, led to the formation of this model, as $94 \%$ of pipe failures occurred in soils with saturated soil resistivity's less than $2000 \Omega$ centimeters. McMullen determined that saturated soil 
resistivity is the dominant factor with the life cycle of a pipe reducing by 28 years for every $1000 \Omega \mathrm{cm}$ reduction (Kleiner, 2001). This model only predicts the age at first failure and is unable to calculate subsequent pipe failures; therefore, it is not useful in predicting all pipe failures in a water distribution system. In addition, the data required to use this model is not typically available and it is costly to obtain. The study resulted in a coefficient of determination $\left(r^{2}\right)$ of 0.375 , which is not high enough to be a strong prediction.

Clark, Stafford, and Goodrich (1982) developed a two-phase model to predict pipe breakage. The first phase is a linear model that predicts the time until the first break, and the second phase is an exponential model that predicts the number of subsequent breaks. The two-phase model is as follows:

$$
N Y=x_{1}+x_{2} D+x_{3} P+x_{4} I+x_{5} R E S+x_{6} L H+x_{7} T
$$

Where: $\quad N Y=$ number of years from installation to first repair

$$
\begin{aligned}
& x_{\mathrm{i}}=\text { regression parameters } \\
& D=\text { diameter of pipe (in) } \\
& P=\text { absolute pressure within pipe (psi) } \\
& I=\text { percentage of pipe overlain by industrial development } \\
& R E S=\text { percentage of pipe overlain by residential development } \\
& L H=\text { length of pipe in highly corrosive soil } \\
& T=\text { pipe type }(0=\text { reinforced concrete, } 1=\text { metallic) }
\end{aligned}
$$




$$
R E P=y_{1} e^{y_{2} t} e^{y_{3}{ }^{T}} e^{y_{4} P R D} e^{y_{5} D E V} S L^{y_{6}} S H^{y_{7}}
$$

Where: $\quad R E P=$ number of repairs

$$
\begin{aligned}
& y_{\mathrm{i}}=\text { regression parameters } \\
& t=\text { age of pipe from its first break } \\
& T=\text { pipe type ( } 0 \text { = reinforced concrete, } 1 \text { = metallic) } \\
& P R D=\text { pressure differential } \\
& D E V=\text { percentage of pipe length in low and moderately corrosive soil } \\
& S L=\text { surface area of pipe in low corrosively soil } \\
& S H=\text { surface area of pipe in highly corrosive soil }
\end{aligned}
$$

Clark, Stafford, and Goodrich (1982) reported a moderate correlation $\left(r^{2}\right)$ of 0.23 to 0.47 for the linear model (first phase) and exponential model (second phase), respectively. Based on these moderate values, completion of further research is necessary to determine the suitability of these equations. The data required to use this model includes time of installation, breakage history, type and diameter of the pipe, as well as information about operating pressures, soil corrosiveness and zoning composition of area overlaying pipe. Additional types of data such as the type of breaks and pipe vintage are required to enhance the model (Kleiner, 2001).

Kettler and Goulter (1985) proposed a linear relationship between pipe breaks and age. The relationship is as follows:

$$
N=k_{0} A
$$

$$
\begin{aligned}
& \text { Where: } \quad \begin{aligned}
N & =\text { number of breaks per pipe per year } \\
k_{0} & =\text { regression parameter } \\
A & =\text { age of pipe }
\end{aligned}
\end{aligned}
$$


Analysis of pipes installed within a 10-year period in Winnipeg, Manitoba resulted in a correlation $\left(r^{2}\right)$ of 0.884 and 0.672 for asbestos cement and cast iron pipes, respectively, with the exclusion of an outlier. Kettler and Goulter found a strong negative correlation between pipe diameter and breakage rate, signifying that smaller pipes break more frequently than larger pipes (Kleiner, 2001). Kettler and Goulter's relationship requires pipe length, installation date and breakage history, and the formation of homogeneous groups based on criteria that includes pipe type, diameter, soil type, break type, overburden characteristics, etc. The regression parameter is dependent on the homogeneous groups and is therefore scenario specific. Thus, extensive and reliable data is required to determine a regression parameter, which makes this relationship unfavorable for an entire water distribution system.

Jacobs and Karney (1994) used linear regression to develop an equation that relates pipe breaks to pipe length and age. The equation is as follows:

$$
P=a_{0}+a_{1} L+a_{2} A
$$

Where: $\quad P=$ reciprocal of the probability of a day with no breaks

$$
\begin{aligned}
& a_{\mathrm{i}}=\text { regression coefficients } \\
& L=\text { length of pipe } \\
& A=\text { age of pipe }
\end{aligned}
$$

Jacobs and Karney (1994) applied this model to 390 kilometers of six-inch cast iron water mains with 3550 breakage events in Winnipeg. Three homogenous groups based on age were formed, $0-18$ years, $19-30$ years, and greater than 30 years. The required data includes pipe length, age and breakage history. More data enables formation of homogenous groups (Kleiner, 2001). The application of (Eq. 7) for all breaks resulted in a relatively high correlation coefficient $\left(r^{2}\right)$ range of $0.704-0.937$ for the three age groups. Jacobs and Karney considered the occurrence of clustering, a break that 
occurs within 90 days of a previous break and/or less than 20 meters from the previous break (Kleiner, 2001). The first break, called an independent break, is often the first to occur in cluster breaks. The application of (Eq. 7) for independent breaks increased the $r^{2}$ value to $0.957-0.969$ for the three age groups (Kleiner, 2001). The results show that independent breaks are distributed more normally compared to all breaks.

\subsubsection{Probabilistic Models}

Probabilistic models are able to consider many variables that cause pipe failures, reducing the partitioning of water mains into homogeneous groups; however, the mathematical framework becomes much more complex (Kleiner, 2001). The data requirement for these models is significant, as the models become more beneficial with larger data inputs. One type of probabilistic model is a probabilistic multi-variate model, which is better suited for identifying individual pipes for rehabilitation or replacement.

Marks et al. (1985) proposed the use of the proportional hazards model (general failure prediction model) produced by $\operatorname{Cox}(1972)$ to predict water main failures by computing the probability of time between consecutive breaks (Kleiner, 2001). The hazard function proposed by Cox (1972) and the baseline hazard function developed by Mars et al. (1985) are as follows:

$$
\begin{gathered}
h(t, Z)=h_{0}(t) e^{b^{T} Z} \\
h_{0}(t)=2 \times 10^{-4}-10^{-5} t+2 \times 10^{-7} t^{2}
\end{gathered}
$$

Where: $\quad h(t, Z)=$ hazard function, instantaneous rate of failure (probability of failure at time $t+\Delta t$ given survival to time $t$ )

$h_{O}(t)=$ arbitrary baseline hazard function

$t=$ survival time 


$$
\begin{aligned}
& b=\text { vector of coefficients to be estimated by regression from data } \\
& T=\text { time to next break } \\
& Z=\text { vector of covariates acting multiplicatively on the hazard function }
\end{aligned}
$$

The baseline hazard function accounts for the time-dependent age component and the covariates represent the environmental and operational stress factors (Kleiner, 2001). Marks et al. (1985) determined that the data required to encompass the most important covariates are: natural log of pipe length, operating pressure, percentage of low land development, pipe "vintage" or period of installation, pipe age at second (or higher) break rate, number of previous breaks in pipe, and soil corrosiveness (Kleiner, 2001). Figure 2.10 exhibits the concept of proportional hazards for a 100-meter-long pipe with no previous breaks, installed in 1950.

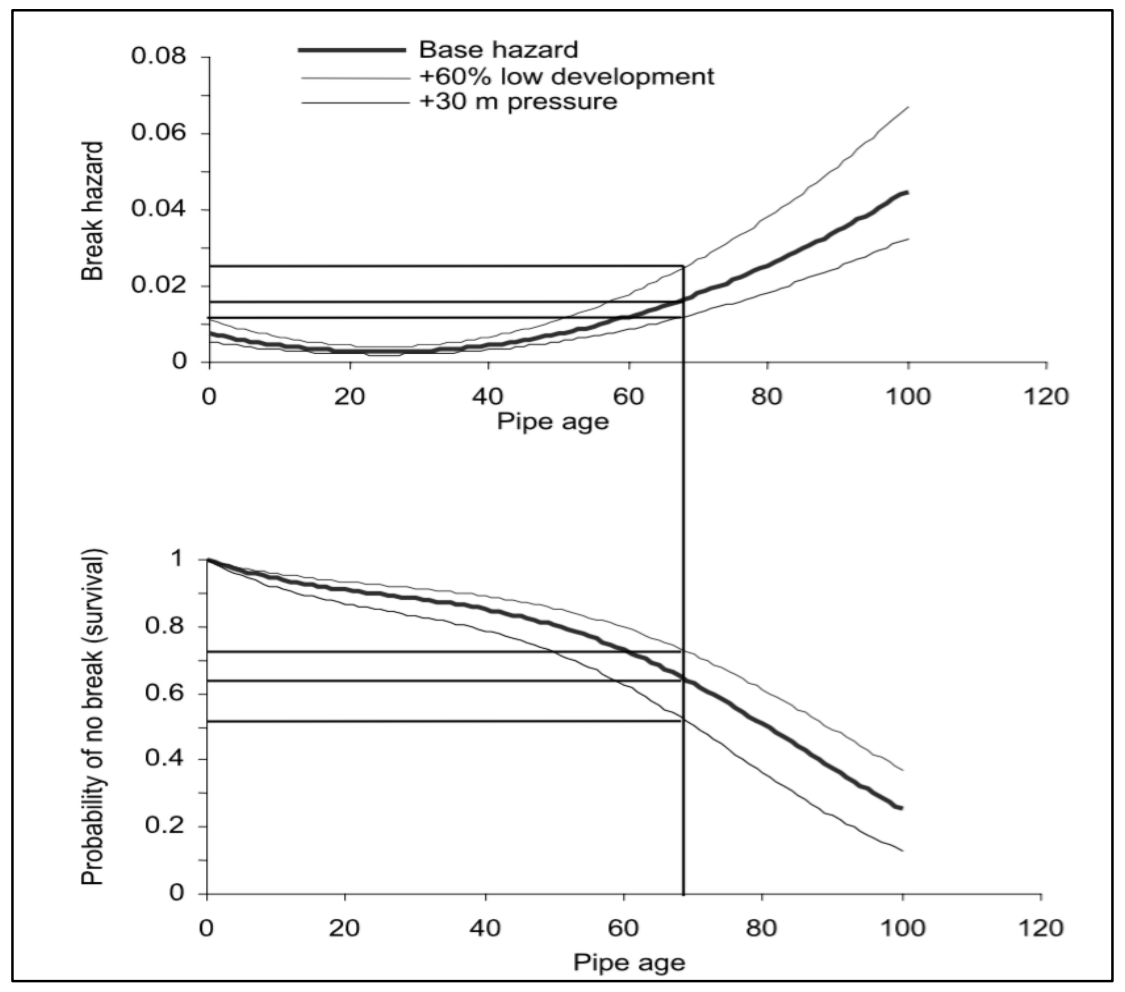

Figure 2.10 Proportional Hazards Model (Kleiner, 2001)

The base hazard model (dark line) represents a pipe overlain by $20 \%$ low land development and an operating pressure of 30 meters. If this pipe were to reach an age 
of 70 without experiencing a break, it has an instantaneous rate of failure in the next year of about $1.5 \%$ (top graph). The probability of this pipe surviving 70 years without a break is about $63 \%$ (bottom graph). The other lines on this graph depict the effects of changing specific covariates on the instantaneous failure rate and probability of survival.

The proportional hazards model produces a base hazard function that is similar in shape to a bathtub curve (Figure 2.8). The base hazard function is at a minimum when the age of the pipe, with no breaks (or after a previous break), is 28 years (Kleiner, 2001). As the pipe matures from first installation or from the time of repair, its instantaneous probability of failure decreases, then the probability of failure begins to increase again after 28 years.

\subsubsection{Physical Models}

Physical/mechanical models attempt to analyze pipe failure by determining the load applied to the pipe in comparison to the resistance capacity of the pipe. Physical models drastically improve the ability to predict water main failures, and a pure physical model would be able to account for all the factors acting on the pipe so that the statistical analysis of breakage history would not be necessary; however, the data requirement for physical modelling to be effective is overwhelming. Most water distribution systems do not have the data required to use a physical model, and the cost of acquiring this data is only justified for large water mains (Kleiner, 2001).

\subsubsection{Model Limitations}

Kleiner (2001) suggested the completion of more research in order to validate the statistical and physical models. The prediction capabilities of statistical and physical models are limited by the accuracy and availability of data collected by the municipality, as data requirements determine the specific model applied. Municipalities vary in the 
reliability and quantity of data collected, and acquiring additional data may be too costly. Thus, a model built for one water distribution system may not work for another (AWWA, 2014). In addition, varying mathematical complexity of these models may pose a challenge for use in municipalities due to the mathematical expertise and time required to perform necessary assessments. Thus, the ideal model is a mathematically simple model that requires data that is readily collected and available, as well as accurate. This will allow for the research and validation of the model through the application of multiple water distribution systems.

\subsection{Jan Devera's Risk Assessment Model}

Devera (2013) developed a risk assessment model that would be mathematically simple and economically affordable, as well as universally applicable and customizable. Based on a model that was started, but never completed, by Water Systems Consulting Inc. (WSC), Devera's model consists of a three-stage procedure: (1) computation of remaining useful life (RUL) and probability of failure score (PF); (2) determination of degree of impact score (IS) due to a failure; and (3) establishment of risk of failure score (RFS).

The calculation of remaining useful life requires data on the installation year, pipe material, and breakage history. The installation year of the pipe determines the age of the pipe. Pipe material regulates the manufacturer's recommended service life, given as a range, which does not consider other factors such as pipe diameter. Devera (2013) calculated anticipated service life (ASL) as the mean of the manufacture's service life. Based on assumptions, break history will cause a percent adjustment. This model only considers breaks that have happened in the past 20 years, from the time that the model is applied (Devera, 2013). Table 2.2 displays different pipe materials and their anticipated service life. Table 2.3 presents the effect of pipe breakage on RUL. 
Table 2.2 Pipe Materials and Anticipated Service Life (Devera, 2013)

\begin{tabular}{|c|c|c|c|}
\hline Pipe Material & Abbreviation & $\begin{array}{c}\text { Manufacturer's Service } \\
\text { Life (Years) }\end{array}$ & $\begin{array}{c}\text { Anticipated Service Life } \\
\text { (ASL) }\end{array}$ \\
\hline Cast Iron & CIP & $50-100$ & 75 \\
\hline Ductile Iron & DIP & $75-125$ & 100 \\
\hline Galvanized Iron & GALV & $40-60$ & 50 \\
\hline Steel & STL & $30-75$ & 40 \\
\hline PVC & PVC & $50-150$ & 100 \\
\hline Composite (Techite) & COMP & $50-150$ & 50 \\
\hline Asbestos Cement & ACP & $75-125$ & 100 \\
\hline unknown & - & $50-150$ & 50 \\
\hline
\end{tabular}

Table 2.3 Break History Adjustment (Devera, 2013)

\begin{tabular}{|c|c|c|c|c|c|}
\hline \multirow{3}{*}{$\begin{array}{l}\text { Original } \\
\text { RUL }\end{array}$} & \multicolumn{4}{|c|}{$\begin{array}{c}\text { Break History Adjustment } \\
\text { (Frequency within the last } 20 \text { years) }\end{array}$} & \multirow[b]{2}{*}{$\begin{array}{l}\text { Number of } \\
\text { Incidents }\end{array}$} \\
\hline & No incidents & 1 incident & 2 incidents & $\begin{array}{l}3 \text { or more } \\
\text { incidents }\end{array}$ & \\
\hline & $100 \%$ & $30 \%$ & $20 \%$ & $10 \%$ & $\begin{array}{c}\text { Percent } \\
\text { Adjustment }\end{array}$ \\
\hline 100 & 100 & 30 & 20 & 10 & \multirow{10}{*}{$\begin{array}{c}\text { Adjusted } \\
\text { Remaining } \\
\text { Useful Life } \\
\text { (RUL) }\end{array}$} \\
\hline 90 & 90 & 27 & 18 & 9 & \\
\hline 80 & 80 & 24 & 16 & 8 & \\
\hline 70 & 70 & 21 & 14 & 7 & \\
\hline 60 & 60 & 18 & 12 & 6 & \\
\hline 50 & 50 & 15 & 10 & 5 & \\
\hline 40 & 40 & 12 & 8 & 4 & \\
\hline 30 & 30 & 9 & 6 & 3 & \\
\hline 20 & 20 & 6 & 4 & 2 & \\
\hline 10 & 10 & 3 & 2 & 1 & \\
\hline
\end{tabular}


RUL for each water main in the water distribution system is calculated using the following equation:

$$
R U L=(A S L-A g e) \times P_{\text {adj }}
$$

$$
\begin{aligned}
& \text { Where: } \quad \begin{aligned}
R U L & =\text { remaining useful life of pipe (years) } \\
A S L & =\text { anticipated service life (years) } \\
A g e & =\text { pipe age from year of installation to present (years) } \\
P_{a d j} & =\text { break history percent adjustment }
\end{aligned}
\end{aligned}
$$

\begin{tabular}{|c|c|c|}
\hline $\begin{array}{l}\text { Remaining Useful Life } \\
\text { (RUL) in Years }\end{array}$ & $\begin{array}{l}\text { Probability of Failure (PF) } \\
\text { Score }\end{array}$ & $\begin{array}{l}\text { Risk } \\
\text { Level }\end{array}$ \\
\hline Less than 2 & 10 & High \\
\hline 2 to 4 & 9 & $\uparrow$ \\
\hline 4 to 6 & 8 & \\
\hline 6 to 8 & 7 & \\
\hline 8 to 10 & 6 & \\
\hline 10 to 12 & 5 & \\
\hline 12 to 14 & 4 & \\
\hline 14 to 17 & 3 & \\
\hline 17 to 19 & 2 & $\downarrow$ \\
\hline Greater than or equal to 20 & 1 & Low \\
\hline
\end{tabular}

The probability of failure is given in a score and is based on the RUL. Table 2.4 exhibits the scoring criteria and relative risk of failure.

Table 2.4 Probability of Failure Scoring Criteria (Devera, 2013)

The degree of impact score attempts to quantify the magnitude of economic consequences that result due to a pipe breakage. Incorporating the effects of a pipe breakage as well as the replacement or rehabilitation of the pipe allows for a model that identifies pipes in a high priority area. Devera (2013) identified the significant impact criteria as customer criticality, pipe material phasing, land use, service demand, traffic 
impact, and estimated cost for pipe replacement. Devera (2013) and WSC researched each criteria and determined a ranking system based on their analysis. Table 2.5 provides the criteria and degree of impact scores.

Table 2.5 Impact Score Criteria (Devera, 2013)

\begin{tabular}{|c|c|c|c|c|c|}
\hline \multirow{2}{*}{$\begin{array}{c}\text { Impact } \\
\text { Criterion }\end{array}$} & \multicolumn{5}{|c|}{ Impact Score } \\
\hline & 1 & 2 & 3 & 4 & 5 \\
\hline $\begin{array}{c}\text { Service } \\
\text { Demand }\end{array}$ & $<160 \mathrm{gpm}$ & $\begin{array}{l}\text { between } \\
160-320 \mathrm{gpm}\end{array}$ & $\begin{array}{l}\text { between } \\
320-480 \mathrm{gpm}\end{array}$ & $\begin{array}{c}\text { between } \\
480-640 \mathrm{gpm}\end{array}$ & $\geq 640 \mathrm{gpm}$ \\
\hline $\begin{array}{l}\text { Customer } \\
\text { Criticality }\end{array}$ & $\begin{array}{c}\text { No critical } \\
\text { customers or } \\
\text { pipe size }<8 \text { " }\end{array}$ & $\begin{array}{l}\text { At least } 1 \text { Critical } \\
\text { Customer }\end{array}$ & $\begin{array}{l}2 \text { Critical } \\
\text { Customers }\end{array}$ & $\begin{array}{l}3 \text { Critical } \\
\text { Customers }\end{array}$ & $\begin{array}{l}4 \text { or more Critical } \\
\text { Customers }\end{array}$ \\
\hline Land Use & $\begin{array}{l}\text { Agriculture, } \\
\text { Open Space }\end{array}$ & $\begin{array}{l}\text { Very low to low } \\
\text { medium Density } \\
\text { Residential }\end{array}$ & $\begin{array}{l}\text { Low medium to } \\
\text { high Density } \\
\text { residential }\end{array}$ & $\begin{array}{l}\text { High to very high } \\
\text { Density residential, } \\
\text { Village core, or } \\
\text { mixed use }\end{array}$ & $\begin{array}{l}\text { Office professional, } \\
\text { Regional } \\
\text { Commercial, or } \\
\text { Community Facility }\end{array}$ \\
\hline $\begin{array}{l}\text { Traffic } \\
\text { Impact }\end{array}$ & Local Streets & Collector Street & Priority 2 Transit & Priority 1 Transit & Arterial Street \\
\hline $\begin{array}{l}\text { Material } \\
\text { Phasing }\end{array}$ & $\mathrm{PVC}$ and $\mathrm{ACP}$ & Ductile Iron & Steel \& Techite & Galvanized Iron & $\begin{array}{l}\text { Unlined Cast Iron or } \\
\text { unknown material }\end{array}$ \\
\hline $\begin{array}{l}\text { Estimated } \\
\text { Total Cost } \\
\text { for Repair }\end{array}$ & $\leq \$ 26,440$ & $\begin{array}{c}\text { between } \\
\$ 26,440-\$ 52,882\end{array}$ & $\begin{array}{c}\text { between } \\
\$ 52,882-\$ 79,322\end{array}$ & $\begin{array}{c}\text { between } \\
\$ 79,322-\$ 105,762\end{array}$ & $\geq \$ 105,762$ \\
\hline
\end{tabular}

The total degree of impact score is calculated using the following equation:

$$
\text { Total IS = IS demand + IS criticality }+I S \text { land use }+I \text { Straffic }+I S \text { phasing }+I S \text { cost }
$$

Where: $\quad$ Total IS = cumulative impact score for each pipe segment

$$
I S_{i}=\text { impact score for the specified criteria }
$$

The product probability of failure score and the sum of the degree of impact scores results in the risk of failure score. The equation is as follows:

$$
\text { RFS }=\text { Total IS } \times P F
$$

Where: $\quad$ RFS = pipe risk of failure score

Total IS = cumulative impact score for each pipe segment $P F=$ probability of failure score 
Figure 2.11 presents the calculation of risk of failure score and the included parameters.

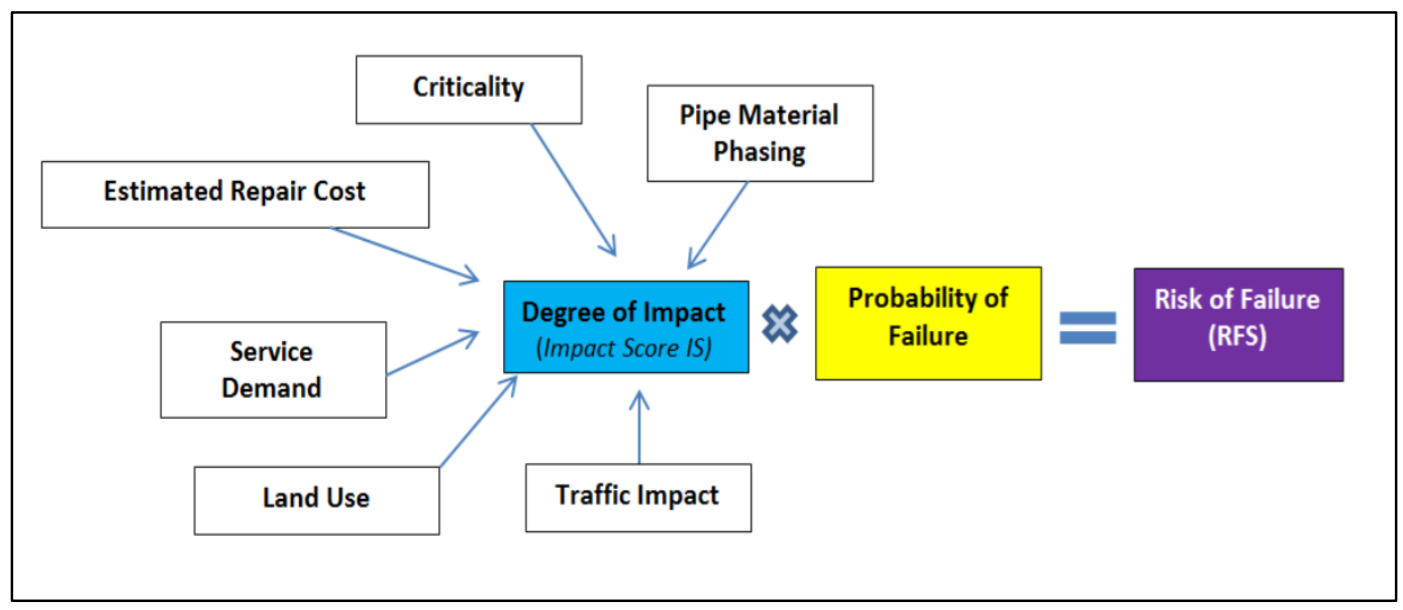

Figure 2.11 Risk of Failure Computation (Devera, 2013)

Table 2.6 displays the risk of failure scores that a pipe can have depending on its probability of failure score and degree of impact score. Table 2.7 provides a legend that categorizes failure risk level from very low to high. Based on data availability, adjustment of values in this table is necessary if the degree of impact criteria changes.

Table 2.6 Risk of Failure Score for Varied PF and IS (Devera, 2013)

\begin{tabular}{|c|c|c|c|c|c|c|c|c|c|c|c|c|c|c|c|c|c|c|c|c|c|c|c|c|c|c|c|c|c|c|}
\hline & \multicolumn{28}{|c|}{ Total Impact Score } & \\
\hline & & 3 & 4 & 5 & 6 & 7 & 8 & 9 & 10 & 11 & 12 & 13 & 14 & 15 & 16 & 17 & 18 & 19 & 20 & 21 & 22 & 23 & 24 & 25 & 26 & 27 & 28 & 29 & 30 & \\
\hline \multirow{10}{*}{ कृ } & 1 & 3 & 4 & 5 & 6 & 7 & 8 & 9 & 10 & 11 & 12 & 13 & 14 & 15 & 16 & 17 & 18 & 19 & 20 & 21 & 22 & 23 & 24 & 25 & 26 & 27 & 28 & 29 & 30 & \\
\hline & 2 & 6 & 8 & 10 & 12 & 14 & 16 & 18 & 20 & 22 & 24 & 26 & 28 & 30 & 32 & 34 & 36 & 38 & 40 & 42 & 44 & 46 & 48 & 50 & 52 & 54 & 56 & 58 & 60 & \\
\hline & 3 & 9 & 12 & 15 & 18 & 21 & 24 & 27 & 30 & 33 & 36 & 39 & 42 & 45 & 48 & 51 & 54 & 57 & 60 & 63 & 66 & 69 & 72 & 75 & 78 & 81 & 84 & 87 & 90 & \\
\hline & 4 & 12 & 16 & 20 & 24 & 28 & 32 & 36 & 40 & 44 & 48 & 52 & 56 & 60 & 64 & 68 & 72 & 76 & 80 & 84 & 88 & 92 & 96 & 100 & 104 & 108 & 112 & 116 & 120 & \\
\hline & 5 & 15 & 20 & 25 & 30 & 35 & 40 & 45 & 50 & 55 & 60 & 65 & 70 & 75 & 80 & 85 & 90 & 95 & 100 & 105 & 110 & 115 & 120 & 125 & 130 & 135 & 140 & 145 & 150 & \\
\hline & 6 & 18 & 24 & 30 & 36 & 42 & 48 & 54 & 60 & 66 & 72 & 78 & 84 & 90 & 96 & 102 & 108 & 114 & 120 & 126 & 132 & 138 & 144 & 150 & 156 & 162 & 168 & 174 & 180 & \\
\hline & 7 & 21 & 28 & 35 & 42 & 49 & 56 & 63 & 70 & 77 & 84 & 91 & 98 & 105 & 112 & 119 & 126 & 133 & 140 & 147 & 154 & 161 & 168 & 175 & 182 & 189 & 196 & 203 & 210 & \\
\hline & 8 & 24 & 32 & 40 & 48 & 56 & 64 & 72 & 80 & 88 & 96 & 104 & 112 & 120 & 128 & 136 & 144 & 152 & 160 & 168 & 176 & 184 & 192 & 200 & 208 & 216 & 224 & 232 & 240 & \\
\hline & 9 & 27 & 36 & 45 & 54 & 63 & 72 & 81 & 90 & 99 & 108 & 117 & 126 & 135 & 144 & 153 & 162 & 171 & 180 & 189 & 198 & 207 & 216 & 225 & 234 & 243 & 252 & 261 & 270 & \\
\hline & 10 & 30 & 40 & 50 & 60 & 70 & 80 & 90 & 100 & 110 & 120 & 130 & 140 & 150 & 160 & 170 & 180 & 190 & 200 & 210 & 220 & 230 & 240 & 250 & 260 & 270 & 280 & 290 & 300 & \\
\hline
\end{tabular}


Table 2.7 Risk of Failure Category (Devera, 2013)

\begin{tabular}{|c|c|c|}
\hline RFS Value & Color & Failure Risk Level \\
\hline $\mathbf{2 0}$ & Blue & Very Low \\
\hline $\mathbf{2 1}$ to $\mathbf{7 0}$ & Green & Low \\
\hline $\mathbf{7 1}$ to $\mathbf{1 5 0}$ & Orange & Medium \\
\hline $\mathbf{2 1 5 1}$ & Red & High \\
\hline
\end{tabular}

\subsection{Hernan Cortez's Risk Assessment Model}

The risk assessment model by Cortez (2015) aimed at comparing and verifying the capabilities of the simplified model proposed by Devera (2013) with a statistically and computationally intensive model. Cortez's model follows the same three-stage procedure as Devera's model with small adjustments; however, the major difference is in the calculation of remaining useful life. The three-stage procedure is as follows: (1) computation of remaining useful life (RUL) and probability of failure score (PF); (2) determination of degree of impact score (IS) due to a failure; and (3) establishment of risk of failure score (RFS).

The calculation of remaining useful life requires data on the pipe age, expected service life, pipe diameter, pipe material, pipe length, internal pressure, percent covered by residential areas, percent covered by industrial areas, and breakage history (Cortez, 2015). Incorporating additional factors attempts to minimize the uncertainty and variation in a pipe's service life based on additional operating conditions. Cortez (2015) chose the linear regression model developed by Clark, Stafford, and Goodrich (1982) because the data required for this model is usually available at municipalities. The linear 
model developed by Clark et al. (1982) is as follows:

$$
N Y=x_{1}+x_{2} D+x_{3} P+x_{4} I+x_{5} R E S+x_{6} L H+x_{7} T
$$

Where: $\quad N Y=$ number of years from installation to first repair

$$
\begin{aligned}
& x_{\mathrm{i}}=\text { regression parameters } \\
& D=\text { diameter of pipe (in) } \\
& P=\text { absolute pressure within pipe (psi) } \\
& I=\text { percentage of pipe overlain by industrial development } \\
& R E S=\text { percentage of pipe overlain by residential development } \\
& L H=\text { length of pipe in highly corrosive soil } \\
& T=\text { pipe type }(0=\text { reinforced concrete, } 1=\text { metallic) }
\end{aligned}
$$

Cortez (2015) modeled the anticipated service life parameter, $x_{1}$, as a normal random variable due to the uncertainty in the service life of a pipe. A Monte Carlo simulation, with 100,000 iterations, was used to determine the most probable anticipated service life of each pipe. The results of each iteration were inserted into Eq. 4 and the expected number of years from installation to first repair of each pipe was calculated. Figure 2.12 provides a histogram for cast iron pipes created from the 100,000 iteration Monte Carlo simulation.

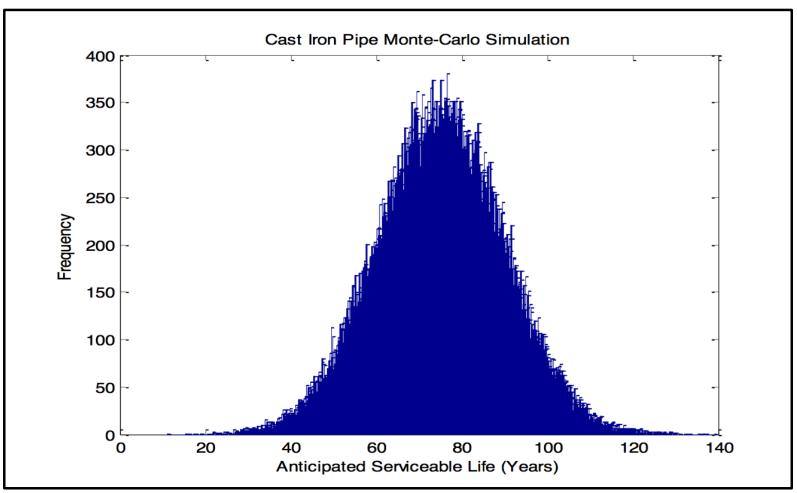

Figure 2.12 Monte Carlo Simulation Histogram for Cast Iron Pipes 
All other regression parameters were determined by the linear regression model presented by Clark et al. (1982). Table 2.8 provides the regression parameters.

Table 2.8 Regression Parameters (Cortez, 2015)

\begin{tabular}{c|cc}
\hline Regression Parameter & Definition & Assigned Value \\
\hline \hline $\mathrm{X}_{1}$ & Anticipated serviceable life. Modeled as & $\begin{array}{c}\text { Varies based on Monte } \\
\text { Carlo Simulation }\end{array}$ \\
$\mathrm{X}_{2}$ & Diameter parameter & 0.338 \\
$\mathrm{X}_{3}$ & Pressure parameter based on the & -0.022 \\
$\mathrm{X}_{4}$ & magnitude of pressure within pipe & -0.265 \\
$\mathrm{X}_{5}$ & Industrial cover parameter & -0.0983 \\
$\mathrm{X}_{6}$ & Residential cover parameter & -0.003 \\
$\mathrm{X}_{7}$ & Length parameter & 13.28 \\
\hline \hline
\end{tabular}

RUL is calculated using the following equation:

$$
R U L=(N Y-A g e)
$$

Where: $\quad R U L=$ remaining useful life of pipe (years)

$N Y=$ number of years from installation to first failure (years)

Age $=$ pipe age from year of installation to present (years)

Cortez (2015) adjusted the RUL for breakage history by decreasing the RUL by $10 \%$ for each previous break. Using the adjusted RUL, the probability of failure score is determined.

Degree of impact score depends on the following criteria: cost of pipe replacement (material only), loss of service, traffic impacts, and affected critical customers (Cortez, 2015).

The risk of failure score is determined as the product of the probability of failure score and the combined degree of impact score. Table 2.9 displays the risk of failure score categorized from low risk to critical risk. 
Table 2.9 Risk of Failure Category (Cortez, 2015)

\begin{tabular}{c|c}
\hline Risk Score & $\begin{array}{c}\text { Risk Category and } \\
\text { Color Designation }\end{array}$ \\
\hline \hline 0 to 40 & Low Risk \\
40 to 80 & Medium Risk \\
80 to 100 & High Risk \\
$\geq 100$ & Critical Risk \\
\hline \hline
\end{tabular}

The content in this chapter has helped in the selection of the proper computational model. Chapter 3 provides the methodology and criteria for the selected model. 


\section{CHAPTER 3}

\section{RISK ASSESSMENT METHODOLOGY}

\subsection{Overview}

The main goal of this study was to evaluate and compare the risk assessment models proposed by Devera (2013), a simplified model, and Cortez (2015), a statistically and computationally complex model. Both models accurately highlight a water distribution system's most critical pipes, with the intention of being universally applicable. Application of these models to the water distribution system of the City of Arroyo Grande allowed for an initial comparison of the models. The models produced a similar result, which suggests that the simplified model provided by Devera (2013) is preferred due to its simplicity and economic affordability. Cortez (2015) recommended that these models be applied to another water distribution system, as the results may differ from the initial comparison. The ultimate goal of this study was to verify the results found by Cortez (2015), validating the effectiveness of the simplified model for future water distribution system analyses.

Both models are composed of a three-stage procedure to calculate a pipe's risk of failure: (1) computation of remaining useful life (RUL) and probability of failure (PF); (2) determination of degree of impact (DI) due to a failure; and (3) establishment of risk of failure (RF).

The first stage of analysis differs between the two models. Devera's simplified model requires data on the installation year, pipe material, and breakage history. Cortez's complex model requires data on the pipe age, expected service life, pipe diameter, pipe material, pipe length, internal pressure, percent covered by residential areas, percent covered by industrial areas, and breakage history. The remaining useful 
life of each pipe is calculated from the required data to determine a numerical score that represents the pipe's probability of failure.

The second stage assesses and quantifies the consequences caused by a pipe's failure. Consequences include the cost of pipe replacement (material only), loss of service, traffic impacts, and affected critical customers. Individual consequences are scaled to reflect a specific water distribution system and consequences may be included or excluded as needed. After all consequences have been considered, a numerical score is determined for each pipe that represents the degree of impact, or the pipe's relative importance.

The final stage combines the results from the first and second stage to determine the pipe's risk of failure. The risk of failure score represents the likelihood of a pipe failure and allows for pipes to be ranked for rehabilitation/replacement purposes.

\subsection{Stage 1: Computing Remaining Useful Life}

The primary focus of this stage was the computation of the remaining useful life of each water main. The RUL is the estimated time before a pipe will experience a failure mode, specifically a pipe break. As mentioned in Section 3.1, the computation of RUL is the main difference between the simplified model and the complex model.

Utilization of Monte Carlo simulations were required for the calculation of RUL due to the uncertainty within a few variables. These variables were modeled as normal random variables based on the histogram results presented by Cortez (2015) in Section 2.7. The number of iterations needed for each Monte Carlo simulation was determined based on the mean and standard deviation of the outputs, the confidence level of the results, and the desired margin of error (Driels, 2004). 10,000 iterations were used for each Monte Carlo simulation, which exceeds the number of iterations necessary for a confidence level of $99.75 \%$ and a desired margin of error of 1 unit. 


\subsubsection{Pipe Age}

Pipe age is determined by calculating the number of years from a pipe's installation year to the present day. It is assumed that the pipe has been continually in service throughout its entire life span.

Pipe installation records are not always available due to incomplete record keeping. To account for this lack of data, an approximate installation date can be calculated from common installation dates of varying pipe materials provided by AWWA (2011). The span of common installation periods can be used to calculate the average and standard deviation of pipe installation dates based on material. Table 3.1 provides the pipe material, common installation periods, mean installation year, and standard deviation of installation year.

Table 3.1 Pipe Material Installation Year

\begin{tabular}{|c|c|c|c|c|}
\hline Pipe Material & Abbreviation & $\begin{array}{c}\text { Common } \\
\text { Installation } \\
\text { Periods }\end{array}$ & $\begin{array}{c}\text { Mean } \\
\text { Installation } \\
\text { Year }\end{array}$ & $\begin{array}{c}\text { Standard } \\
\text { Deviation of } \\
\text { Installation } \\
\text { Year }\end{array}$ \\
\hline $\begin{array}{c}\text { Asbestos } \\
\text { Cement }\end{array}$ & $\mathrm{ACP}$ & $1950-1970$ & 1960 & 3.33 \\
\hline Ductile Iron & DIP & $1960-2016$ & 1988 & 9.33 \\
\hline $\begin{array}{l}\text { Polyvinyl } \\
\text { Chloride }\end{array}$ & PVC & $1970-2016$ & 1993 & 7.67 \\
\hline Steel & STL & 1940-2016 & 1978 & 12.67 \\
\hline
\end{tabular}

Pipe age was calculated by the following equation:

$$
\text { Age }=(\text { Present Year }- \text { Installation Year })
$$

$$
\begin{array}{ll}
\text { Where: } & \text { Age }=\text { age of pipe (years) } \\
& \text { Present Year }=\text { current year (years) } \\
\text { Installation Year }=\text { year of installation (years) }
\end{array}
$$


Due to the uncertainty of a pipe's age, it was modeled as a normal random variable. A Monte Carlo simulation, with 10,000 iterations, was utilized to determine the most probable pipe age for each pipe material. The result of each iteration was inserted into the RUL equations, provided in Sections 3.2.2.2 and 3.3.3.3.

\subsubsection{Simplified Model}

The following sections provide an explanation of the data and procedure used to calculate the RUL of each pipe with the simplified model.

\subsubsection{Pipe Material and Anticipated Service Life}

The longevity, based on the structural strength and operational efficiency of a pipe, varies depending on the pipe material. Pipe manufacturers often specify a manufacturer recommended service life (MRSL), given in a range of years, for which the pipe will remain structurally and operationally intact. For this study, it is assumed that the MRSL only takes into account the pipe's material type and all other factors are excluded. The MRSL for each pipe material was obtained from Devera (2013). Anticipated service life (ASL) of each pipe material is calculated as the mean of the MRSL. Table 3.2 provides the pipe material, pipe material abbreviation, MRSL, ASL, and the standard deviation of ASL.

Table 3.2 Pipe Material Anticipated Service Life

\begin{tabular}{|c|c|c|c|c|}
\hline Pipe Material & Abbreviation & MRSL (years) & ASL (years) & $\begin{array}{c}\text { Standard } \\
\text { Deviation of } \\
\text { ASL (years) }\end{array}$ \\
\hline \multirow{5}{*}{$\begin{array}{c}\text { Asbestos Cement } \\
\text { Ductile Iron } \\
\text { Polyvinyl Chloride } \\
\text { Steel } \\
\text { unknown }\end{array}$} & $\mathrm{ACP}$ & $75-125$ & 100 & 8.33 \\
\hline & DIP & $75-125$ & 100 & 8.33 \\
\hline & PVC & $50-150$ & 100 & 16.67 \\
\hline & STL & $30-75$ & 52.5 & 7.5 \\
\hline & - & $50-150$ & 100 & 16.67 \\
\hline
\end{tabular}


This study used the ASL as a conservative estimate of the structural and operational service life of a pipe. ASL is modeled as a normal random variable due to uncertainty within this parameter. A Monte Carlo simulation, with 10,000 iterations, was utilized to determine the most probable ASL for each pipe material. The result of each iteration was inserted into the RUL equation provided in Section 3.2.2.2.

The unknown pipe material class estimates the MRSL and ASL for instances where pipe material is unknown due to missing data or other circumstances.

\subsubsection{Calculating RUL}

RUL is the difference between the pipe's age and ASL. Slightly modified from the equation presented by Devera (2013) in Section 2.6, the calculation of RUL used the following equation:

$$
R U L=(A S L-A g e)
$$

Where: $\quad R U L=$ remaining useful life of pipe (years)

$$
A S L=\text { anticipated service life (years) }
$$

Age $=$ pipe age from year of installation to present (years)

As mentioned in Sections 3.2.1 and 3.2.2.1, pipe age and anticipated service life are estimated using 10,000 Monte Carlo simulations. Each iteration is inserted into Eq. 15 (Eq. 15 is calculated 10,000 times for each pipe) and the mean RUL was calculated for each pipe.

\subsubsection{Complex Model}

The following sections provide an explanation of the data and procedure used to calculate the RUL of each pipe with the complex model. 


\subsubsection{Clark et al. Model}

Clark et al. (1982) provides a linear model that predicts the number of years from installation until the first break. Cortez (2015) concluded that based on available data the Clark et al. (1982) linear model offered the best results. The data required to use this model includes time of installation, breakage history, type and diameter of the pipe, as well as information about operating pressures, soil corrosiveness, and zoning composition of area overlaying pipe. The required data suits a universally applicable risk assessment model, as most municipalities will be able to provide this data from records. The Clark et al. (1982) linear model, as stated in Section 2.5.1.1, is as follows:

$$
N Y=x_{1}+x_{2} D+x_{3} P+x_{4} I+x_{5} R E S+x_{6} L H+x_{7} T
$$

Where: $\quad N Y=$ number of years from installation to first repair

$$
\begin{aligned}
& x_{i}=\text { regression parameters } \\
& D=\text { diameter of pipe }(\text { in }) \\
& P=\text { absolute pressure within pipe (psi) } \\
& I=\text { percentage of pipe overlain by industrial development } \\
& R E S=\text { percentage of pipe overlain by residential development } \\
& L H=\text { length of pipe in highly corrosive soil } \\
& T=\text { pipe type }(0=\text { reinforced concrete, } 1=\text { metallic) }
\end{aligned}
$$

Percentage of pipe overlain by industrial or residential development is determined based on land use. Percentage cover values were based on the estimated number of passenger cars (residential) and heavy vehicles (industrial) that would travel on a roadway. Table 3.3 provides residential and industrial percentage cover values based on values recommended by Cortez (2015). 
Table 3.3 Percent Residential and Industrial Cover

\begin{tabular}{|c|c|c|}
\hline Land Use & $\%$ Residential & $\%$ Industrial \\
\hline Agricultural & 75 & 25 \\
\hline Commercial & 96 & 4 \\
\hline Industrial & 50 & 50 \\
\hline Public & 96 & 4 \\
\hline Residential & 100 & 0 \\
\hline${ }^{*}$ Mixed Use & 96 & 4 \\
\hline **Industrial Mixed Use & 25 & 75 \\
\hline
\end{tabular}

*Mixed Use designates a combination of land uses (excludes Industrial)

**Industrial Mixed Use designates a combination of land uses (includes Industrial)

The length of pipe in highly corrosive soil is assumed to be equal to the total length of the pipe. Determining the length of pipe exposed to corrosive soil would be exhaustive and it is not information that a municipality commonly collects. Assuming that the entire pipe is in highly corrosive soil slightly affects the accuracy of the model; however, it accounts for the worst-case scenario.

Cortez (2015) provided values for the pipe type variable depending on pipe material. Table 3.4 specifies the pipe type value based on pipe material.

Table 3.4 Pipe Type

\begin{tabular}{c|cc}
\hline Pipe Material & Abbreviation & Pipe Type \\
\hline Asbestos Cement & ACP & 0.1 \\
Ductile Iron & DIP & 0.8 \\
Polyvinyl Chloride & PVC & 0.3 \\
Steel & STL & 1 \\
\hline
\end{tabular}

\subsubsection{Regression Parameters and Pipe Materials}

Table 3.5 provides the regression parameters, $x_{i}$, determined by Clark et al. (1982). 
Table 3.5 Clark Model Regression Parameters

\begin{tabular}{|c|c|c|}
\hline $\begin{array}{l}\text { Regression } \\
\text { Parameter }\end{array}$ & Definition & Assigned Value \\
\hline $\mathrm{x}_{1}$ & $\begin{array}{l}\text { Anticipated Service Life parameter } \\
\text { (modeled as a random variable) }\end{array}$ & $\begin{array}{c}\text { Varies based on Monte } \\
\text { Carlo simulation and pipe } \\
\text { material }\end{array}$ \\
\hline$x_{2}$ & Diameter parameter & 0.338 \\
\hline$x_{3}$ & Pressure parameter & -0.022 \\
\hline $\mathrm{x}_{4}$ & Industrial cover parameter & -0.265 \\
\hline$x_{5}$ & Residential cover parameter & -0.0983 \\
\hline $\mathrm{x}_{6}$ & Corrosive soil length parameter & -0.0003 \\
\hline$x_{7}$ & Pipe material parameter & 13.28 \\
\hline
\end{tabular}

As mention in Section 3.2.2.1, anticipated service life is modeled as a normal random variable due to uncertainty within this parameter. Table 3.6 provides the pipe material, pipe material abbreviation, MRSL, ASL, and the standard deviation of ASL.

Table 3.6 Pipe Material Anticipated Service Life

\begin{tabular}{|c|c|c|c|c|}
\hline Pipe Material & Abbreviation & $\begin{array}{l}\text { Manufacturer } \\
\text { Recommended } \\
\text { Service Life } \\
\text { (years) }\end{array}$ & $\begin{array}{c}\text { Anticipated } \\
\text { Service Life } \\
\text { (years) }\end{array}$ & $\begin{array}{c}\text { Standard } \\
\text { Deviation of } \\
\text { Anticipated } \\
\text { Service Life } \\
\text { (years) }\end{array}$ \\
\hline \multirow{5}{*}{$\begin{array}{c}\text { Asbestos Cement } \\
\text { Ductile Iron } \\
\text { Polyvinyl Chloride } \\
\text { Steel } \\
\text { unknown }\end{array}$} & $\mathrm{ACP}$ & $75-125$ & 100 & 8.33 \\
\hline & DIP & $75-125$ & 100 & 8.33 \\
\hline & PVC & $50-150$ & 100 & 16.67 \\
\hline & STL & $30-75$ & 52.5 & 7.5 \\
\hline & - & $50-150$ & 100 & 16.67 \\
\hline
\end{tabular}

A Monte Carlo simulation, with 10,000 iterations, was utilized to determine the most probable ASL for each pipe material. The result of each iteration was inserted into the Clark et al. (1982) linear model (Eq. 4) and the mean was calculated to determine the number of years until the first failure of each pipe (NY). 


\subsubsection{Calculating RUL}

RUL is the difference between the pipe's age and NY. Presented by Cortez (2015) in Section 2.7, RUL was calculated using the following equation:

$$
R U L=(N Y-A g e)
$$

$$
\begin{aligned}
& \text { Where: } \quad \begin{array}{l}
R U L \\
N Y=\text { remaining useful life of pipe (years) } \\
A g e=\text { pipe age from year of installation to present (years) }
\end{array}
\end{aligned}
$$

As mentioned in Section 3.2.1 and Section 3.2.3.2, pipe age and NY of each pipe are estimated using 10,000 Monte Carlo simulations. Each iteration is inserted into Eq. 13 (Eq. 13 is calculated 10,000 times for each pipe) and mean RUL was calculated for each pipe.

\subsubsection{Break History Adjustment}

Devera (2013) and Cortez (2015) applied an adjustment factor to the RUL of each pipe to account for previous break events. Although the models used different adjustment factors based on the number of breaks, it is evident that previous break history drastically decreases the RUL of a pipe. Cortez (2015) provides the following two equations to adjust the RUL for break history:

$$
\operatorname{Hist}_{a d j}=1-(0.1 * N)
$$

Where: $\quad$ Hist $_{\text {adj }}=$ adjustment factor based on historical break data

$$
N=\text { number of historical breaks }
$$




$$
R U L_{a d j}=R U L{ }^{*} H_{i s t} t_{a d j}
$$

Where: $\quad R U L_{a d j}=$ adjusted remaining useful life of pipe (years)

$$
\begin{aligned}
& R U L=\text { remaining useful life of pipe (years) } \\
& H i s t_{a d j}=\text { adjustment factor based on historical break data }
\end{aligned}
$$

The adjustment factor decreases the RUL of a pipe by $10 \%$ for each break event in its history.

Adjusting the RUL for previous break events requires detailed records. Municipalities may not have historical break events recorded due to a lack of record keeping of individual pipe breaks, the replacement of entire pipe segments after a break, or the water distribution system has not experienced any breaks.

\subsection{Stage 1: Determining Probability of Failure}

The final step of the first stage is to determine the probability of failure of each pipe. Neither model has the capability of calculating the PF of a pipe directly; therefore, a numerical score represents each pipe's PF. The numerical scoring criterion was derived by Devera (2013), which was based on a more conservative scoring system presented by WSC's risk assessment model. Table 3.7 provides the numerical scoring criteria for the PF. 
Table 3.7 Probability of Failure Score Criteria

\begin{tabular}{c|cc}
\hline Remaining Useful Life (years) & Probability of Failure Score & Risk Level \\
\hline$<2$ & 10 & High \\
2 to 4 & 9 & \\
4 to 6 & 8 & \\
6 to 8 & 7 & \\
8 to 10 & 6 & \\
10 to 12 & 5 & \\
12 to 14 & 4 & \\
14 to 16 & 3 & \\
16 to 20 & 2 & Low \\
$>20$ & 1 & \\
\hline
\end{tabular}

The PF of each pipe has an inverse correlation to its calculated RUL because as the RUL of a pipe decreases, its PF increases. As discussed in Section 2.2, structural and operational deterioration occurs as a pipe ages, which will increase its probability of failure.

\subsection{Stage 2: Computing Degree of Impact}

The ultimate goal of the second stage was to quantify the consequences of an individual pipe failure to determine its degree of impact. The consequences analyzed were the cost of pipe replacement (material only), loss of service, traffic impacts, and affected critical customers. Each consequence was assigned a scoring system that allowed each consequence to be comparable and equally weighted. The scoring system was based on those presented by Devera (2013) and Cortez (2015), with modifications made to account for a different water distribution system. The sum of all the consequences for an individual pipe determined its DI. Degree of impact was 
calculated using the following equation:

$$
D I=\Sigma I S_{i}
$$

$$
\begin{aligned}
& \text { Where: } \quad \begin{aligned}
D I & =\text { Degree of } I m p a c t \\
I S_{i} & =\text { Impact score for } \mathrm{i}^{\text {th }} \text { consequence component }
\end{aligned}
\end{aligned}
$$

The following sections provide an explanation of each consequence and impact score criteria.

\subsubsection{Cost of Pipe Replacement}

The estimation for cost of pipe replacement only accounts for the cost to replace the pipe material. Excluded from this estimation are the costs required for construction labor, surveying and engineering labor, excavation and fill, traffic control, phasing, and additional installation components (such as pipe fittings). These cost factors are subjective in nature and may vary from one municipality to the next. Since both models intend to be universally applicable, the exclusion of the additional cost factors was beneficial. It is assumed that the cost of replacing the pipe material alone is representative of all cost factors included in the replacement of a pipe.

Pipe material and diameter determine the price per linear foot of a pipe. Devera (2013) obtained the price per linear foot of pipe for each material, which were verified by WSC, Cortez (2015), and also during this study using manufacturer pricing and RSMeans (2013). Table 3.8 provides the pipe cost estimates based on material and diameter. 
Table 3.8 Pipe Cost Estimates

\begin{tabular}{|c|c|c|c|}
\hline Pipe Material & Abbreviation & Diameter (inches) & Price Per Linear Foot (\$/foot) \\
\hline \multirow{8}{*}{ Asbestos Cement } & \multirow{8}{*}{$\mathrm{ACP}$} & 2 & $\$ 30.00$ \\
\hline & & 4 & $\$ 42.00$ \\
\hline & & 6 & $\$ 55.00$ \\
\hline & & 8 & $\$ 64.00$ \\
\hline & & 10 & $\$ 69.00$ \\
\hline & & 12 & $\$ 77.00$ \\
\hline & & 14 & $\$ 87.00$ \\
\hline & & 16 & $\$ 98.00$ \\
\hline \multirow{5}{*}{ Ductile Iron } & \multirow{5}{*}{ DIP } & 6 & $\$ 20.00$ \\
\hline & & 8 & $\$ 22.00$ \\
\hline & & 10 & $\$ 24.00$ \\
\hline & & 14 & $\$ 40.00$ \\
\hline & & 16 & $\$ 50.00$ \\
\hline \multirow{8}{*}{ Polyvinyl Chloride } & \multirow{8}{*}{ PVC } & 2 & $\$ \quad 2.00$ \\
\hline & & 4 & $\$ \quad 5.00$ \\
\hline & & 6 & $\$ \quad 8.00$ \\
\hline & & 8 & $\$ 12.00$ \\
\hline & & 10 & $\$ 19.00$ \\
\hline & & 12 & $\$ 28.00$ \\
\hline & & 14 & $\$ 33.00$ \\
\hline & & 16 & $\$ 43.00$ \\
\hline Steel & STL & 8 & $\$ 138.00$ \\
\hline
\end{tabular}

A cost impact score was assigned to the cost of pipe replacement in order to scale it and make it comparable to the other consequences. Table 3.9 provides the cost impact range, cost impact score, and cost impact level.

Table 3.9 Cost Impact Score Criteria

\begin{tabular}{|c|c|c|}
\hline Cost Impact Range & Cost Impact Score & Cost Impact Level \\
\hline$>\$ 80,000$ & 5 & High \\
\hline$\$ 50,000-\$ 80000$ & 4 & \multirow{3}{*}{$\downarrow$} \\
\hline$\$ 25,000-\$ 50,000$ & 3 & \\
\hline$\$ 10,000-\$ 25,000$ & 2 & \\
\hline$\$ 0-\$ 10,000$ & 1 & Low \\
\hline
\end{tabular}




\subsubsection{Loss of Service}

A pipe failure interrupts service to customers within the water distribution system. The magnitude of the service interruption is proportional to the demand of water that the pipe is supplying, as greater demands correlate to a larger numbers of customers being served. A flow rate impact score was applied to the demand supplied by a pipe in order to scale it and make it comparable to the other consequences. Table 3.10 provides the flow rate range, flow rate impact score, and flow rate impact level.

Table 3.10 Flow Rate Impact Criteria

\begin{tabular}{c|cc}
\hline Flow Rate (GPM) & Flow Rate Impact Score & Flow Rate Impact Level \\
\hline$>800$ & 5 & High \\
$600-800$ & 4 & $\uparrow$ \\
$400-600$ & 3 & $\downarrow$ \\
$200-400$ & 2 & Low \\
$0-200$ & 1 & \\
\hline
\end{tabular}

\subsubsection{Traffic Impact}

A pipe failure disrupts the surface above the pipe as well as areas in the immediate vicinity. Disruptions occur initially after failure due to water breaching the surface or during the construction required to replace the pipe. These disruptions will cause traffic to be relocated to another route because of road closures. Calculating the amount of traffic displaced for every pipe failure is exhaustive, so it was determined that the magnitude of traffic being displaced is proportional to the type of roadway that is affected. Roadway classifications include freeway, arterial, collector, office/commercial, public collector, local, and "no traffic". "No traffic" defines areas where there are no roadways. A traffic impact score was applied to each roadway classification in order to 
scale it and make it comparable to the other consequences. Table 3.11 provides the traffic designation, traffic impact score, and traffic impact level.

Table 3.11 Traffic Impact Criteria

\begin{tabular}{|c|c|c|}
\hline Traffic Designation & Traffic Impact Score & Traffic Impact Level \\
\hline Freeway & 5 & High \\
\hline Arterial & 4 & \multirow[t]{4}{*}{$\uparrow$} \\
\hline Collector & 3 & \\
\hline Office/Commercial & 3 & \\
\hline Public Collector & 2 & \\
\hline Local & 1 & $\downarrow$ \\
\hline No Traffic & 0 & Low \\
\hline
\end{tabular}

\subsubsection{Critical Customers}

Customer criticality, or level of importance, is dependent on the services that the customer provides to society. Critical customers include hospitals, sheriff stations, fire stations, senior care or day care centers, schools, and "other". "Other" defines all customers that are not lifeline services or other important institutions. The criticality of the customer is proportional to the magnitude of the consequence of a failure. It was assumed that a pipe failure within a quarter mile of a critical customer could possibly cause a service disruption. A critical customer score was applied to each customer in order to scale it and make it comparable to the other consequences. Table 3.12 provides the critical customer, the critical customer impact score, and the critical customer impact level. 
Table 3.12 Critical Customer Impact Criteria

\begin{tabular}{|c|c|c|}
\hline Critical Customer & $\begin{array}{l}\text { Critical Customer Impact } \\
\text { Score }\end{array}$ & $\begin{array}{c}\text { Critical Customer Impact } \\
\text { Level }\end{array}$ \\
\hline Hospital & 5 & High \\
\hline Sheriff Station & 4 & $\uparrow$ \\
\hline Fire Station & 4 & \\
\hline $\begin{array}{c}\text { Senior Care or Day Care } \\
\text { Center }\end{array}$ & 3 & \\
\hline School & 2 & $\downarrow$ \\
\hline Other & 1 & Low \\
\hline
\end{tabular}

\subsection{Stage 3: Computing Risk of Failure}

The final stage combines the results from the first and second stage to determine the pipe's risk of failure. The risk of failure score represents the likelihood of a pipe failure and allows for the categorization of pipes for rehabilitation/replacement purposes. Risk of failure was calculated using the following equation:

$$
R F=P F{ }^{*} D I
$$

$$
\text { Where: } \begin{aligned}
& R F=\text { Risk of Failure score } \\
& P F=\text { Probability of Failure score } \\
& D I=\text { Degree of Impact score }
\end{aligned}
$$

Risk of failure allows for an equally weighted comparison of pipes within a water distribution system. Risk of failure categories are designated based on the results of the comparison. Table 3.13 provides the risk of failure score and risk of failure categories. 
Table 3.13 Risk of Failure Categories

\begin{tabular}{c|c}
\hline Risk of Failure Score & Risk of Failure Category \\
\hline$>100$ & Critical Risk \\
$80-100$ & High Risk \\
$40-80$ & Medium Risk \\
$0-40$ & Low Risk \\
\hline
\end{tabular}

The risk of failure score and risk of failure categories form a rehabilitation ranking system that municipalities may utilize to improve their allocation of resources.

The simplified model and a complex model were applied to the City of Buellton water distribution system to examine the validity of both models and to compare their results. Chapter 4 provides an explanation of the application of this model to the City of Buellton, California.

\subsection{Sensitivity Analyses}

Sensitivity analyses were completed to determine the effect of assumed variables on the risk analysis results. Each sensitivity analysis repeated the three-stage procedure outlined in Sections 3.2 to 3.5 . The assumed variables analyzed were pipe age and anticipated service life. The adjusted values evaluated the worst-case scenario for each variable.

Lack of data on the installation year of each pipe required an analysis of the oldest installation date. For example, the mean installation year for asbestos cement pipes in the original analysis was 1960 and for the sensitivity analyses it was 1950 . Table 3.14 displays the adjusted installation year, utilized to determine pipe age.

Factors not accounted for in this study to predict anticipated service life called for an analysis of the lowest recommended manufacturer service life. For instance, the anticipated service life for asbestos cement pipes utilized in the original analysis was 
100 years and for the sensitivity analysis it was 75 years. Table 3.15 shows the adjusted anticipated service life.

Table 3.14 Adjusted Pipe Material Installation Year

\begin{tabular}{|c|c|c|c|c|}
\hline Pipe Material & Abbreviation & $\begin{array}{c}\text { Common } \\
\text { Installation } \\
\text { Periods }\end{array}$ & $\begin{array}{c}\text { Mean } \\
\text { Installation } \\
\text { Year }\end{array}$ & $\begin{array}{c}\text { Standard } \\
\text { Deviation of } \\
\text { Installation } \\
\text { Year }\end{array}$ \\
\hline $\begin{array}{c}\text { Asbestos } \\
\text { Cement }\end{array}$ & ACP & 1950-1970 & 1950 & 3.33 \\
\hline Ductile Iron & DIP & 1960-2016 & 1960 & 9.33 \\
\hline $\begin{array}{l}\text { Polyvinyl } \\
\text { Chloride }\end{array}$ & PVC & $1970-2016$ & 1990 & 7.67 \\
\hline Steel & STL & $1940-2016$ & 1940 & 12.67 \\
\hline
\end{tabular}

Table 3.15 Adjusted Pipe Material Anticipated Service Life

\begin{tabular}{|c|c|c|c|c|}
\hline Pipe Material & Abbreviation & $\begin{array}{c}\text { Manufacturer } \\
\text { Recommended } \\
\text { Service Life } \\
\text { (years) }\end{array}$ & $\begin{array}{c}\text { Anticipated } \\
\text { Service Life } \\
\text { (years) }\end{array}$ & $\begin{array}{c}\text { Standard } \\
\text { Deviation of } \\
\text { Anticipated } \\
\text { Service Life }\end{array}$ \\
\hline $\begin{array}{c}\text { Asbestos } \\
\text { Cement }\end{array}$ & ACP & $75-125$ & 75 & 8.33 \\
\hline Ductile Iron & DIP & $75-125$ & 75 & 8.33 \\
\hline $\begin{array}{l}\text { Polyvinyl } \\
\text { Chloride }\end{array}$ & PVC & $50-150$ & 50 & 16.67 \\
\hline Steel & STL & $30-75$ & 30 & 7.5 \\
\hline unknown & - & $50-150$ & 50 & 16.67 \\
\hline
\end{tabular}

The installation year of polyvinyl chloride in Table 3.14 was the only value that was not decreased to its minimum value. The City of Buellton verified that most polyvinyl chloride pipes were installed in the early 1990s; therefore, to keep the model as accurate as possible, 1990 was determined as the mean installation year. 


\section{CHAPTER 4}

\section{CASE STUDY: CITY OF BUELLTON}

\subsection{Data Acquisition}

The City of Buellton delivered all data and models available for their water distribution system (WDS). The 1738-pipe WDS includes laterals (2-inch - 4-inch diameter pipes) and mains (4-inch or greater diameter pipes) within the City of Buellton. The obtained model was a Bentley's WaterCAD hydraulic model of the 628 mains within the WDS. The 628 pipes are composed of 392 asbestos cement pipes, 19 ductile iron pipes, 215 polyvinyl chloride pipes, and 2 steel pipes. The acquired data contained parcel and land use information, roadway names and classifications, and physical and hydraulic properties of each pipe- size, length, demand, and pressure.

The City of Buellton did not have specific installation dates for each pipe; however, they offered rough installation dates for each type of pipe material. These estimated installation dates paralleled the mean installation dates calculated in Table 3.1 in Section 3.2.1. Therefore, the dates determined in Table 3.1 were applied to account for any uncertainties in installation dates.

The City of Buellton provided records of pipe replacements within the WDS, but there were no records of break history events that resulted in rehabilitation only. Break history adjustments are only applied for a pipe that has been rehabilitated after a break, not completely replaced. Thus, break history adjustments were not included in this study.

\subsection{Computer Modeling and Data Analysis}

Efficient and accurate analysis of the 628 pipes within the WDS required the application of computer modeling and data analysis programs. The programs utilized were Bentley's WaterCAD Version 8i, Microsoft's Excel and Visual Basic for Applications 
(VBA) 2013, and ESRI's ArcGIS 10.4. The following sections contain an explanation of the application of each program in the context of this study.

\subsubsection{Bentley's WaterCAD}

Bentley's WaterCAD is a hydraulic modeling application for the analysis, design, and operation of water distribution systems. WaterCAD has the capability to assess and compare any number of physical and operational scenarios. Data may be imported from essentially any external data format and the model may be exported to programs such as AutoCAD and ArcGIS.

For this study, WaterCAD was used to develop the base of an ArcGIS model of the WDS, which included information on the physical and hydraulic properties for each pipe. The WaterCAD file provided by the City of Buellton was calibrated to accurately represent the maximum hourly demand of the WDS. Based on this scenario, WaterCAD tabulated the physical and hydraulic properties of each pipe in a flex table that was exported to Excel, where the data may be processed and the RUL could be computed. In addition, the flex table was exported to ArcGIS as a shapefile (a file that stores the location, shape, and attributes of a feature). This shapefile will be used as the basis of a model that further data will be added to.

\subsubsection{Microsoft's Excel and Visual Basic for Applications (VBA)}

Microsoft's Excel is a spreadsheet application that assists in the organization of data and completion of analyses. Excel has a number of supplied functions aimed at answering statistical and engineering questions/problems.

Microsoft's Visual Basic for Applications (VBA) is a programming language that is a dialect of Visual Basic, which is embedded in Excel. VBA allows for spreadsheet and data manipulation that is difficult or impossible to complete with standard spreadsheet 
functions. In addition, VBA may be utilized to create a user interface. Code may be written, debugged, and executed in the Visual Basic Editor (VBE) window.

For this study, Excel was utilized as a data organization tool and a secondary calculation tool. Data was imported from WaterCAD and ArcGIS and organized in the "WDS Data" spreadsheet in Excel. The VBA analysis references the WDS Data spreadsheet and outputs the results for Age, ASL, NY, and RUL into the "Risk Analysis" spreadsheet. In addition, the criteria tables in Chapter 3 were imported into a "Criteria" spreadsheet. Referencing the WDS Data and Criteria spreadsheets, Excel computes PF, DI, and RF. The Risk Analysis spreadsheet is exported to ArcGIS and added to the model for visual representation. See Appendix A for the imported data and risk analysis results.

For this study, VBA functioned as the primary calculation tool. A code was written to reference the data within the WDS Data spreadsheet, which includes the mean and standard deviation of installation year and ASL, pipe diameter, length, pressure, percent of pipe covered by residential and industrial development, and the pipe type. The program completes 10,000 Monte Carlo simulations in order to calculate the Age, ASL, NY, and RUL of each pipe. See the code in Appendix B.

\subsubsection{ESRI's ArcGIS}

Environmental Systems Research Institute's (ESRl's) ArcGIS is a geographic information system (GIS). Through the georeferencing of information, ArcGIS allows the creation of maps, compilation of geographic data, analyzation of mapped information, management of geographic information databases, and visual representation of geographic information in the forms of exhibits, tables, and maps.

For this study, ArcGIS was used as the primary visualization tool. The foundation of the ArcGIS model was the shapefile exported from WaterCAD. Analysis and 
manipulation of the mapped data in ArcGIS allowed for the determination of other variables required for the study, which were exported to Excel for processing. The results from the risk analysis completed in Excel and VBA were exported to ArcGIS for visual representation. Exhibits were developed throughout this analysis in order to visually display the results of the study. Figure 4.1 displays the City of Buellton water distribution system.

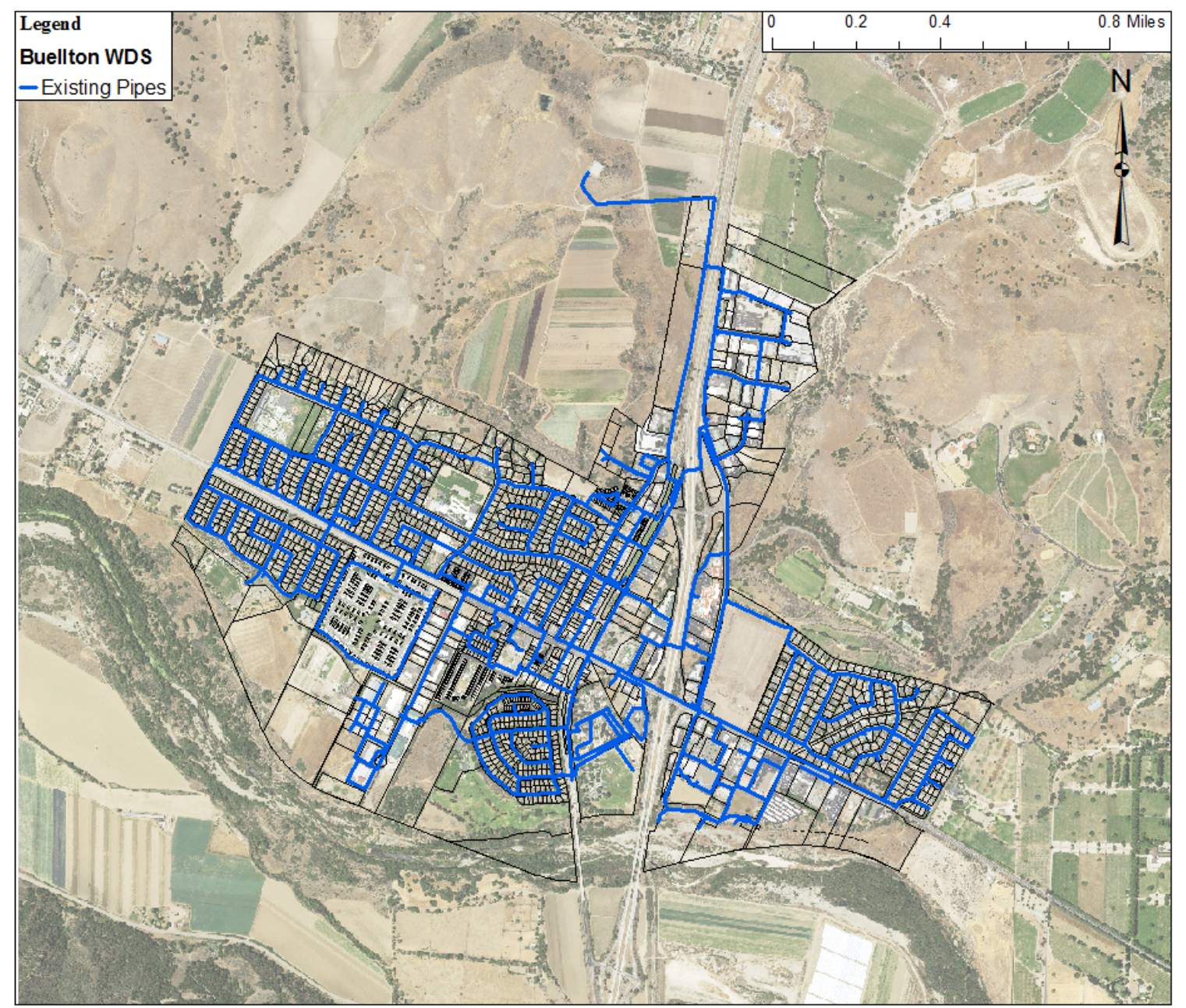

Figure 4.1 City of Buellton WDS

\subsubsection{Establishment of an ArcGIS Model for Analysis}

As mentioned in Section 4.2.1 and 4.2.3, the ArcGIS model is based on the shapefile exported from WaterCAD. This shapefile contained critical data pertaining to 
the physical and hydraulic properties of each pipe. In addition, the City of Buellton provided shapefiles with parcel, land use information, and roadway names and classifications, as well as a base map of the City of Buellton. Tools within ArcGIS allowed for the combination of this information. This combined ArcGIS file, called the Buellton WDS shapefile, established the ArcGIS model and contains all the necessary information for the risk analysis. The critical information included in the Buellton WDS shapefile are as follows: FID (a unique ArcGIS assigned identification number), label (i.e. P-1), pipe material, diameter (inches), length (feet), demand (gallons per minute), velocity (feet per second), pressure (pounds per square inch), elevation (feet), hydraulic grade line (feet), land use, street names, and street classifications. Figure 4.2 displays the varying pipe material within the City of Buellton WDS. Figure 4.3 shows the varying pipe diameters within the City of Buellton WDS. Figure 4.4 exhibits the roadway classifications and land use within the City of Buellton. 


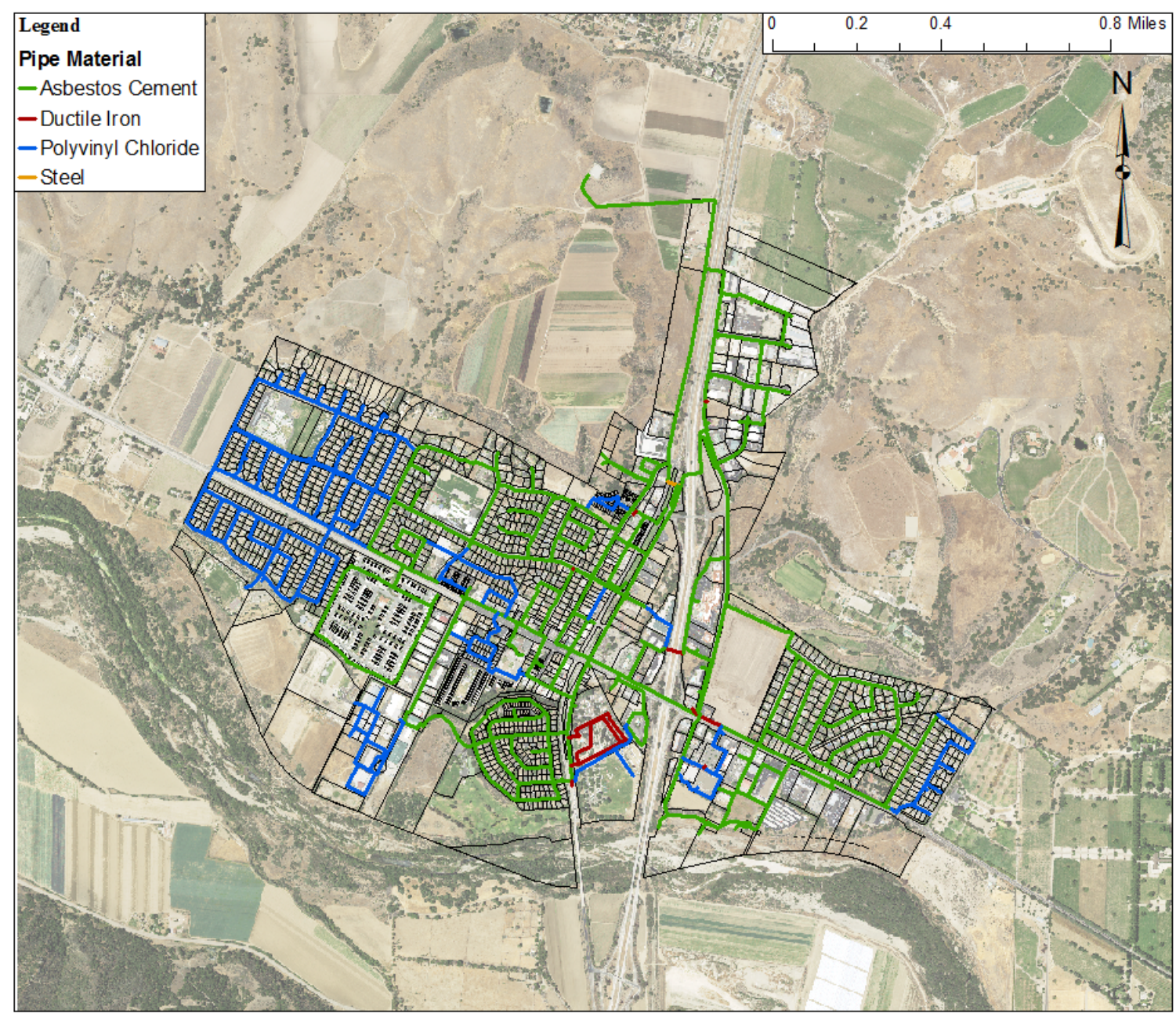

Figure 4.2 City of Buellton WDS by Pipe Material 


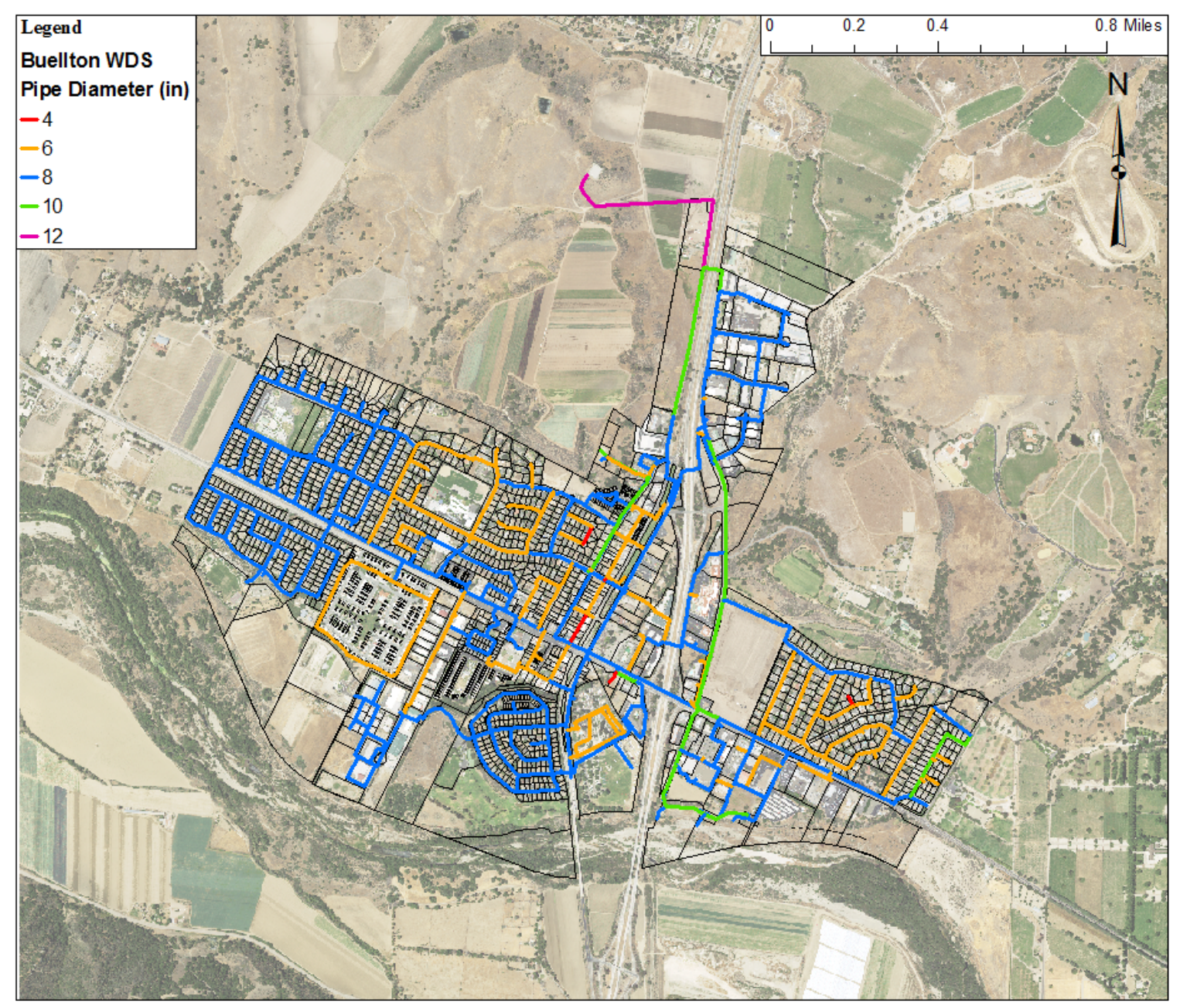

Figure 4.3 City of Buellton WDS by Pipe Diameter 


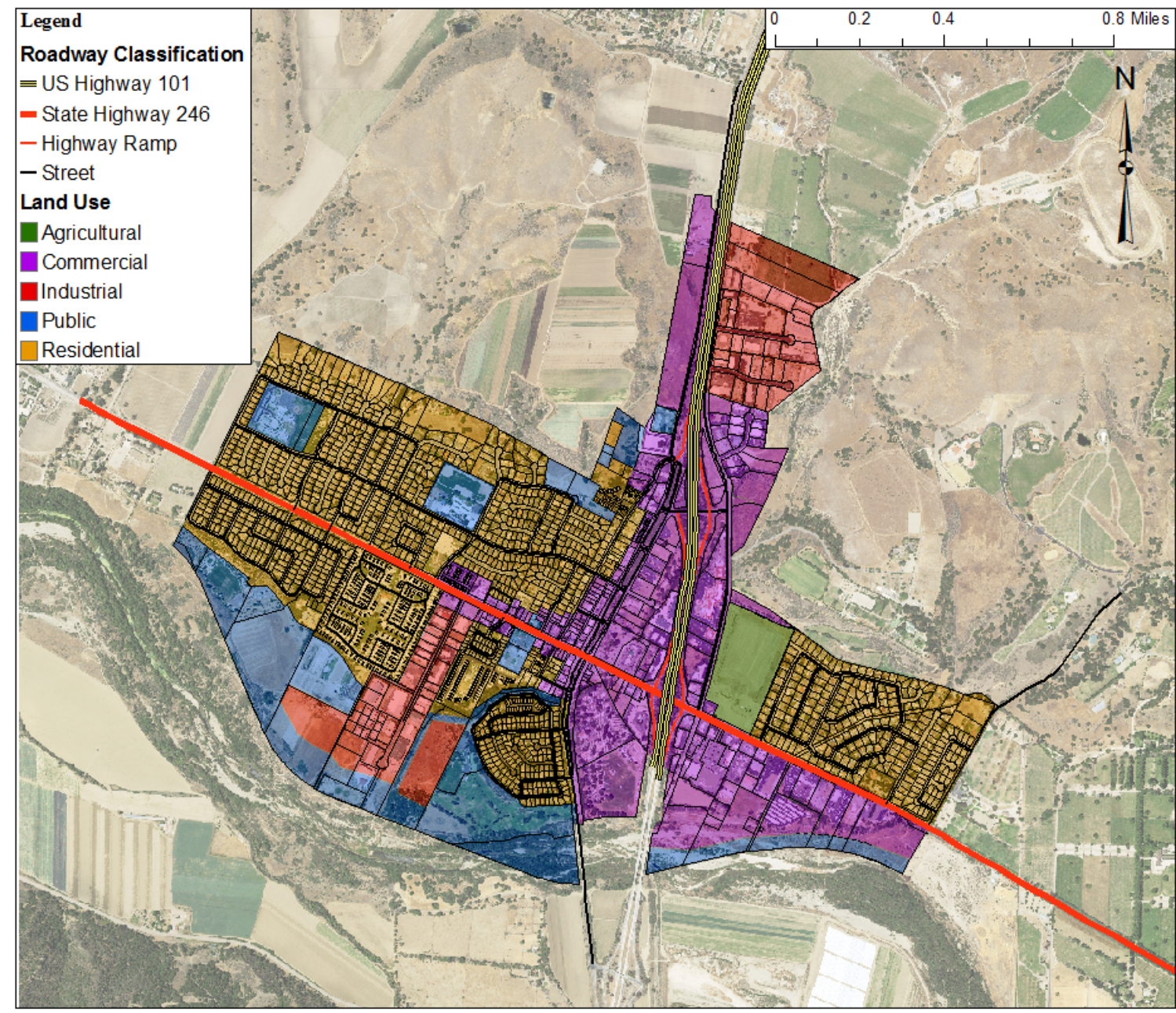

Figure 4.4 City of Buellton Roadway Classifications and Land Use

\subsubsection{Data Additions to the ArcGIS Model}

The completion of the risk analysis relied on the addition of data to the Buellton WDS shapefile based on the methodology and criteria detailed in Chapter 3. Each piece of additional data was either determined by a geographic analysis of the Buellton WDS shapefile in ArcGIS, computation of 10,000 Monte Carlo simulations in VBA, or calculations in Excel. The following paragraphs detail the process completed to insert additional data into the Buellton WDS shapefile.

Pipe age was calculated in VBA based on Eq. 14 and criteria provided in Table 3.1: Installation Year Based on Pipe Material. Values for pipe age were exported from 
Excel into the Buellton WDS attributes table as the "Age (years)" field. Figure 4.5 displays the mean age of each pipe within the Buellton WDS.

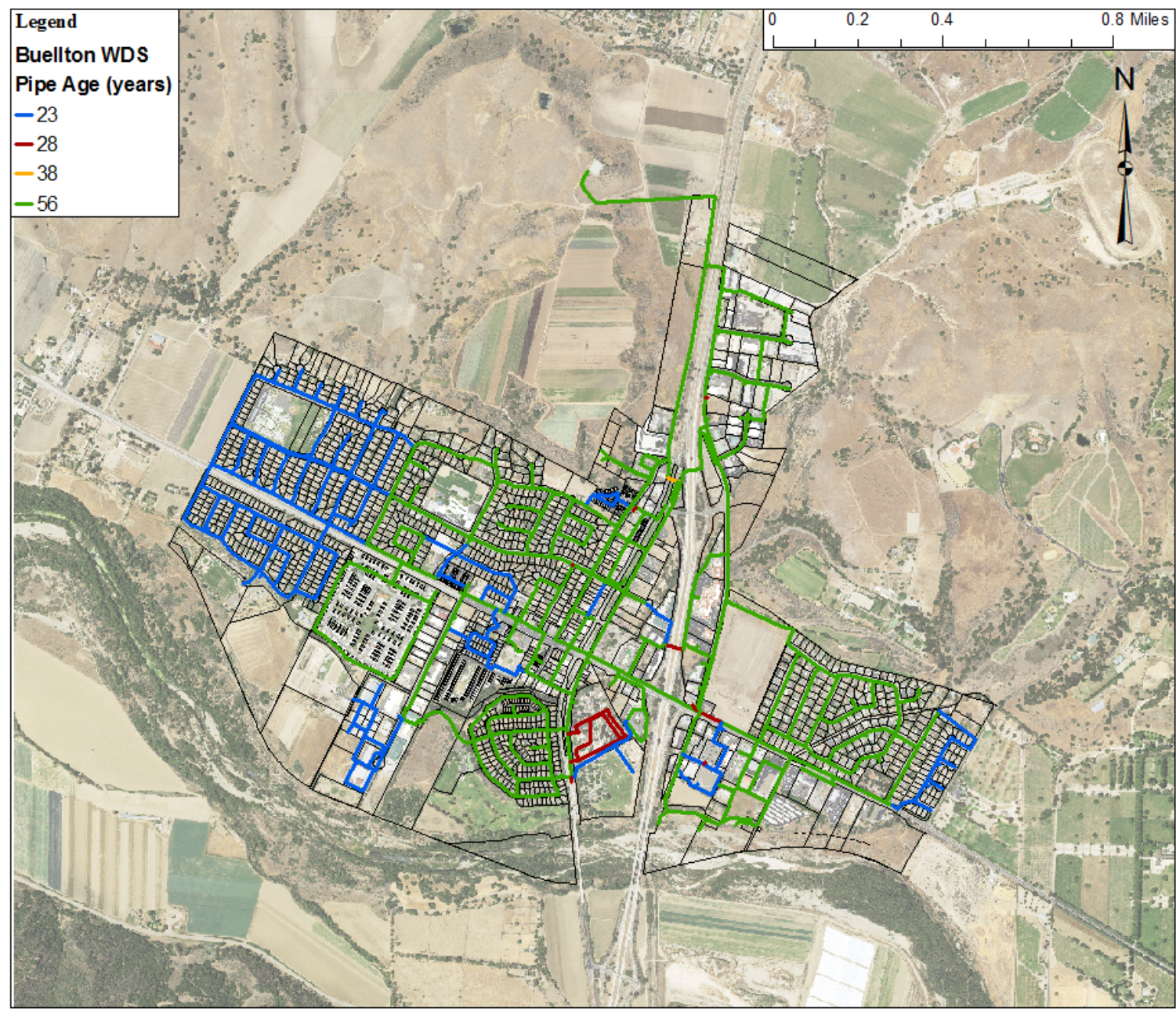

Figure 4.5 City of Buellton WDS Mean Pipe Age

Anticipated service life of each pipe was determined in VBA based on criteria provided in Table 3.2: Pipe Material Anticipated Service Life. Values for anticipated service life were exported from Excel into the Buellton WDS attributes table as the "ASL (years)" field.

Number of years until first failure of each pipe was computed in VBA based on Eq. 4. The variables within Eq. 4 are based on data provided in the Buellton WDS shapefile (diameter, pressure, and length) and criteria provided in Table 3.3: Percent 
Residential and Industrial Cover, Table 3.4: Pipe Type, Table 3.5: Clark Model Regression Parameters, and Table 3.6: Pipe Material Anticipated Service Life. Values for number of years until first failure were exported from Excel into the Buellton WDS attributes table as the "NY (years)" field.

After pipe age, ASL, and NY were calculated, the remaining useful life of each pipe was calculated in VBA. The RUL for the simplified model is based on Eq. 15 and the RUL for the complex model is based on Eq. 13. After computation of the RUL, the probability of failure score was determined for each model in Excel based on Table 3.7: Probability of Failure Score Criteria. Values for RUL and PF scores for each model were exported from Excel into the Buellton WDS attributes table as the "RUL Simplified (years)" field, "RUL Complex (years)" field, "PF Simplified" field, and "PF Complex" field.

The cost impact score was computed in Excel based on criteria provided in Table 3.8: Pipe Cost Estimates and Table 3.9: Cost Score Impact Criteria. The flow rate impact score was calculated in Excel based on criteria provided in Table 3.10: Flow Risk Impact Criteria. The traffic impact score was determined in Excel based on criteria provided in Table 3.11: Traffic Impact Criteria. The critical customer impact score was calculated in Excel based on criteria provided in Table 3.12: Critical Customer Impact Criteria. Figure 4.6 displays the critical customers within the City of Buellton. Values for each impact score were exported from Excel into the Buellton WDS attribute table as the "Cost IS" field, "Flow Rate IS" field, "Traffic IS" field, and "Customer Criticality IS" field. 


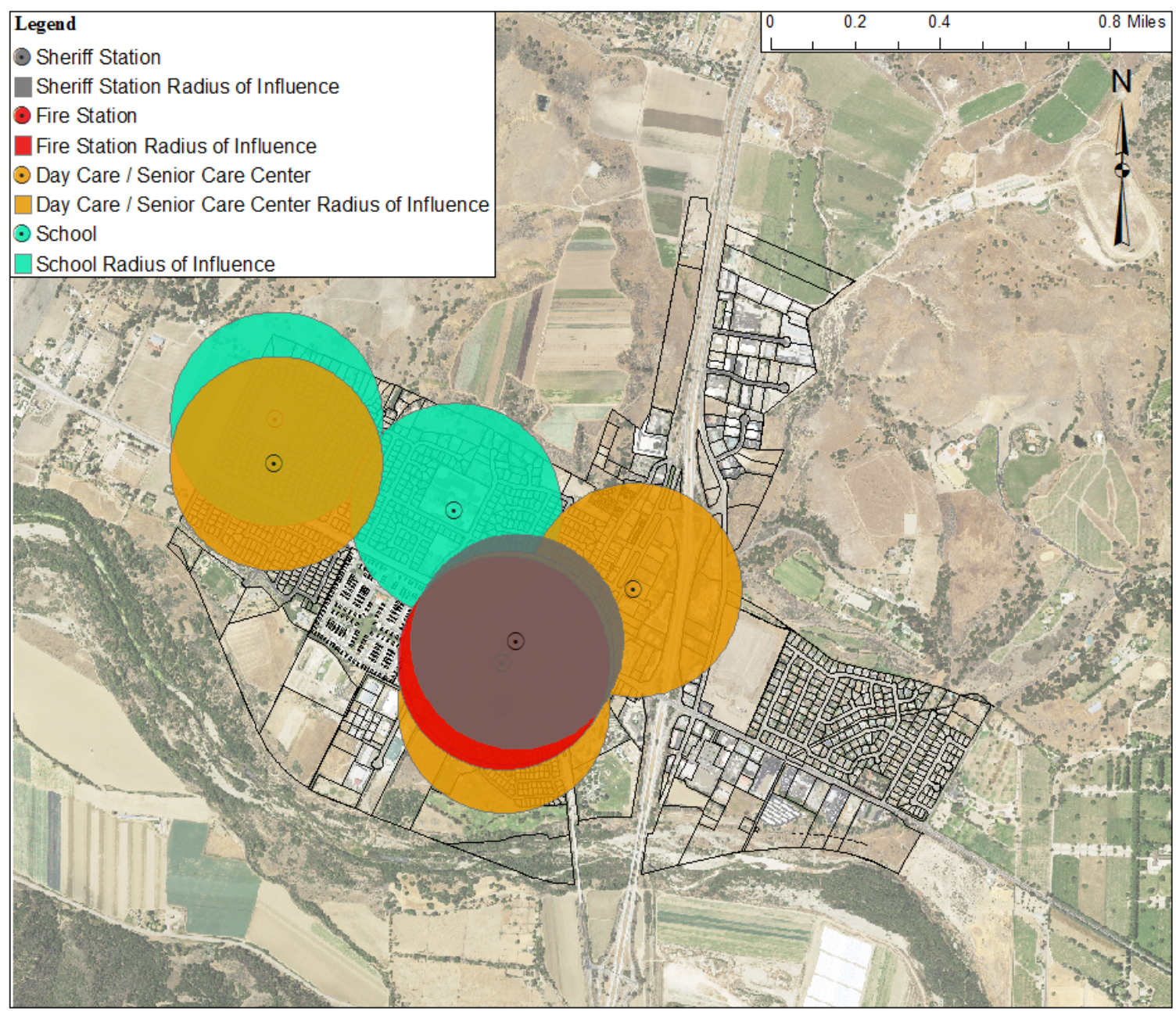

Figure 4.6 City of Buellton Critical Customers

After each impact score is computed, the degree of impact score was determined in Excel based on Eq.18. Values for the DI were exported from Excel into the Buellton WDS attribute table as the "Degree of Impact" field.

After the calculation of the DI score and PF score, the risk of failure was determined in Excel based on Eq. 19 and criteria provided in Table 3.13: Risk of Failure Categories. Values for the RF of both models were exported from Excel into the Buellton WDS attribute table as the "Risk of Failure Simplified" field and "Risk of Failure Complex" field. 
Once the risk of failure of each pipe was determined, the risk analysis was complete. The results of the risk analysis were visually represented in ArcGIS. Chapter 5 provides the ArcGIS exhibits identifying the risk of failure of each pipe, as well as the results of the sensitivity analyses. 


\section{CHAPTER 5}

\section{RESULTS}

\subsection{Risk Analysis Visual Representation}

Visualization of the risk analysis results allows the municipality to implement a pipe replacement/rehabilitation ranking system. An exhibit allows for more variables to be taken into consideration during the implementation of this ranking system, as opposed to the numerical results of the risk analysis. For instance, the most critical risk pipe within the system stands alone, while a number of high risk pipes are grouped together. Based on the numerical value, the stand-alone critical risk pipe appears to be the optimal pipe to replace; however, based on the exhibit, the group of high risk pipes appear to be the top candidates for replacement.

Results of the risk analysis were visually represented in ArcGIS based on the criteria provided in Table 5.1 .

Table 5.1 Risk of Failure Categories

\begin{tabular}{cc}
\hline Risk of Failure Score & Risk of Failure Category \\
\hline$>100$ & Critical Risk \\
$80-100$ & High Risk \\
$40-80$ & Medium Risk \\
$0-40$ & Low Risk \\
\hline
\end{tabular}

\subsection{Risk Analysis Results}

The results of the simplified model and complex model were compared to determine the validity of each risk assessment model. Figure 5.1 provides the results of the simplified model. Figure 5.2 displays the results of the complex model. 


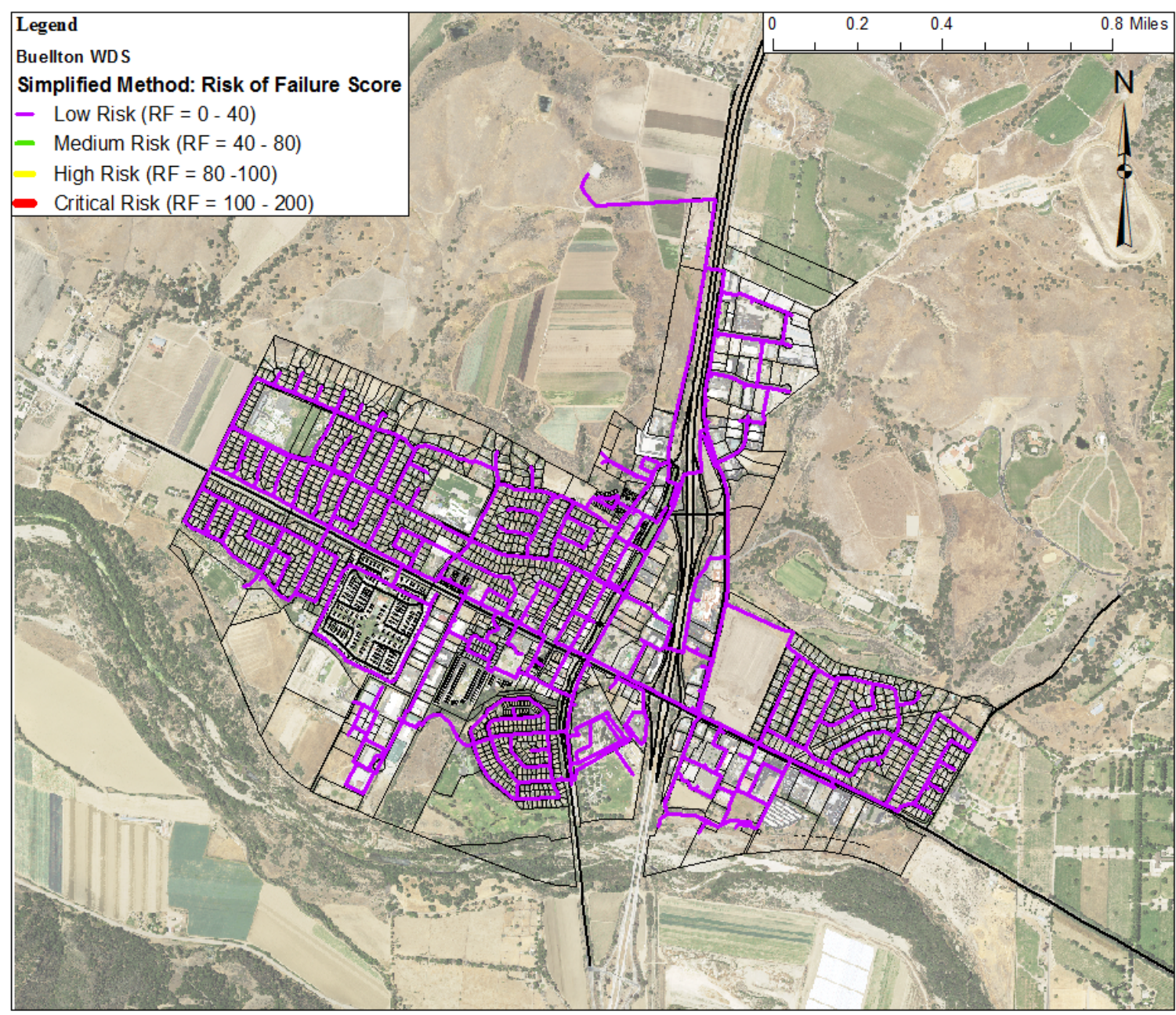

Figure 5.1 City of Buellton WDS: Simplified Model Results 


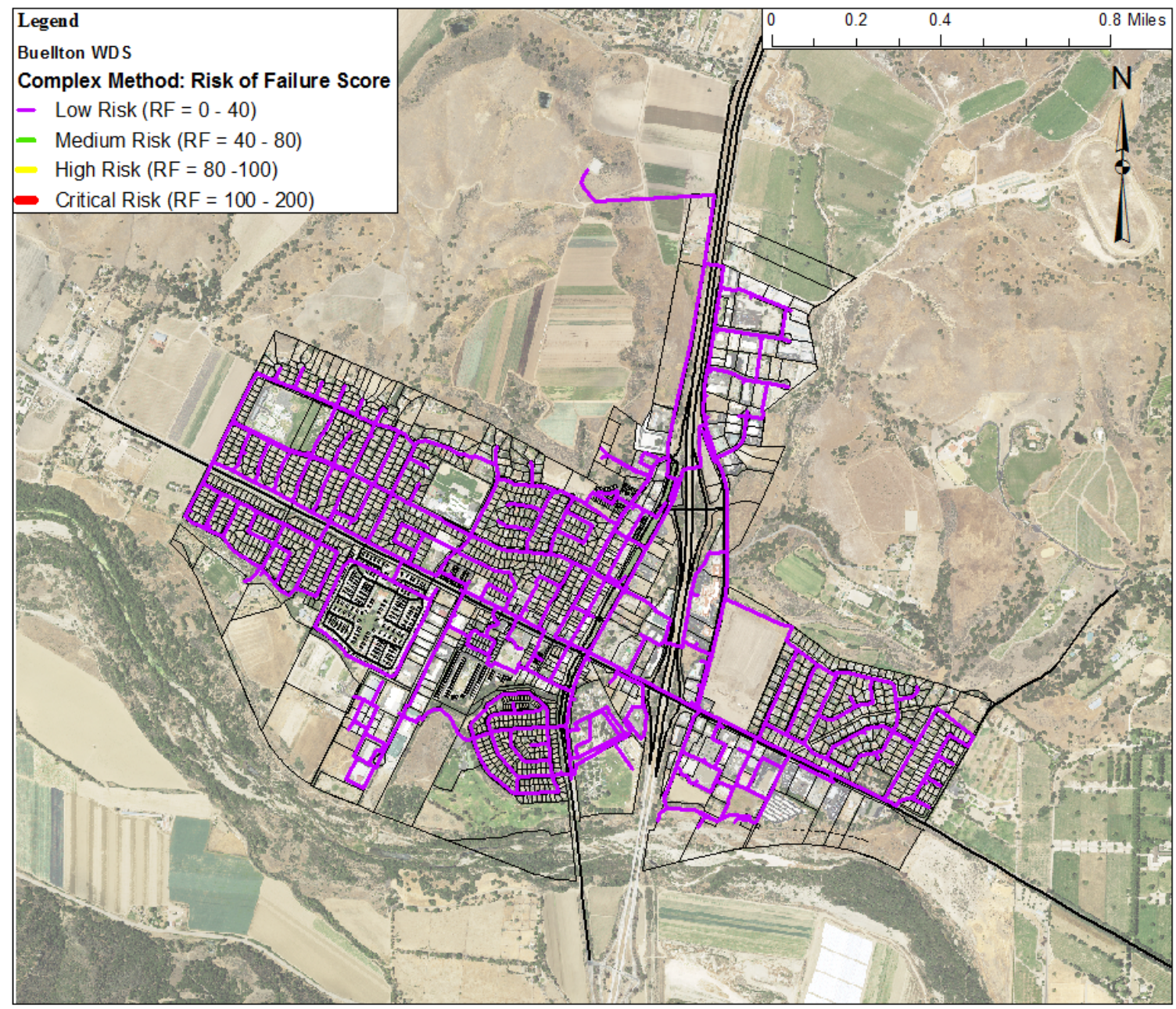

Figure 5.2 City of Buellton WDS: Complex Model Results

Table 5.2 provides a comparison of the number of pipes in each risk of failure category within the WDS.

Table 5.2 Risk of Failure Comparison

\begin{tabular}{c|cc}
\hline Risk of Failure Category & Simplified Model & Complex Model \\
\hline Critical Risk & 0 & 0 \\
High Risk & 0 & 0 \\
Medium Risk & 0 & 0 \\
Low Risk & 628 & 628 \\
\hline
\end{tabular}

Figure 5.1, Figure 5.2, and Table 5.2 portray that both models have a similar result, 628 low risk pipes within the WDS. A further analysis was completed to determine 
how "similar" the results actually were. Evaluation of the RUL results showed that there were slight differences between the models. Table 5.3 provides the average RUL for each model.

Table 5.3 Remaining Useful Life Comparison

\begin{tabular}{c|ccccc}
\hline \multicolumn{1}{c}{$\begin{array}{c}\text { Pipe } \\
\text { Material }\end{array}$} & $\begin{array}{c}\text { Average } \\
\text { Age } \\
\text { (years) }\end{array}$ & $\begin{array}{c}\text { Average } \\
\text { ASL } \\
\text { (years) }\end{array}$ & $\begin{array}{c}\text { Average } \\
\text { NY (years) }\end{array}$ & $\begin{array}{c}\text { Average RUL } \\
\text { Simplified } \\
\text { (years) }\end{array}$ & $\begin{array}{c}\text { Average RUL } \\
\text { Complex (years) }\end{array}$ \\
\hline $\begin{array}{c}\text { Asbestos } \\
\text { Cement }\end{array}$ & 56.00 & 100.00 & 90.95 & 44.00 & 34.95 \\
$\begin{array}{c}\text { Ductile } \\
\text { Iron }\end{array}$ & 27.99 & 100.00 & 100.33 & 72.02 & 72.35 \\
$\begin{array}{c}\text { Polyvinyl } \\
\text { Chloride }\end{array}$ & 23.00 & 100.00 & 93.87 & 77.01 & 70.87 \\
Steel & 37.95 & 52.52 & 55.59 & 14.58 & 17.64 \\
\hline
\end{tabular}

As seen in Table 5.3, differences exist within the results of the RUL for each model, but due to the criteria and methodology presented in Chapter 3 , the results of the risk analysis are the same.

Although similarities exist between the results, the complex model may be more favorable than the simplified model. While both models rely on a number of assumptions, the complex model has the capability of more accurately calculating the risk of failure due to the additional factors included in its statistical approach to calculate RUL. These additional factors allow calibration of the complex model based on a water distribution system's break history. The simplified model cannot be calibrated to the same level of accuracy because calculation of RUL is only based on one factor, pipe age. Thus, continued application of the complex model may result in an accurate predictive model that municipalities can apply to determine a rehabilitation/replacement schedule.

The models were further examined through the completion of three sensitivity analyses. The results of the sensitivity analyses are presented in the following section. 


\subsection{Sensitivity Analysis}

Sensitivity analyses were completed to examine the effect of the assumed variables on the risk analysis. The variables analyzed were pipe age and anticipated service life. Since the installation year of each pipe was not specified by the City of Buellton, it was necessary to analyze the oldest installation date. Likewise, anticipated service life varies depending on factors not accounted for in this study, so the lowest recommended manufacturer service life was analyzed.

As in Section 5.2, the simplified model and complex model results were compared for each sensitivity analysis. The following three sensitivity analyses were evaluated: (1) adjusted pipe age (older pipe age); (2) adjusted anticipated service life (lower ASL); (3) adjusted pipe age and adjusted anticipated service life.

The sensitivity analyses reinforced the conclusion drawn in Section 5.2, that the complex model is the favorable and more accurate model due to its additional factors.

\subsubsection{Pipe Age Sensitivity Analysis Results}

Figure 5.3 provides the results of the simplified model with older pipe age. Figure 5.4 displays the results of the complex model with older pipe age. 


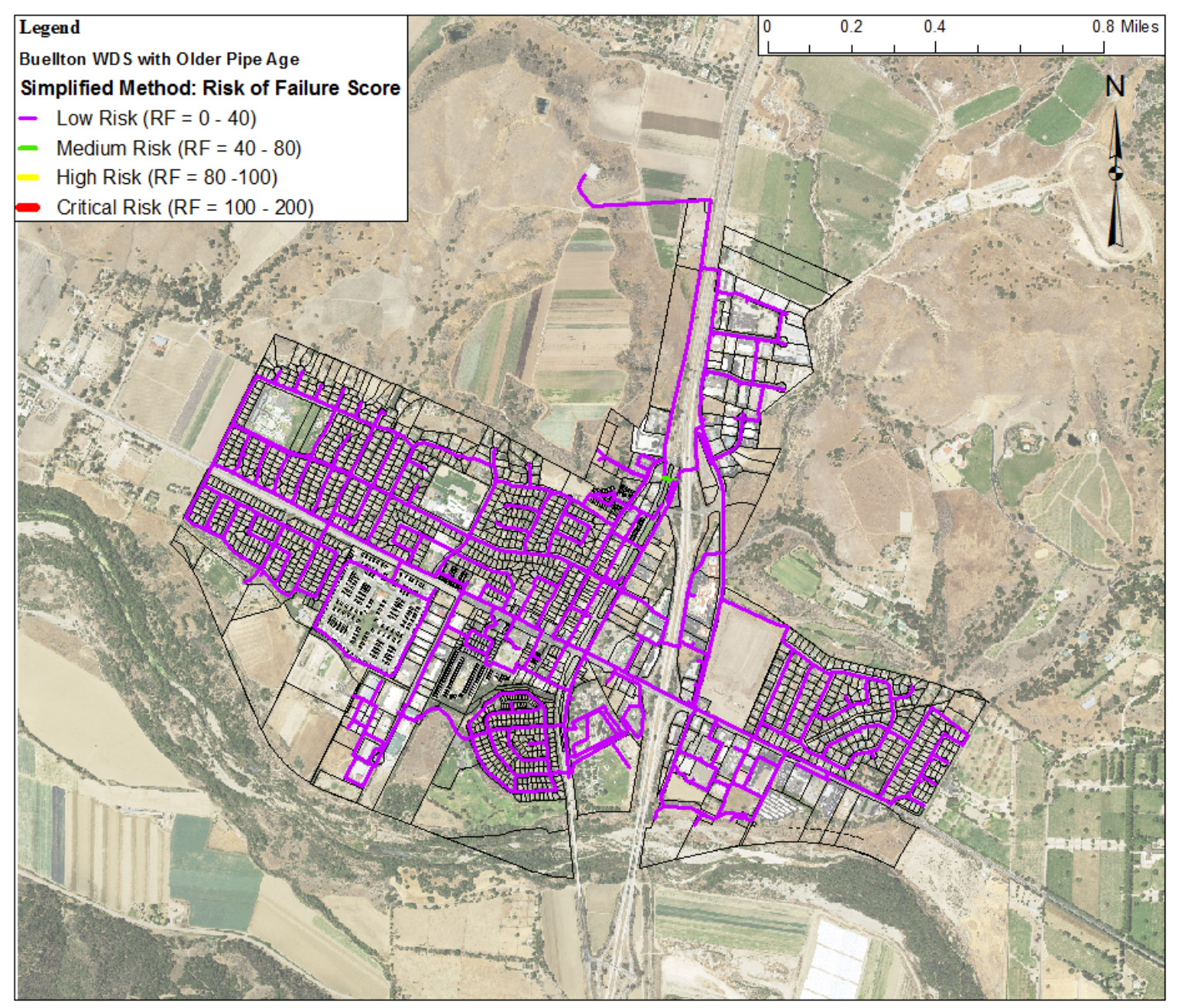

Figure 5.3 City of Buellton WDS with Older Pipe Age: Simplified Model Results 


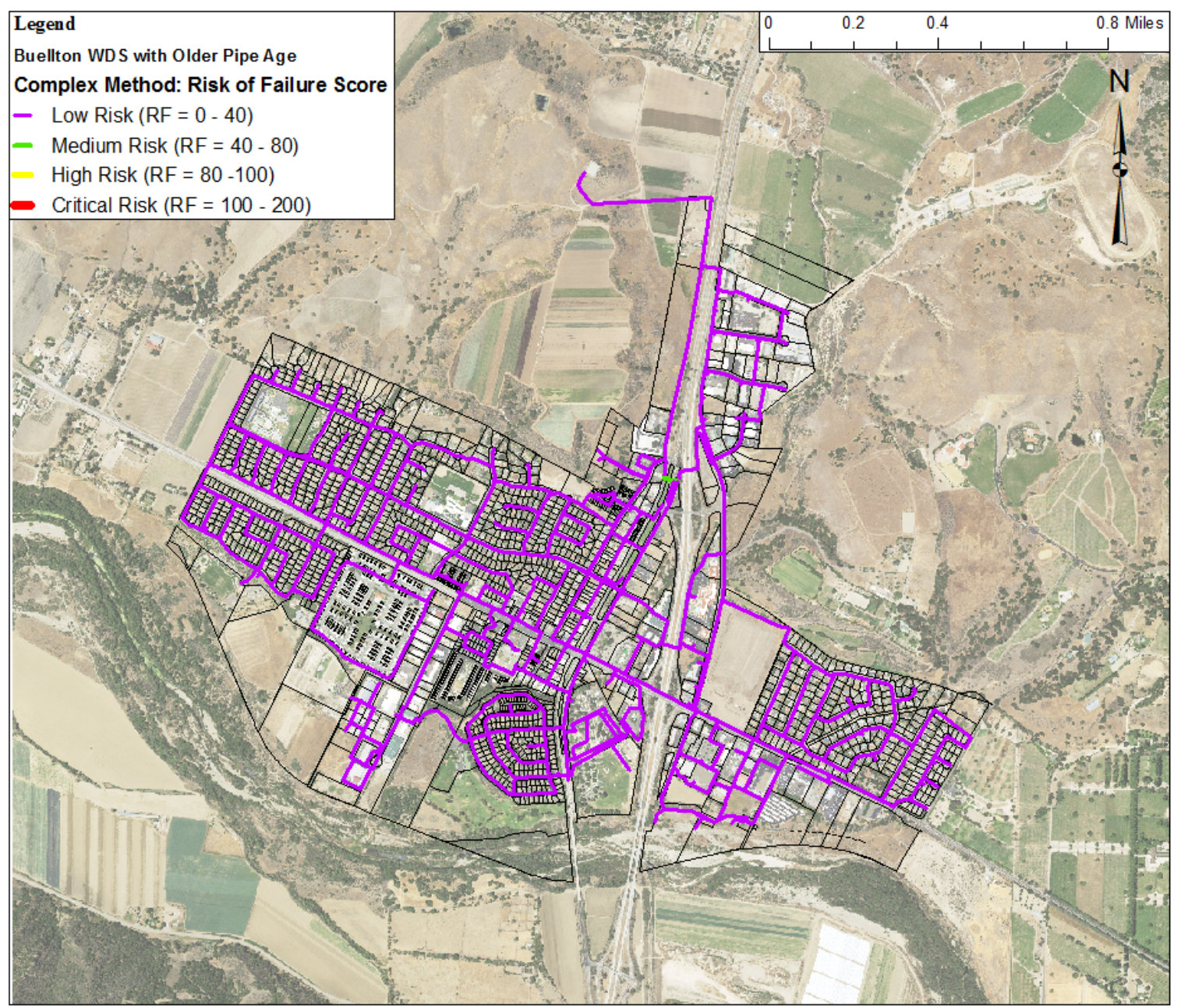

Figure 5.4 City of Buellton WDS with Older Pipe Age: Complex Model Results

Table 5.4 provides a comparison of the number of pipes in each risk of failure category within the WDS.

Table 5.4 Risk of Failure Comparison: Older Pipe Age

\begin{tabular}{c|cc}
\hline Risk of Failure Category & Simplified Model & Complex Model \\
\hline Critical Risk & 0 & 0 \\
High Risk & 0 & 0 \\
Medium Risk & 2 & 2 \\
Low Risk & 626 & 626 \\
\hline
\end{tabular}

This sensitivity analysis provides slightly different results than the original analysis; however, both models produced the same results. The two pipes that were 
categorized as medium risk were the two steel pipes within the water distribution system. The steel pipes have a higher estimated age and lower anticipated service life than the other pipes. Table 5.5 provides the average RUL for each model.

Table 5.5 Remaining Useful Life Comparison: Older Pipe Age

\begin{tabular}{c|ccccc}
\hline \multicolumn{1}{c}{$\begin{array}{c}\text { Pipe } \\
\text { Material }\end{array}$} & $\begin{array}{c}\text { Average } \\
\text { Age } \\
\text { (years) }\end{array}$ & $\begin{array}{c}\text { Average } \\
\text { ASL } \\
\text { (years) }\end{array}$ & $\begin{array}{c}\text { Average } \\
\text { NY (years) }\end{array}$ & $\begin{array}{c}\text { Average RUL } \\
\text { Simplified } \\
\text { (years) }\end{array}$ & $\begin{array}{c}\text { Average RUL } \\
\text { Complex (years) }\end{array}$ \\
\hline $\begin{array}{c}\text { Asbestos } \\
\text { Cement } \\
\text { Ductile } \\
\text { Iron }\end{array}$ & 66.00 & 100.00 & 90.95 & 34.00 & 24.95 \\
$\begin{array}{c}\text { Polyvinyl } \\
\text { Chloride } \\
\text { Steel }\end{array}$ & 55.99 & 100.00 & 100.33 & 44.02 & 44.35 \\
\hline
\end{tabular}

The negative RUL values may be explained by an earlier installation date, an anticipated service life that is greater than the average ASL, and/or the failure of the models to accurately calculate RUL. Actual installation dates and the continued observation of the system would verify the correct explanation.

The RUL values presented in Table 5.5 differ from the RUL values calculated in the original analysis by the adjusted pipe age. Thus, if the original pipe ages are correct, this analysis displays the risk of failure of each pipe within the WDS in the number of years that the pipe age was adjusted by. For example, asbestos cement pipe age was adjusted by 10 years, so the results would be valid for asbestos cement pipes in 10 years.

\subsubsection{Anticipated Service Life Sensitivity Analysis Results}

Figure 5.5 provides the results of the simplified model with lower ASL. Figure 5.6 displays the results of the complex model with lower ASL. 


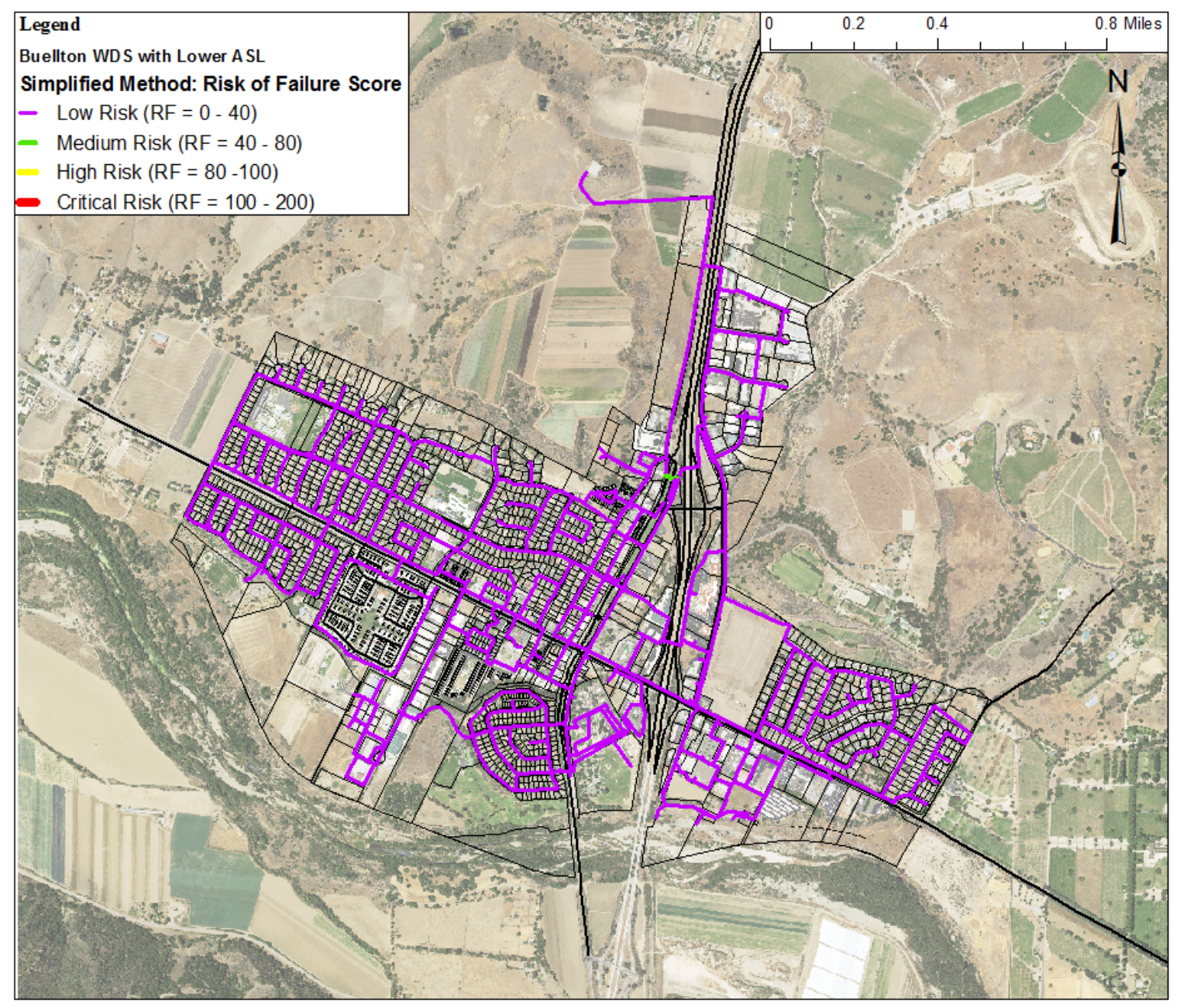

Figure 5.5 City of Buellton WDS with Lower ASL: Simplified Model Results 


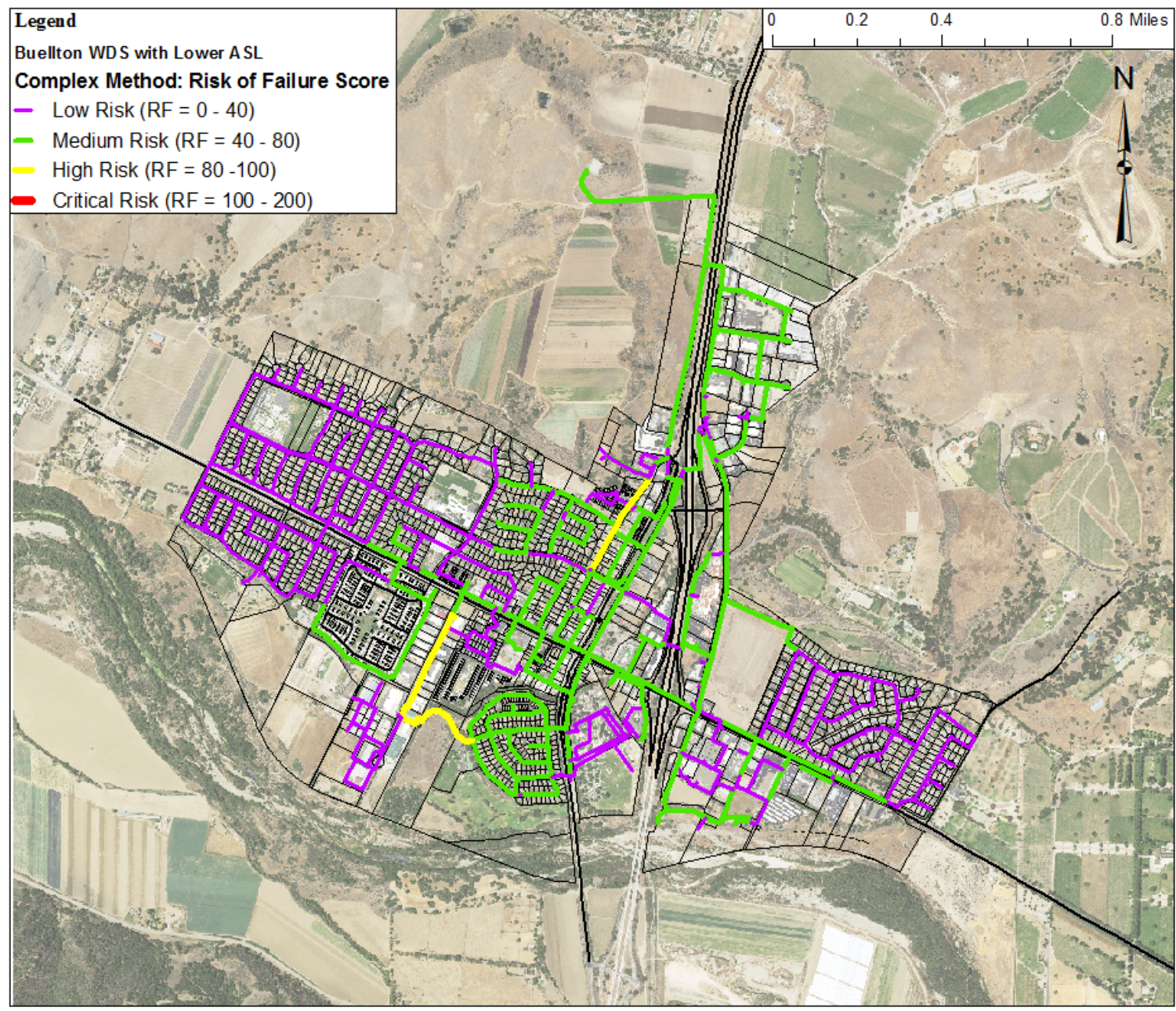

Figure 5.6 City of Buellton WDS with Lower ASL: Complex Model Results

Table 5.6 provides a comparison of the number of pipes in each risk of failure category within the WDS.

Table 5.6 Risk of Failure Comparison: Lower ASL

\begin{tabular}{c|cc}
\hline Risk of Failure Category & Simplified Model & Complex Model \\
\hline Critical Risk & 0 & 0 \\
High Risk & 0 & 9 \\
Medium Risk & 2 & 283 \\
Low Risk & 626 & 336 \\
\hline
\end{tabular}


Figure 5.5, Figure 5.6, and Table 5.6 display the difference between the models for this sensitivity analysis. The simplified model and complex model identify the two steel pipes as medium risk. In addition, the complex model identifies 281 medium risk asbestos cement pipes and 9 high risk asbestos cement pipes. The difference in results is attributed to the differences in RUL. The probability of failure criteria presented in Table 3.7 shows that as RUL drops below 20 years, its failure probability greatly increases. Table 5.7 provides the average RUL for each model.

Table 5.7 Remaining Useful Life Comparison: Lower ASL

\begin{tabular}{c|ccccc}
\hline \multicolumn{1}{c}{$\begin{array}{c}\text { Pipe } \\
\text { Material }\end{array}$} & $\begin{array}{c}\text { Average } \\
\text { Age } \\
\text { (years) }\end{array}$ & $\begin{array}{c}\text { Average } \\
\text { ASL } \\
\text { (years) }\end{array}$ & $\begin{array}{c}\text { Average } \\
\text { NY (years) }\end{array}$ & $\begin{array}{c}\text { Average RUL } \\
\text { Simplified } \\
\text { (years) }\end{array}$ & $\begin{array}{c}\text { Average RUL } \\
\text { Complex (years) }\end{array}$ \\
\hline $\begin{array}{c}\text { Asbestos } \\
\text { Cement } \\
\text { Ductile } \\
\begin{array}{c}\text { Iron } \\
\text { Polyvinyl } \\
\text { Chloride }\end{array}\end{array}$ & 56.00 & 74.99 & 65.94 & 18.99 & 9.94 \\
Steel & 27.98 & 74.99 & 75.32 & 47.01 & 47.34 \\
\hline
\end{tabular}

The RUL values presented in Table 5.7 differ from the RUL values calculated in the original analysis by the adjusted anticipated service life. Thus, if the original anticipated service life values are accurate; this analysis displays the risk of failure of each pipe within the WDS in the number of years that the anticipated service life was adjusted by. For example, asbestos cement pipe ASL was adjusted by 25 years, so the results would be valid for asbestos cement pipes in 25 years.

\subsubsection{Combined Sensitivity Analysis Results}

Figure 5.7 provides the results of the simplified model with older pipe age and lower ASL. Figure 5.8 displays the results of the complex model with older pipe age and lower ASL. 


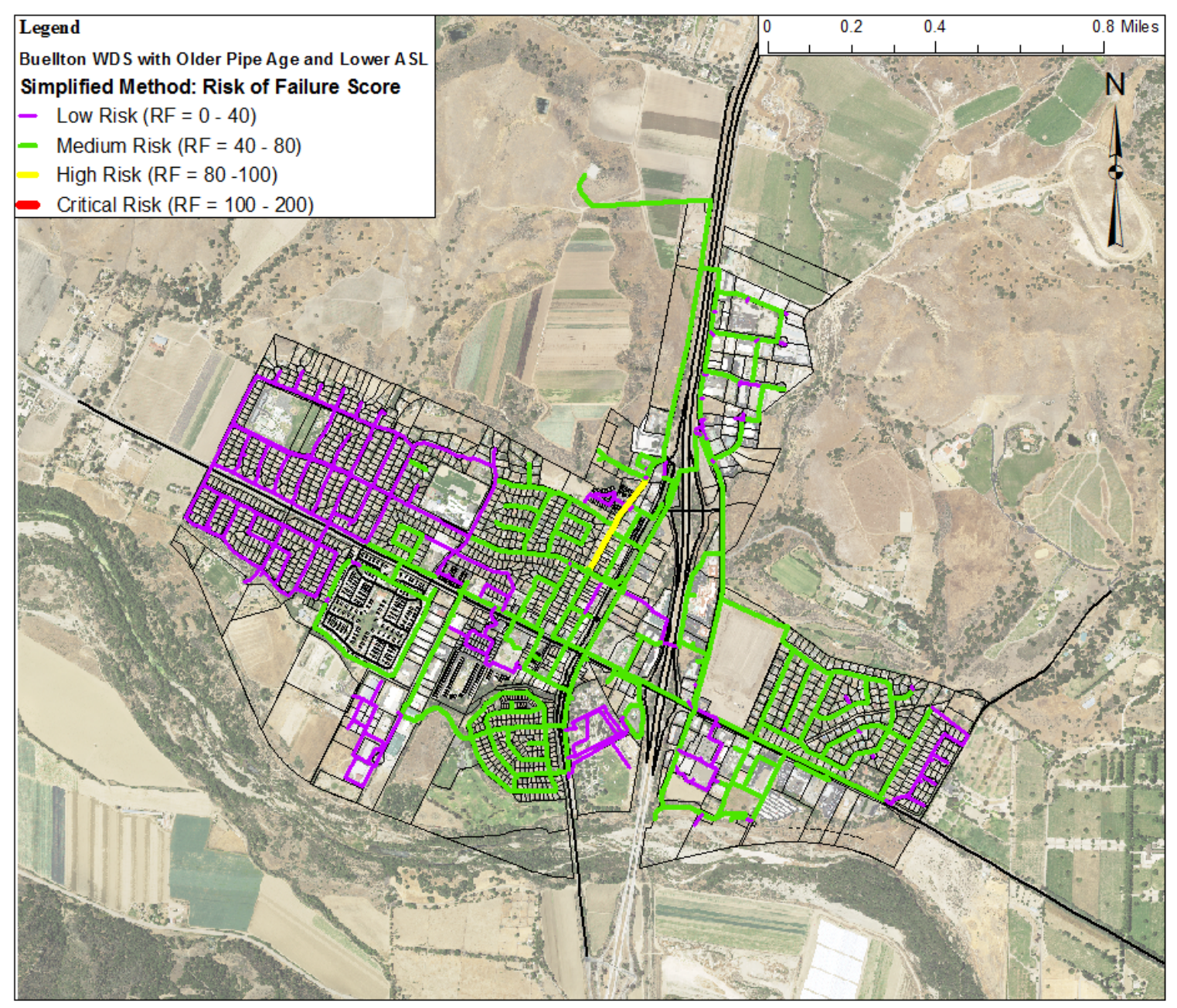

Figure 5.7 City of Buellton WDS with Older Pipe Age and Lower ASL: Simplified Model Results 


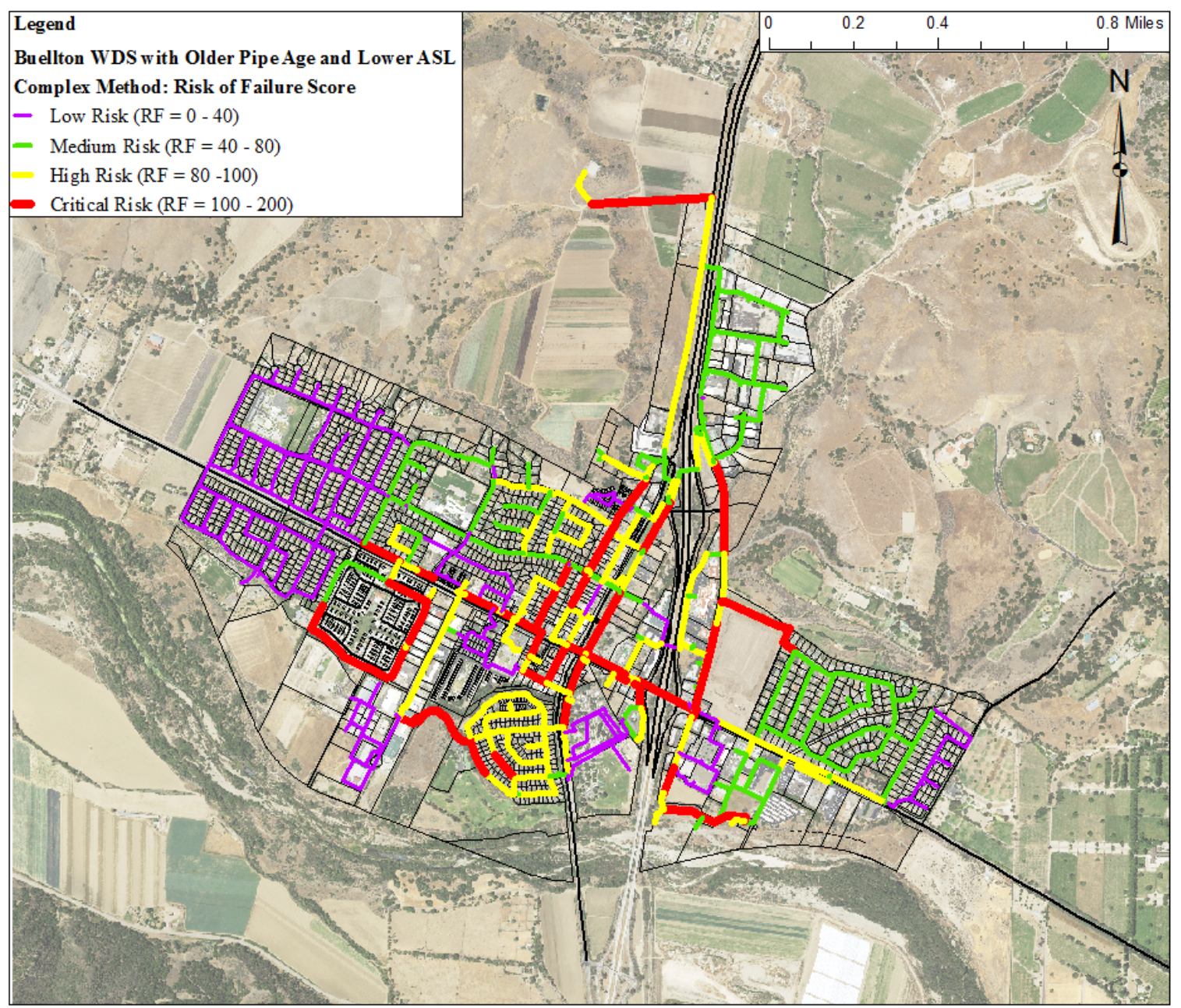

Figure 5.8 City of Buellton WDS with Older Pipe Age and Lower ASL: Complex Model Results

Table 5.8 provides a comparison of the number of pipes in each risk of failure category within the WDS.

Table 5.8 Risk of Failure Comparison: Older Pipe Age and Lower ASL

\begin{tabular}{c|cc}
\hline Risk of Failure Category & Simplified Model & Complex Model \\
\hline Critical Risk & 0 & 111 \\
High Risk & 1 & 149 \\
Medium Risk & 330 & 137 \\
Low Risk & 297 & 231 \\
\hline
\end{tabular}

Figure 5.7, Figure 5.8, and Table 5.8 show the difference between the models for this sensitivity analysis. The simplified model identified two medium risk steel pipes, 328 
medium risk asbestos cement pipes, and one high risk asbestos cement pipe. The complex model identified two medium risk steel pipes, three medium risk polyvinyl chloride pipes, 132 medium risk asbestos cement pipes, 149 high risk asbestos cement pipes, and 111 critical risk asbestos cement pipes. All critical risk pipes had the max probability of failure score of 10 , as well as having an average consequence score of 10.6. The differences in the results are attributed to the differences in the RUL as the probability of failure greatly increases as RUL drops below 20 years. Table 5.9 provides the average RUL for each model.

Table 5.9 Remaining Useful Life Comparison: Older Pipe Age and Lower ASL

\begin{tabular}{c|ccccc}
\hline \multicolumn{1}{c}{$\begin{array}{c}\text { Pipe } \\
\text { Material }\end{array}$} & $\begin{array}{c}\text { Average } \\
\text { Age } \\
\text { (years) }\end{array}$ & $\begin{array}{c}\text { Average } \\
\text { ASL } \\
\text { (years) }\end{array}$ & $\begin{array}{c}\text { Average } \\
\text { NY (years) }\end{array}$ & $\begin{array}{c}\text { Average RUL } \\
\text { Simplified } \\
\text { (years) }\end{array}$ & $\begin{array}{c}\text { Average RUL } \\
\text { Complex (years) }\end{array}$ \\
\hline $\begin{array}{c}\text { Asbestos } \\
\text { Cement } \\
\text { Ductile }\end{array}$ & 66.00 & 75.00 & 65.94 & 9.00 & -0.06 \\
$\begin{array}{c}\text { Iron } \\
\begin{array}{c}\text { Polyvinyl } \\
\text { Chloride } \\
\text { Steel }\end{array}\end{array}$ & 55.99 & 75.03 & 75.36 & 19.04 & 19.37 \\
\hline
\end{tabular}

The RUL values presented in Table 5.9 differ from the RUL values calculated in the original analysis by the adjusted pipe age and anticipated service life. Thus, if the original pipe age and anticipated service life values are accurate; this analysis displays the risk of failure of each pipe within the WDS in the number of years that pipe age and anticipated service life were adjusted by. For example, asbestos cement pipe age was adjusted by 10 years and the ASL was adjusted by 25 years, so the results would be valid for asbestos cement pipes in 35 years. 


\section{CHAPTER 6}

\section{CONCLUSIONS AND RECOMMENDATIONS}

\subsection{Summary and Evaluation of Results}

The results proved that the complex model presented by Cortez (2015) provides a more successful evaluation of the risk of failure of each pipe within a water distribution system compared to the simplified model presented by Devera (2013). The complex model incorporates additional factors into the calculation of remaining useful life, which allows for more accuracy and the potential for calibration. Thus, the complex model could provide municipalities with a more precise rehabilitation/replacement schedule, allowing them to allocate their capitol effectively.

Both models were used to evaluate the 628-pipe water distribution system for the City of Buellton, California. An original risk analysis was completed with approximated installation years and average anticipated service life based on pipe materials. In addition, three sensitivity analyses were completed to examine the effect of each of the assumed variables on the risk analysis and to evaluate the worst-case scenario. The results of the simplified and complex model for each of the risk analyses are presented in Table 6.1.

Table 6.1 Risk Analysis Results

\begin{tabular}{|c|c|c|}
\hline Risk Analysis & Simplified Model & Complex Model \\
\hline Original Analysis & All pipes were low risk & All pipes were low risk \\
\hline $\begin{array}{l}\text { Sensitivity Analysis: } \\
\text { Older Pipe Age }\end{array}$ & Identified 2 medium risk pipes & Identified 2 medium risk pipes \\
\hline $\begin{array}{l}\text { Sensitivity Analysis: } \\
\text { Lower ASL }\end{array}$ & Identified 2 medium risk pipes & $\begin{array}{l}\text { Identified } 9 \text { high risk pipes } \\
\text { and } 283 \text { medium risk pipes }\end{array}$ \\
\hline $\begin{array}{c}\text { Sensitivity Analysis: } \\
\text { Older Pipe Age and } \\
\text { Lower ASL }\end{array}$ & $\begin{array}{l}\text { Identified } 1 \text { high risk pipe and } \\
330 \text { medium risk pipes }\end{array}$ & $\begin{array}{l}\text { Identified } 111 \text { critical risk } \\
\text { pipes, } 149 \text { high risk pipes, } \\
\text { and } 137 \text { medium risk pipes }\end{array}$ \\
\hline
\end{tabular}


This study proved that the use of either risk assessment model is beneficial to municipalities in the maintenance and expansion of their water distribution system. As the water distribution system is expanded, a risk assessment model can be used to evaluate the anticipated lifetime of the expanding WDS. If all the data of the existing WDS is provided, a risk assessment model will provide a rehabilitation/replacement ranking system. If the data is unknown or has uncertainties, sensitivity analyses can be completed to determine the worst-case scenario for the WDS.

Application of computer modeling and data analysis programs is recommended for the efficient and effective use of either risk assessment model. WaterCAD is essential for the calculation of the hydraulic properties of the water distribution system. Excel is useful as a data organization tool. Visual Basic for Applications is crucial for the millions of calculations necessary to determine the remaining useful life of each pipe. ArcGIS is valuable as a visual representation of the results, as well as for manipulation of geographic information to gather the additional required data to complete the risk assessment.

\subsection{Assessment of the Reliability of Data}

The City of Buellton provided all of the physical and hydraulic properties of each pipe, except for pipe ages. The provided properties were determined to be reliable.

Pipe age was estimated based on common installation periods for each region within the United States based on a study completed by AWWA (2011). The City of Buellton verified that the estimated installation dates approximated the actual installation dates. Although pipe age contained some uncertainty, the estimation was found to be reliable.

Assumptions were made to determine the criteria/parameters outlined in Chapter 3. These assumptions were necessary as acquiring all of the data necessary would have 
been exhaustive. For the purpose of this study, these values are reliable because it allows for a comparison between the two models. However, for more accurate results, these values are should be re-evaluated.

Reliable data is necessary for the application of either risk assessment model. It is recommended that municipalities obtain as much data on their water distribution system as economically plausible. With an abundance of accurate data, a municipality can acquire more precise results by including more factors in the risk analysis. With a lack of accurate data, the results become less accurate and the risk analysis becomes harder, if not impossible, to complete.

\subsection{Recommendations for Improvement and Further Research}

Due to the nature of this academic study, assumptions were made to account for time constraints, resource constraints, and lack of information. Time and resources permitting, the following criteria/parameters should be re-evaluated: traffic impacts, service interruptions (flow rate), percent of pipe covered by industrial and residential development, length of pipe exposed to corrosive soil, cost of replacement, and customer criticality. Re-evaluation of these criteria/parameters requires the collection of data, whether it be immediate or in the future. As data is collected and the criteria updated, the risk assessment model will become more accurate.

In addition, pipe break events should be recorded so that these models may take them into consideration. A pipe with break history is at higher risk to break again; therefore, not having this data will skew the results.

Another recommendation is the continuous application of the complex risk assessment model to the same WDS. As the WDS ages and pipes experience breaks, the model can be calibrated, which will generate a more accurate model over time. In 
addition, calibration can be completed as new pipes are added to the system because data necessary for the risk analysis can be collected at that time.

It is recommended that application of both models to different WDS be completed to verify the results concluded in this study. Additional comparisons of the two models will prove whether the complex model or the simplified model is better suited at identifying critical risk pipes and developing a rehabilitation/replacement ranking system.

Furthermore, application of computer modeling and data analysis programs is recommended. Utilization of programs allows for the completion of complex calculations, the visual representation of results, and data organization that is necessary to efficiently and accurately apply risk assessment models. Programs are crucial in the universal application of a risk assessment model, which would improve the maintenance and expansion of water distribution systems by allowing municipalities to effectively utilize their capitol. 


\section{REFERENCES}

ASCE (2103). "Report Card for America's Infrastructure." American Society of Civil Engineers (ASCE). ASCE, 2013. Web. 8 March 2016.

AWWA (2011). "Buried No Longer: Confronting America's Water Infrastructure Challenge." American Water Works Association (AWWA).

AWWA (2014). "M28 Rehabilitation of Water Mains," Third Edition. American Water Works Association (AWWA), 30028-3E, Chapter 1.

Clark, Robert M., Stafford, C. L., and Goodrich, J. A. (1982). "Water distribution systems: A spatial and cost evaluation." Journal of Water Resources Planning and Management, ASCE, 108(3), pp. 243-256.

Clark, Robert M. (2010). "Condition assessment modeling for distribution systems using shared frailty analysis." American Water Works Association (AWWA), Vol. 102. No. 7 (July 2010), pp. 81-91.

Cortez, Hernan (2015). "A Risk Analysis Model for the Maintenance and Rehabilitation of Pipes in a Water Distribution System: A Statistical Approach." California Polytechnic University, San Luis Obispo, a master's thesis presented to the faculty of Cal Poly.

Cox, D. R. (1972). "Regression models and life tables." Journal of Royal Statistical Society, 34(B), pp. 187-220.

Devera, Jan C. (2013). "Risk Assessment Model for Pipe Rehabilitation and Replacement in a Water Distribution System." California Polytechnic State University, San Luis Obispo, a master's thesis presented to the faculty of Cal Poly.

Driels, Morris R., Shin, Young S. (2004). "Determining the Number of Iterations for Monte Carlo Simulations of Weapon Effectiveness." Naval Postgraduate School, Monterey California, a master's thesis prepared for Defense Threat Reduction Agency.

Jacobs, P., and Karney, B. (1994). "GIS development with application to cast iron water main breakage rate." 2nd International Conference on Water Pipeline Systems. BHR Group Ltd., Edinburgh, Scotland.

Kettler, A.J., and Goulter, I.C. (1985). "An analysis of pipe breakage in urban water distribution networks." Canadian Journal of Civil Engineering, 12, pp. 286-293.

Kleiner, Y., and Rajani, B. B. (2001). "Comprehensive Review of Structural Deterioration of Water Mains: Statistical Models." Urban Water, 3 (3), pp. 131-150.

Makar, J.M. (2001). "Failure modes and mechanisms in gray cast iron pipe." Presented at Underground Infrastructure Research 2001. Waterloo, Ontario. Natural Research Council Canada.

Marks, H. D. et al. 1985). "Predicting urban water distribution maintenance strategies: A case study of New Haven Connecticut." US Environmental Protection Agency (Co- 
operative Agreement CR8 1 0558), M.I.T. Office of Sponsored Projects No. 94211. Boston, MA.

Mavin, K., (1996). "Predicting the Failure Performance of Individual Water Mains." Urban Water Research Association of Australia, Research Report No. 11 4, Melbourne, Australia.

Mays, L. W., ed. (2000). Water distribution systems handbook. McGraw-Hill, New York.

McMullen, L.D. (1982). "Advanced concepts in soil evaluation for exterior pipeline corrosion." In proceeding of the American Water Works Association Annual Conference, Miami, FL.

Shamir, U. and Howard, C.D.D. (1979). "An analytic approach to scheduling pipe replacement." Journal of American Water Works Association, 71(5), pp. 248-258.

Rajani, B. B., and Kleiner, Y. (2001). "Comprehensive review of structural deterioration of water mains: physically based models." Urban Water, 3 (2001), pp. 151-164.

RSMeans (2013). "Heavy Construction Cost Data." RSMeans, $27^{\text {th }}$ Annual Edition, pp. 165-183.

Walski, T. M., and Pellicia, A. (1982). "Economic Analysis of Water Main Breaks." Journal of American Water Works Association, 74(3), pp. 140-147.

Wang, Yong (2009). "Prediction Models for Annual Break Rates of Water Mains." ASCE, Journal of Performance of Constructed Facilities, Jan/Feb 2009. Pp. 47-54.

WSC Inc. (2012, December). "City of Arroyo Grande Water System Master Plan December 2012." City of Arroyo Grande.

Yamijala, S. (2007). "Statistical Estimation of Water Distribution System Pipe Break Risk (Unpublished master's thesis)." Texas A\&M University. 


\section{APPENDICES}

Appendix A: City of Buellton Data and Results 
Table A.1 Example of Required Data from the "WDS Data" Spreadsheet

\begin{tabular}{c|lccccccc}
\hline Label & Material & $\begin{array}{c}\text { Present } \\
\text { Year }\end{array}$ & $\begin{array}{c}\text { Installation } \\
\text { Year }\end{array}$ & $\begin{array}{c}\text { Standard Deviation of } \\
\text { Installation Year } \\
\text { (years) }\end{array}$ & $\begin{array}{c}\text { Age } \\
\text { (years) }\end{array}$ & $\begin{array}{c}\text { ASL } \\
\text { (years) }\end{array}$ & $\begin{array}{c}\text { Standard } \\
\text { Deviation of ASL } \\
\text { (years) }\end{array}$ & $\begin{array}{c}\text { NY } \\
\text { (years) }\end{array}$ \\
\hline$P-1$ & Asbestos Cement & 2016 & 1960 & 3.33 & 56 & 100 & 8.33 & 88.30 \\
$P-10$ & Asbestos Cement & 2016 & 1960 & 3.33 & 56 & 100 & 8.33 & 82.73 \\
$P-100$ & Asbestos Cement & 2016 & 1960 & 3.33 & 56 & 100 & 8.33 & 92.38 \\
$P-101$ & Asbestos Cement & 2016 & 1960 & 3.33 & 56 & 100 & 8.33 & 92.38 \\
$P-103$ & Asbestos Cement & 2016 & 1960 & 3.33 & 56 & 100 & 8.33 & 92.51 \\
\hline
\end{tabular}

\begin{tabular}{c|cccccccc}
\hline Label & Diameter (in) & Length (ft) & Demand (GPM) & Velocity (ft/s) & Elevation (ft) & HGL (ft) & Pressure (psi) & Pipe Type \\
\hline$P-1$ & 6 & 469 & 208 & 0.59 & 550 & 612 & 42 & 0.10 \\
$P-10$ & 6 & 382 & 30 & 0.19 & 400 & 612 & 106 & 0.10 \\
$P-100$ & 8 & 347 & 9 & 0.10 & 363 & 509 & 78 & 0.10 \\
$P-101$ & 8 & 351 & 26 & 0.30 & 363 & 509 & 78 & 0.10 \\
$P-103$ & 8 & 86 & 61 & 0.39 & 369 & 510 & 76 & 0.10 \\
\hline
\end{tabular}

\begin{tabular}{c|cccccccc}
\hline Label & Land Use & $\begin{array}{c}\% \\
\text { Industrial }\end{array}$ & $\begin{array}{c}\% \\
\text { Residential }\end{array}$ & $\begin{array}{c}\text { Pipe Cost per } \\
\text { Linear Foot }(\$ / f t)\end{array}$ & $\begin{array}{c}\text { Pipe Cost } \\
(\$)\end{array}$ & Street Name & $\begin{array}{c}\text { Street } \\
\text { Class }\end{array}$ & $\begin{array}{c}\text { Traffic } \\
\text { Designation }\end{array}$ \\
\hline$P-1$ & Agriculture & 25 & 75 & $\$ 55.00$ & $\$ 25,795.00$ & Unknown & Street & No Traffic \\
$P-10$ & Industrial & 50 & 50 & $\$ 55.00$ & $\$ 21,010.00$ & Unknown & Street & No Traffic \\
$P-100$ & Residential & 0 & 100 & $\$ 64.00$ & $\$ 22,208.00$ & Kendale & Street & Local \\
$P-101$ & Residential & 0 & 100 & $\$ 64.00$ & $\$ 22,464.00$ & Kendale & Street & Local \\
$P-103$ & Residential & 0 & 100 & $\$ 64.00$ & $\$ 5,504.00$ & State Hwy 246 & Highway & Arterial \\
\hline
\end{tabular}




\begin{tabular}{c|cccccc}
\hline Label & Sheriff Station & Fire Station & Senior Care or Day Care Center & School & Shopping Center & Business Center \\
\hline$P-1$ & No & No & No & No & No & No \\
$P-10$ & No & No & No & No & No & Yes \\
$P-100$ & No & No & No & No & Yes & No \\
$P-101$ & No & No & No & No & No & No \\
$P-103$ & No & No & No & & \\
\hline
\end{tabular}


Table A.2 Example of Original Risk Analysis Results from the "Risk Analysis" Spreadsheet

\begin{tabular}{|c|c|c|c|c|c|c|c|c|}
\hline Label & $\begin{array}{c}\text { Pipe } \\
\text { Material }\end{array}$ & Age (years) & ASL (years) & NY (years) & $\begin{array}{c}R U L \\
\text { Simplified } \\
\text { (years) }\end{array}$ & $\begin{array}{c}R U L \\
\text { Complex } \\
\text { (years) }\end{array}$ & $\begin{array}{c}P F \\
\text { Simplified }\end{array}$ & $\begin{array}{c}P F \\
\text { Complex }\end{array}$ \\
\hline$P-1$ & $\begin{array}{c}\text { Asbestos } \\
\text { Cement }\end{array}$ & 56.03 & 99.94 & 88.24 & 43.91 & 32.21 & 1 & 1 \\
\hline$P-10$ & $\begin{array}{c}\text { Asbestos } \\
\text { Cement }\end{array}$ & 56.02 & 100.02 & 82.75 & 44.00 & 26.73 & 1 & 1 \\
\hline$P-100$ & $\begin{array}{c}\text { Asbestos } \\
\text { Cement }\end{array}$ & 55.98 & 100.00 & 92.38 & 44.02 & 36.40 & 1 & 1 \\
\hline$P-101$ & $\begin{array}{c}\text { Asbestos } \\
\text { Cement }\end{array}$ & 56.00 & 100.01 & 92.39 & 44.02 & 36.40 & 1 & 1 \\
\hline$P-103$ & $\begin{array}{c}\text { Asbestos } \\
\text { Cement }\end{array}$ & 55.96 & 100.03 & 92.54 & 44.07 & 36.58 & 1 & 1 \\
\hline
\end{tabular}

\begin{tabular}{c|ccccccccc}
\hline Label & $\begin{array}{c}\text { Cost } \\
\text { Impact } \\
\text { Score }\end{array}$ & $\begin{array}{c}\text { Flow Rate } \\
\text { Score }\end{array}$ & $\begin{array}{c}\text { Traffic } \\
\text { Impact } \\
\text { Score }\end{array}$ & $\begin{array}{c}\text { Critical } \\
\text { Customer } \\
\text { Score }\end{array}$ & $\begin{array}{c}\text { Conseque } \\
\text { nce Score }\end{array}$ & $\begin{array}{c}\text { Risk } \\
\text { Simplified }\end{array}$ & $\begin{array}{c}\text { Risk } \\
\text { Complex }\end{array}$ & $\begin{array}{c}\text { Risk } \\
\text { Category } \\
\text { Simplified }\end{array}$ & $\begin{array}{c}\text { Risk } \\
\text { Category } \\
\text { Complex }\end{array}$ \\
\hline$P-1$ & 3 & 2 & 3 & 1 & 9 & 9 & 9 & Low Risk & Low Risk \\
$P-10$ & 2 & 1 & 3 & 1 & 7 & 7 & 7 & Low Risk & Low Risk \\
$P-100$ & 2 & 1 & 3 & 1 & 7 & 7 & 7 & Low Risk Low Risk \\
$P-101$ & 2 & 1 & 3 & 1 & 7 & 7 & 7 & Low Risk Low Risk \\
$P-103$ & 1 & 1 & 4 & 1 & 7 & 7 & 7 & Low Risk Low Risk \\
\hline
\end{tabular}


Appendix B: Visual Basic Code 
Sub RUL()

"'Select Input values by specifying a range

Dim Pipematrix As Variant
Sheet1.Activate
Range("B1").Select
Range(Selection, Selection.End(xIDown)).Select
Range(Selection, Selection.End(xIToRight)).Select
Pipematrix $=$ Selection. Value

MsgBox ("Number of Rows:" \& vbNewLine \& vbNewLine \& Selection.Rows.Count)

MsgBox ("Number of Columns:" \& vbNewLine \& vbNewLine \&

Selection.Columns.Count)

'Enter the number of Rows and Columns

Const Rows $=629$

Const Columns $=30$

"'Define Variables Needed for MonteCarlo Simulation

'RowCounter, ColCounter, and i are to iterate each equation 10,000 times

Dim RowCounter As Integer

Dim ColCounter As Integer

Dim i As Integer

'The mean and standard deviation variables are the output of one iteration

'The sum of mean and sum of standard deviation variables are then summation of the 10,000 iterations

Dim meanAge(Rows, Columns) As Variant

Dim stdAge(Rows, Columns) As Variant

Dim summeanAge(Rows, Columns) As Variant

Dim sumstdAge(Rows, Columns) As Variant

Dim meanASL(Rows, Columns) As Variant

Dim stdASL(Rows, Columns) As Variant

Dim summeanASL(Rows, Columns) As Variant

Dim sumstdASL(Rows, Columns) As Variant

Dim meanNY(Rows, Columns) As Variant

Dim stdNY(Rows, Columns) As Variant

Dim summeanNY(Rows, Columns) As Variant

Dim sumstdNY(Rows, Columns) As Variant

Dim meanRULSimple(Rows, Columns) As Variant

Dim summeanRULSimple(Rows, Columns) As Variant

Dim stdRULSimple(Rows, Columns) As Variant

Dim sumstdRULSimple(Rows, Columns) As Variant

Dim meanRULComplex(Rows, Columns) As Variant

Dim summeanRULComplex(Rows, Columns) As Variant

Dim stdRULComplex(Rows, Columns) As Variant

Dim sumstdRULComplex(Rows, Columns) As Variant 


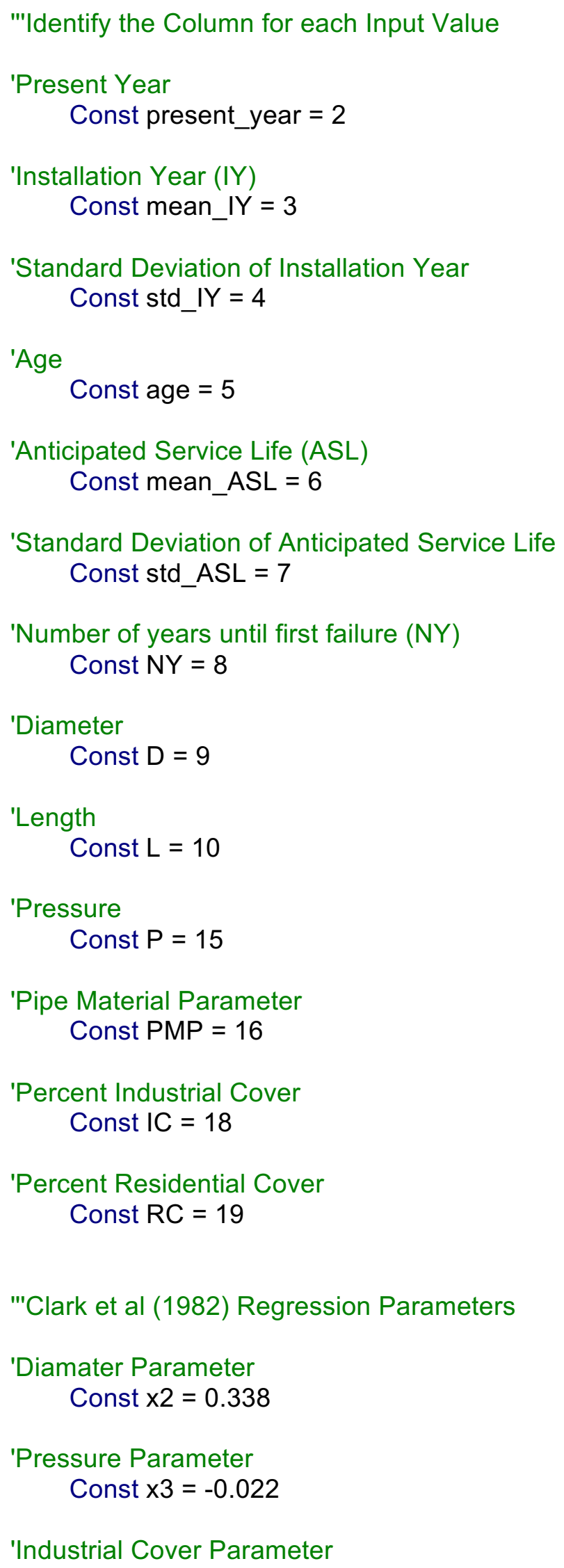


Const $x 4=-0.265$

'Residential Cover Parameter

Const $x 5=-0.0983$

'CorrosAgee Soil Length Parameter

Const $x 6=-0.0003$

'Pipe Material Parameter

Const $x 7=13.28$

"'Compute calculations for each pipe with 10,000 Itereations

For RowCounter $=2$ To Rows

ColCounter $=1$

For $\mathrm{i}=1$ To 10000

'Calculate the mean and sum of mean for Age

On Error GoTo meanAgeError

meanAge(RowCounter, ColCounter $)=$ Pipematrix(RowCounter, present_year) -

Application.WorksheetFunction.Norm_Inv(Rnd(), Pipematrix(RowCounter, mean_IY), Pipematrix(RowCounter, std_IY))

summeanAge (RowCounter, ColCounter $)=$ summeanAge $($ RowCounter,

ColCounter) + meanAge(RowCounter, ColCounter)

On Error GoTo 0

'Calculate the mean and sum of mean for ASL

On Error GoTo meanASLError

meanASL(RowCounter, ColCounter $)=$

Application.WorksheetFunction.Norm_Inv(Rnd(), Pipematrix(RowCounter, mean_ASL), Pipematrix(RowCounter, std_ASL))

summeanASL(RowCounter, ColCounter) = summeanASL(RowCounter, ColCounter) + meanASL(RowCounter, ColCounter)

On Error GoTo 0

'Calculate the mean and sum of mean for NY

meanNY(RowCounter, ColCounter $)=$ meanASL $($ RowCounter, ColCounter $)+x 2$ *

Pipematrix(RowCounter, D) + x3 * Pipematrix(RowCounter, $P)+x 4$ *

Pipematrix(RowCounter, IC) + x5 * Pipematrix(RowCounter, RC) + x6 *

Pipematrix(RowCounter, L) + x7 * Pipematrix(RowCounter, PMP)

summeanNY(RowCounter, ColCounter $)=$ summeanNY(RowCounter,

ColCounter) + meanNY(RowCounter, ColCounter)

'Calculate the mean and sum of mean for RUL (Simplified)

meanRULSimple(RowCounter, ColCounter) = meanASL(RowCounter, ColCounter)

- (meanAge(RowCounter, ColCounter))

summeanRULSimple(RowCounter, ColCounter $)=$

summeanRULSimple(RowCounter, ColCounter) +

meanRULSimple(RowCounter, ColCounter)

'Calculate the mean and sum of mean for RUL (Complex) 
meanRULComplex (RowCounter, ColCounter $)=$ meanNY (RowCounter, ColCounter) - meanAge(RowCounter, ColCounter)

summeanRULComplex(RowCounter, ColCounter) $=$ summeanRULComplex(RowCounter, ColCounter) + meanRULComplex(RowCounter, ColCounter)

'A single iteration has been completed, move onto next Iteration

Next i

'Calculate the Mean Age

meanAge(RowCounter, ColCounter $)=$ summeanAge(RowCounter, ColCounter $) /$ 10000

'Calculate the Mean ASL

meanASL(RowCounter, ColCounter $)=$ summeanASL $($ RowCounter, ColCounter $) /$ 10000

'Calculate the Mean NY

meanNY(RowCounter, ColCounter $)=$ summeanNY(RowCounter, ColCounter $) /$ 10000

'Calculate the Mean RUL (Simplified)

meanRULSimple $($ RowCounter, ColCounter $)=($ summeanRULSimple $($ RowCounter, ColCounter)) / 10000

'Calculate the Mean RUL (Complex) meanRULComplex(RowCounter, ColCounter $)=$ (summeanRULComplex(RowCounter, ColCounter)) / 10000

'Ouput results into Risk Analysis Sheet

Sheet3.Cells $($ RowCounter, 3).Value $=$ meanAge $($ RowCounter, ColCounter $)$ Sheet3.Cells (RowCounter, 4).Value $=$ meanASL(RowCounter, ColCounter $)$ Sheet3.Cells $($ RowCounter, 5).Value $=$ meanNY(RowCounter, ColCounter $)$ Sheet3.Cells $($ RowCounter, 6).Value $=$ meanRULSimple $($ RowCounter, ColCounter $)$ Sheet3.Cells $($ RowCounter, 7$)$.Value $=$ meanRULComplex $($ RowCounter, ColCounter)

'All 10,000 Iterations have been completed, move onto next pipe Next RowCounter

Sheet3.Activate

MsgBox ("Calculation Complete")

Exit Sub

'Error handling statement for Error 1004. This error occurs when Excel cannot access the worksheetfunction (occurs once each time the application is run)

meanAgeError:

Select Case Err.Number 
